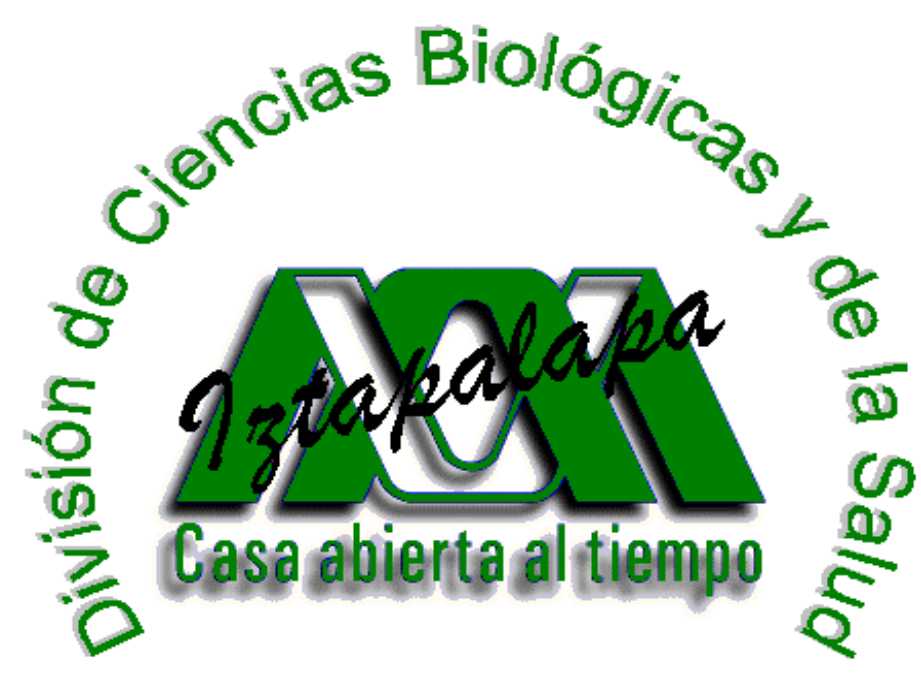

DEPARTAMENTO DE BIOTECNOLOGÍA

\title{
DIGESTIÓN ANAEROBIA EN DOS ETAPAS DE LODOS PRIMARIOS Y SECUNDARIOS CON REACTORES ANAEROBIOS DE FLUJO ASCENDENTE
}

TESIS QUE PARA OBTENER EL GRADO DE:

DOCTOR EN BIOTECNOLOGÍA

PRESENTA

M. en B. JESÚS TERREROS MECALCO

COMITÉ TUTORAL

DIRECTORA: DRA. FLORINA RAMÍREZ VIVES. ASESORES: DR. OSCAR A. MONROY HERMOSILLO. DR. ADALBERTO NOYOLA ROBLES 
CONSTANCIA DE PRESENTACION DE EXAMEN DE GRADO

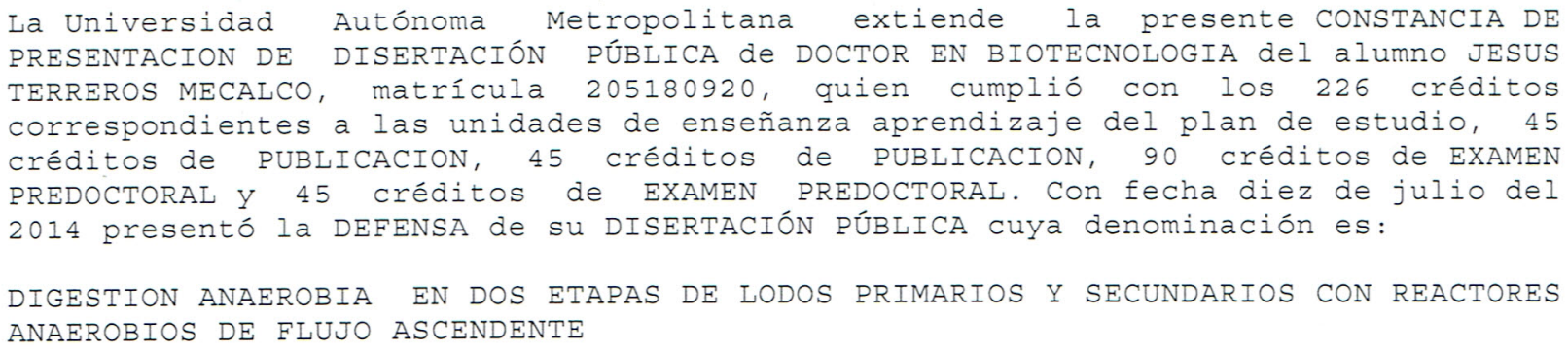

El jurado del examen ha tenido a bien otorgarle la calificación de:

t probar

JURADO

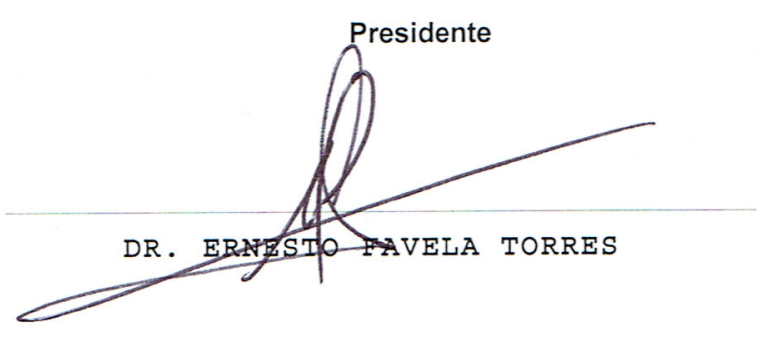

Vocal

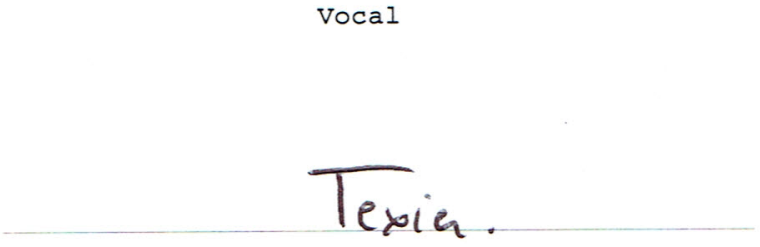

DRA. ANNE CLAIRE TEXIER

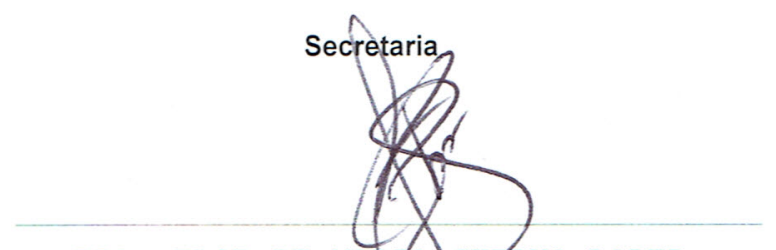

DRA. FLOR DE MARTA CUERVO LOPEZ

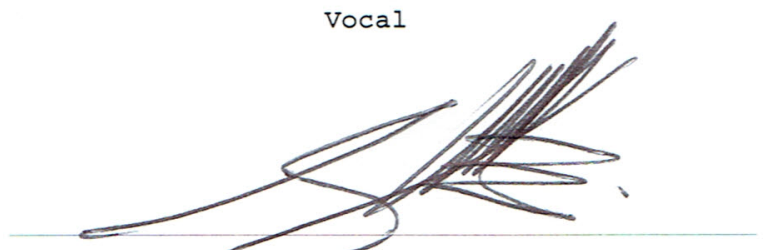

DR. SERGIO VIGUERAS CARMONA 


\section{AGRADECIMIENTOS}

Agradezco al Dr. Oscar Monroy por su perseverancia para lograr la conclusión de esta Tesis y por todo el apoyo durante mi larga estancia en la UAMI.

Mi más sinceros agradecimientos al Dr. Adalberto Noyola, Dra. Anne Claire Texier Valentin, Dr. Ernesto Favela Torres, Dr. Alejandro Olmos Dichara y al Dr. Sergio Esteban Vigueras Carmona por su tiempo y recomendaciones para mejorar esta tesis.

Un especial agradecimiento a la Dra. Mónica Meráz por brindarme las facilidades para la realización de este trabajo de investigación en el laboratorio de Tratamiento de Aguas Residuales y Microbiología Ambiental.

Agradezco a la Dra. Carmén Fajardo por compartir sus conocimientos en el manejo de equipos de cromatografía durante el tiempo en que realicé el trabajo experimental .

Agradezco al Dr. Eugenio Gómez Reyes por todo su apoyo y por compartir sus conocimientos y experiencia de hidrología que me ha ayudado a comprender mejor el comportamiento del agua subterránea.

Agradezco a Elena Burns Stuck y al Dr. Pedro Moctezuma Barragán por todo su apoyo. A quienes admiro por su labor, por sus logros, retos y trayectoria y quienes son un ejemplo a seguir.

Pero sobre todo, doy mis más infinitas gracias a la Dra. Florina Ramírez Vives por todo su apoyo a lo largo de mi estancia en el laboratorio, por sus consejos y palabras de aliento para que siguiera adelante en los momentos más difíciles de mi vida, gracias Dra. Florina, en verdad muchas gracias por todo su apoyo. 


\section{DEDICACIÓN}

Dedico de manera muy especial la culminación de esta tesis a 3 personas muy importantes en mi vida y que son parte medular para mi superación tanto personal como profesional: Ana Maria, Lialiana Guadalupe y Jesús Terreros Gutiérrez a quienes amo y de quienes estaré siempre al pendiente en todos los momentos de su vida mientras Dios me de la oportunidad para poder hacerlo.

Gracias hijos por todos los momentos de dicha y felicidad que hemos compartido juntos durante todos estos años y los que faltan por venir, que Dios los bendiga y que todas sus metas y propósitos se cumplan, pero recuerden que todo requiere un gran esfuerzo y dedicación y que algún día a cambio de, cosecharán los frutos de su gran esfuerzo, por lo que quiero dejar plasmado en sus memorias con la culminación de esta tesis, un ejemplo a seguir.

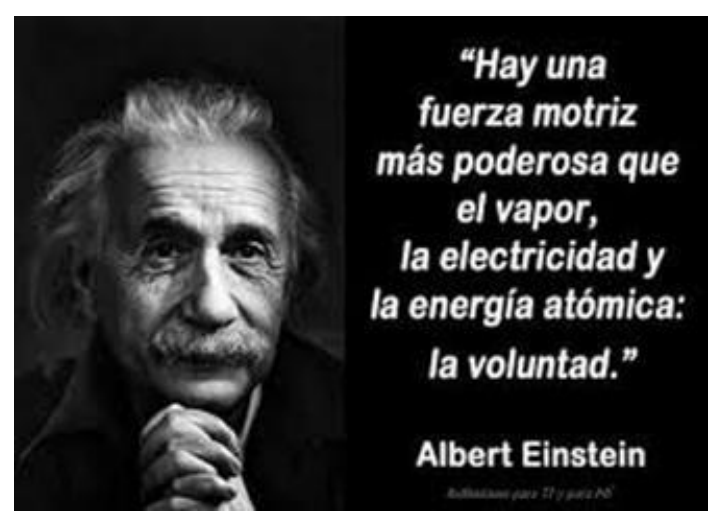


El Doctorado en Biotecnología de la Universidad Autónoma Metropolitana está incluido en el Programa Nacional de Posgrados de Calidad (PNPC) del CONACyT y además cuenta con apoyo del mismo Consejo.

Esta tesis se realizó en el Laboratorio de Tratamiento de Aguas Residuales y Microbiología Ambiental del Departamento de Biotecnología de la División de Ciencias Biológicas y de la Salud, de la Universidad Autónoma Metropolitana unidad Iztapalapa y fue financiado a través de la beca otorgada por el Consejo Nacional de Ciencia y Tecnología. 
Iztapalapa, D.F., a 10 de julio del 2014.

El jurado designado por la División de Ciencias Biológicas y de la Salud de la Universidad Autónoma Metropolitana Unidad Iztapalapa, aprobó la tesis:

\title{
"DIGESTIÓN ANAEROBIA EN DOS ETAPAS DE LODOS PRIMARIOS Y SECUNDARIOS CON REACTORES ANAEROBIOS DE FLUJO ASCENDENTE".
}

\author{
Que presentó: \\ M. en B. Jesús Terreros Mecalco
}

Comité tutorial:

Directora: Dra. Florina Ramírez Vives.

Asesor: Dr. Oscar A. Monroy Hermosillo.

Asesor: Dr. Adalberto Noyola Robles

H. Jurado:

Presidente: Dr. Ernesto Favela Torres

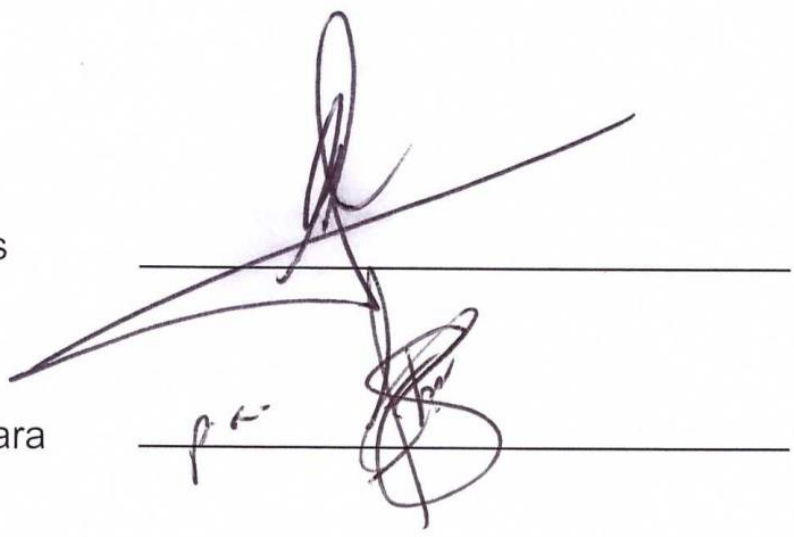

Vocal: Dra. Anne Claire Texier Valentin

Vocal: Dr. Sergio Vigueras Carmona

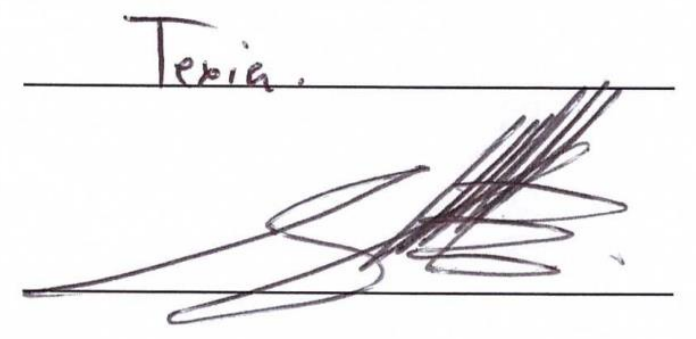




\section{ÍNDICE GENERAL}

Resumen

Abstract

Índice de cuadros

Índice de figuras

Página

Capítulo 1. Introducción

1.1 Justificación

1.2 Hipótesis

1.3 Objetivos

i Objetivo general

iv

ii Objetivos particulares 3

1.4 Antecedentes

1.4.1 Clasificación de lodos en plantas de tratamiento de aguas residuales (PTAR)

1.4.1.1 Lodo primario (LP)

1.4.1.2 Lodo secundario (LS)

1

2

3

3

3

3

4.2 Características de los lodos residuales (LR) 5

1.4.2.1 Biológicas

1.4.2.2 Físicas

1.4.2.3 Químicas

1.4.3 Producción de biosólidos

4

4

4

1.4.4 Tratamiento de lodos

1.4.4.1 Espesamiento

1.4.4.2 Estabilización

1.4.4.2.1 Estabilización química

1.4.4.2.2 Estabilización biológica

1.4.4.3 Acondicionamiento

1.4.4.4 Exprimido

1.4.4.5 Secado

1.5 Procesos anaerobios en la estabilización de lodos residuales 19

1.5.1 Digestión ácido-gas

1.5.2 Digestión mesofílica en una etapa

1.5.3 Digestión termofílica en una etapa

1.5.4 Digestión anaerobia en dos etapas $\quad 21$

1.6 Reactores anaerobios de lodos

1.6.1 Reactores de baja tasa $\quad 22$

1.6.2 Reactores de alta tasa

23

1.6.3 Digestión anaerobia de flujo ascendente

24

1.7 Conclusiones

Capítulo 2. Materiales y Métodos 
2.4 Tamizado de lodo primario

2.5 Contenido de sólidos en lodos residuales $\quad 28$

2.6 Preparación de la mezcla de lodos residuales 28

2.7 Diseño experimental 28

2.8 Condiciones de operación de los reactores 29

2.9 Caracterización de los lodos del rAM y rMT 29

2.10 Técnicas analíticas 30

2.11 Cálculo de variables de respuesta en los reactores rAM y rMT 31

2.12 Análisis de los reactores rAM y rMT 33

Capítulo 3. Reactor acidogénico mesofílico (rAM) 35

3.1 Caracterización de los lodos primarios y secundarios 36

3.2 Comportamiento del reactor acidogénico mesofílico 37

3.2.1 Reactor de lodos de flujo ascendente como sedimentador 37

3.2.2 Hidrólisis de sólidos suspendidos volátiles (SSV) y formación de $\mathrm{DQO}_{\mathrm{S}} \quad 38$

3.2.3 Efecto de la proporción de LP:LS en la velocidad de destrucción de sólidos

3.2.4 Producción de AGV 41

3.2.5 Producción y composición de biogás en el rAM 43

3.2.6 Análisis cinético del reactor rAM 45

3.2.7 Evolución de $\mathrm{pH} \quad 46$

3.2.8 Hidrólisis de proteínas $\quad 48$

3.2.9 Estimación de constantes de velocidad de reacción (k) 50

3.2.10 Conclusiones parciales $\quad 50$

Capítulo 4 Reactor metanogénico termofílico (rMT) 51

4.1 Comportamiento del reactor metanogénico termofílico 52

4.1.1 Reactor de lodos de flujo ascendente como sedimentador 52

4.1.2 Destrucción de sólidos suspendidos volátiles (SSV) y DQO $S$

4.1.3 Eliminación de $\mathrm{DQO}_{\text {total }} \quad 55$

4.1.4 AGV no convertidos a metano $\left(\mathrm{CH}_{4}\right) \quad 56$

4.1.5 Producción de biogás $\quad 57$

4.1.6 Análisis cinético del reactor rMT $\quad 59$

4.1.7 Estimación de constantes de velocidad de reacción (k) 61

4.1.8 Hidrólisis de proteínas $\quad 62$

4.1.9 Eliminación de microorganismos patógenos y de parásitos 63

4.1.10 Conclusiones parciales 65

Capítulo 5 Conclusiones generales y recomendaciones 66

$\begin{array}{ll}5.1 \text { Conclusiones generales } & 67\end{array}$

$\begin{array}{ll}5.2 \text { Recomendaciones } & 67\end{array}$

$\begin{array}{ll}\text { Referencias } & 69\end{array}$ 


\section{RESUMEN}

En esta tesis se estudió un tren de tratamiento de mezclas de lodos primarios (LP) y lodos secundarios (LS) en reactores tubulares de vidrio de flujo ascendente con chaqueta, volumen de diseño $10 \mathrm{~L}$ y volumen útil de $8.6 \mathrm{~L}$ en dos etapas. La primera de hidrólisisacidogénesis se operó en mesofília $\left(35 \pm 3^{\circ} \mathrm{C}\right)$, sin pre concentrar los lodos con el objeto de lograr su compactación con el flujo ascendente y al mismo tiempo, de actuar como sedimentador-reactor y así retener sólidos como huevos de helminto, y permitir la solubilización de los sólidos hidrolizados convertidos en AGV por fermentación dejando al lodo predigerido con cierto porcentaje de sólidos. Se encontró la mejor destrucción de sólidos a TRS de $12.5 \mathrm{~d}$ en un $29 \%$ y tasa de producción de metano de $0.009 \mathrm{~L}_{\mathrm{CH}_{4}} / \mathrm{L}_{\mathrm{R}} \cdot \mathrm{d}$. En una segunda etapa termofílica (fase metanogénica) a $55 \pm 1^{\circ} \mathrm{C}$, el reactor también actuó como sedimentador-reactor. Se encuentró la mejor destrucción de sólidos a TRS de $7.4 \mathrm{~d}$ en un $66 \%$ con Bv de $3.5 \mathrm{kgSSV} / \mathrm{m}^{3}$ d y del $55 \%$ a Bv de $7.2 \mathrm{KgSSV} / \mathrm{m}^{3} \mathrm{~d}$ con TRS de $15.2 \mathrm{~d}$ con tasas de producción de metano de 0.005 y $0.09 \mathrm{~L}_{\mathrm{CH}_{4}} / \mathrm{L}_{\mathrm{R}} \cdot \mathrm{d}$ y una eliminación aparente del 97,99 y $85 \%$ de coliformes fecales, Salmonella spp y huevos de helminto. Sin embargo el contenido final de microorganismos en el lodo tratado por este reactor, indica que no se logró su estabilización como se esperaba dado que no cumple con los límites máximos permisibles de patógenos y parásitos en lodos y biosólidos que establece la NOM-004-SEMARNAT-2002 para su reúso. Se observa que no hay influencia de la proporción de LP:LS sobre la tasa de reacción, pero sí de la carga orgánica ya que a mayor carga orgánica, mayor tasa de reacción $\left(U_{S}\right)$, mayor destrucción de sólidos y menor el TRS. 


\section{ABSTRACT}

This thesis presents a treatment train primary sludge mixtures (LP) and secondary sludge (LS) in glass tube reactors upflow jacket design volume $10 \mathrm{~L}$ and working volume of $8.6 \mathrm{~L}$ was studied in two stages. The first hydrolysis-acidogenesis is operated in mesofília $\left(35 \pm 3^{\circ} \mathrm{C}\right)$ without pre concentrate sludge in order to achieve their compaction and the upward flow at the same time act as a settler-solids reactor and there by retain as eggs helminth, and allow the solubilization of the solid hydrolyzate converted by fermentation AGV predigested slurry leaving a certain percentage of solids. The best solids destruction TRS $12.5 \mathrm{~d}$ at $29 \%$ and rate of methane production was found $0.009 \mathrm{LCH}_{4} / \mathrm{L}_{\mathrm{R}} \cdot \mathrm{d}$. In a second stage thermophilic (methanogenic phase) at $55 \pm 1^{\circ} \mathrm{C}$, the reactor also acted as settler-reactor. The best solids destruction TRS $7.4 \mathrm{~d}$ encounter by $66 \%$ with $\mathrm{Bv} 3.5$ $\mathrm{kgSSV} / \mathrm{m}^{3} \cdot \mathrm{d}$ and $55 \%$ to $\mathrm{Bv} 7.2 \mathrm{KgSSV} / \mathrm{m}^{3} \cdot \mathrm{d}$ TRS $15.2 \mathrm{~d}$ with methane production rates of 0.005 and $0.09 \mathrm{LCH}_{4} / \mathrm{L}_{\mathrm{R}} \cdot \mathrm{d}$ an apparent elimination of 97,99 and $85 \%$ of fecal coliforms, Salmonella spp and helminth eggs. However, the final content of microorganisms in the sludge treated by the reactor, indicating that stabilization was not achieved as expected since it does not meet the maximum permissible levels of pathogens and parasites in sludge and biosolids establishing the NOM-004-SEMARNAT-2002 for reuse. It is observed that there is no influence of the proportion of LP: LS on the reaction rate, but the organic load and the higher the organic load, the higher reaction rate (US), more solid and less destruction of the TRS. 


\section{ÍNDICE DE CUADROS}

Página

Cuadro 1.1. Características microbiológicas en aguas y lodos residuales $\quad 6$

Cuadro 1.2. Límites máximos permisibles de metales pesados en biosólidos $\quad 8$

Cuadro1.3. Límites máximos permisibles de patógenos y parásitos en lodos y

biosólidos 8

Cuadro 1.4. Aprovechamiento de biosólidos 8

Cuadro 1.5. Dosis de cal en la estabilización de lodos residuales 10

$\begin{array}{ll}\text { Cuadro 1.6. Caracteristicas generales del biogás } & 12\end{array}$

Cuadro 1.7. Componentes del biogás en función del sustrato 12

Cuadro 1.8. Nutrientes para el desarrollo de bacterias anaerobias 14

$\begin{array}{ll}\text { Cuadro 1.9. Eliminación de patógenos y huevos de helminto } & 17\end{array}$

Cuadro 1.10. Eficiencia de remoción de sólidos suspendidos y producción de metano en la digestión anaerobia mesofílica de lodos residuales primarios y secundarios $\quad 20$

Cuadro 1.11. Eficiencia de remoción de sólidos suspendidos y producción de metano en la digestión anaerobia termofílica de lodos residuales primario y secundario $\quad 21$

Cuadro 1.12. Investigaciones realizadas en la estabilización de lodos residuales $\quad 21$

Cuadro 1.13. Eliminación de patógenos y de parásitos en lodos residuales 22

Cuadro 2.1. Condiciones de operación del rAM 29

$\begin{array}{lr}\text { Cuadro 2.2. Condiciones de operación del rMT } & 29\end{array}$

Cuadro 3.1. Caracterización del lodos primario y secundario $(n=16) \quad 36$

Cuadro 3.2. Caracterización y corrientes de alimentación del rAM 36

Cuadro 3.3. Características del lodo hidrolizado y biogás en el rAM 44

Cuadro 3.4. Constantes de velocidad de reacción (k) en el rAM 50

Cuadro 4.1. Características del lodo y biogás a la salida del rMT 59

$\begin{array}{ll}\text { Cuadro 4.2. Constantes de velocidad de reacción (k) en el rMT } & 61\end{array}$

Cuadro 4.3. Eliminación de microorganismos patógenos y de parásitos 64 


\section{ÍNDICE DE FIGURAS}

Página

Figura 1.1. Esquema de la digestión anaerobia de lodos residuales $\quad 11$

Figura 1.2. Esquema de estabilización de lodos residuales 13

Figura 1.3. Destrucción de sólidos en función del TRS 17

$\begin{array}{ll}\text { Figura 1.4. Digestor anaerobio de baja tasa } & 23\end{array}$

Figura 1.5. Digestor anaerobio de alta tasa 24

Figura 2.1. Esquema de los dos reactores de flujo ascendente en serie para la digestión anaerobia de lodos residuales $\quad 27$

Figura 2.2. Descripción del proceso 28

Figura 2.3. Velocidades de reacción de la digestión anaerobia (DA) 31

Figura 3.1. Efecto de la carga orgánica en la concentración de sólidos a diferentes $\begin{array}{ll}\text { alturas de la cama de lodo } & 37\end{array}$

Figura 3.1a. Promedio de la concentración de SST a distinta altura 37

Figura 3.2. Concentración de SSV y formación de $\mathrm{DQO}_{\mathrm{S}}$ en el reactor rAM 39

Figura 3.2a. Efecto de la carga orgánica (Bv) en la velocidad de destrucción de sólidos

Figura 3.3. Efecto de la carga orgánica en la destrucción de sólidos con distinta proporción de LP:LS.

Figura 3.3a. Efecto de la carga orgánica en la destrucción de sólidos en el rAM

Figura 3.4. Efecto del TRS en la velocidad de destrucción de sólidos en mezclas de LP:LS

Figura 3.5. AGV formados en el reactor acidogénico mesofílico 43

Figura 3.6. Producción y composición de biogás en el reactor acidogénico 44

Figura 3.7. Efecto de la carga orgánica (Bv) en la eliminación de $\mathrm{DQO}_{\text {total }} \quad 45$

Figura 3.8. Estimación de $k_{1}$. 45

Figura 3.8a. Estimación de $\mathrm{k}_{2}$. 46

Figura 3.9. Evolución de $\mathrm{pH}$ en el reactor acidogénico 46

Figura 3.10. Estimación de la tasa de formación de AGV no ionizados (B') a partir de $\begin{array}{ll}\text { la } \mathrm{DQO}_{\mathrm{S}}(\mathrm{SD}) & 47\end{array}$

$\begin{array}{ll}\text { Figura 3.11. Estimación de } k_{3} & 48\end{array}$ 
Figura 3.12. Hidrólisis de proteínas en el reactor rAM 49

Figura 3.13. Efecto de la carga orgánica en la hidrólisis de proteínas en el rAM $\quad 49$

Figura 4.1. Efecto de la carga orgánica (Bv) en la concentración de sólidos a distinta altura 52

Figura 4.1a. Concentración de sólidos a distinta altura en la cama de lodo 52

Figura 4.1b. Efecto del TRH en la concentración de sólidos a distinta altura de la cama de lodo

Figura 4.2. Concentración de SSV y DQOS en el efluente del reactor rMT.

Figura 4.2a. Efecto de la carga orgánica (Bv) en la velocidad de destrucción de sólidos

Figura 4.3. Concentración de $\mathrm{DQO}_{\text {Total }}$ en el reactor rMT

Figura 4.3a. Efecto de la carga orgánica (Bv) en la eliminación de DQO Total 56

Figura 4.4. AGV remanentes en el lodo estabilizado por el reactor metanogénico $\quad 57$

Figura 4.5. Producción y composición de biogás en el reactor metanogénico 58

Figura 4.6. Estimación de $\mathrm{k}_{1} \quad 59$

$\begin{array}{ll}\text { Figura 4.6a. Estimación de } k_{2} & 60\end{array}$

Figura 4.6b. Estimación de la tasa de formación de AGV no ionizados $\left(\mathrm{B}^{-}\right)$a partir de

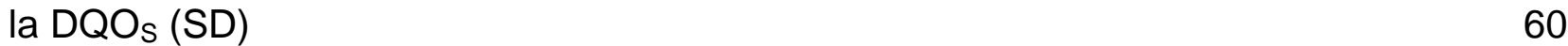

$\begin{array}{ll}\text { Figura 4.6c. Estimación de } \mathrm{k}_{3} & 61\end{array}$

Figura 4.7. Concentración de proteína en el reactor rMT 62

Figura 4.7a. Efecto de la carga orgánica (Bv) en la hidrólisis de proteína 62

Figura 4.8. Efecto del TRH en la eliminación de coliformes fecales. 64

Figura 4.8a. Efecto del TRH en la eliminación de Salmonella spp. 65 


\section{CAPÍTULO 1 INTRODUCCIÓN.}

En este capítulo se presenta un nuevo estudio sobre la digestión anaerobia de lodos primarios y secundarios con base en las variables de respuesta: la destrucción de sólidos volátiles y la eliminación de patógenos y parásitos haciendo uso del efecto de temperatura sobre la velocidad de reacción de las dos etapas anaerobias. Con el flujo ascendente se espera concentrar los lodos hasta $40 \mathrm{~g} / \mathrm{L}$, sin necesidad de un proceso previo de espesamiento.

Con base en esta justificación se fijan los objetivos de los experimentos para tratar de demostrar que el método de digestión basado en una etapa hidrolíticoacidogénica mesofílica a $35^{\circ} \mathrm{C}$ seguido de una segunda etapa metanogénica termofílica a $55^{\circ} \mathrm{C}$ da como resultado la producción de biosólidos de mejor calidad.

Se definen los lodos objeto del estudio, la bioquímica de la digestión anaerobia (DA) y se revisa la literatura referente a la hidrólisis de los lodos residuales primarios y secundarios recabando información sobre el tipo de acondicionamiento (concentración de sólidos y tamaño de partícula), las condiciones de operación y la caracterización de los sólidos que se requiere para mejorar las velocidades de reacción reportadas. 


\subsection{Justificación}

México hasta el año 2009 contaba con 2,029 plantas de tratamiento de aguas residuales municipales, con una capacidad instalada de $120.86 \mathrm{~m}^{3} / \mathrm{s}$ y un caudal tratado de 88.13 $\mathrm{m}^{3} / \mathrm{s}$ que representa el $42.1 \%$ de los $209.1 \mathrm{~m}^{3} / \mathrm{s}$ recolectados en los sistemas de alcantarillado. Entre sus principales sistemas de tratamiento destacan los de lodos activados (46.43\%) (CNA, 2010), con una producción alrededor de 3,195 ton peso seco/día de lodos residuales de los cuales más del $90 \%$ no son tratados, considerados como residuos de manejo especial por la NOM-052-ECOL-1993. El exceso de lodo presenta un serio problema en su disposición al no recibir un tratamiento previo para reducir el contenido de microorganismos patógenos, parásitos y de estabilizar la materia orgánica. En muchos casos gran parte de los lodos generados son descargados en sistemas de alcantarillado, cuerpos de agua o dispuestos en tiraderos a cielo abierto generando problemas de contaminación ambiental y de salud (Aguilar y Llaguno, 2003). Esta práctica es al mismo tiempo un desperdicio de sus propiedades benéficas a la agricultura, al aprovechar los nutrientes y aporte de materia orgánica al suelo, o para el mejoramiento de suelos erosionados por su capacidad de retención de humedad (Barrios y col., 2000). La utilización del biosólido en terrenos agrícolas es una práctica que se ha extendido alrededor del mundo al aprovechar los nutrientes, la materia orgánica y los minerales que contiene (Méndez y col., 2002). Actualmente, los procesos de tratamiento de lodos que cumplen con los requisitos para la producción de biosólidos requieren de varias operaciones unitarias entre ellas, el espesamiento. La digestión anaerobia es el método comúnmente utilizado para estabilizar los lodos residuales primarios y secundarios que se generan en las Plantas de Tratamiento de Aguas Residuales (PTAR). Los lodos primarios (LP) y los lodos secundarios (LS) por su composición poseen características de biodegradación diferente. El lodo primario por su origen está constituido de materia orgánica proveniente principalmente de las heces fecales, y residuos vegetales (Murto y col., 2004). El lodo secundario está formado por agregados celulares unidos por sustancias extracelulares de díficil degradación (Inman, 2004; Boehler y Siegri, 2006). Por esta razón, presentan menor biodegradabilidad durante la digestión anaerobia que los lodos residuales primarios atribuido a la naturaleza recalcitrante de sus componentes celulares (exopolímeros y pared celular) (Ghosh, 1991). Durante la estabilización de LP y 
LS, en algunas plantas se mezclan a diferentes proporciones, pero se quiere demostrar que hay una proporción óptima de LP y LS en la mezcla de lodos a estabilizar debido a la presencia de materiales más digeribles en el lodo primario que permite el crecimiento de biomasa activa capaz de degradar a los lodos secundarios. Lo anterior justifica investigar si un reactor anaerobio mesofílico a $35^{\circ} \mathrm{C}$ sin pre concentrar los lodos, con el flujo ascendente logrará su espesamiento y al mismo tiempo, al actuar como filtro permitirá la retención de sólidos como huevos de helminto, permitiendo la solubilización de los sólidos dejando el lodo predigerido con cierto porcentaje de sólidos para la segunda etapa (fase metanogénica) en la que se espera que el reactor de flujo ascendente termofílico a $55^{\circ} \mathrm{C}$ lleve hasta metano los productos de la acidogénesis y una fracción sólida adicional no digerida además de que con las temperaturas necesarias para la desinfección del lodo, se reduzca la cantidad de bacterias indicadoras y patógenas así como de parásitos (huevos de helminto).

\subsection{Hipótesis}

H1: El flujo ascendente en reactores tubulares permitirá el espesamiento de los lodos dentro del reactor a una concentración que permita operar a TRS adecuados.

H2: Con la separación de la fase de hidrólisis y acidogénesis en un primer reactor se promoverá la formación rápida de AGV y en un segundo reactor la metanización termofílica para producir metano y sólidos desinfectados.

H3: La mezcla de lodo primario y lodo secundario en la primera etapa mejorará la digestión anaerobia debido a que el primero por ser más digerible permitirá que se desarrollen las condiciones de $\mathrm{pH}$ y mayores cantidades de biomasa activa, capaz de hidrolizar a los lodos secundarios.

\subsection{Objetivos}

\section{i. Objetivo General}

Evaluar la digestión anaerobia (DA) en dos etapas de mezclas de lodos primarios y secundarios en reactores de flujo ascendente en serie.

ii. Objetivos Particulares

1. Determinar la hidrólisis y la acidogénesis mesofílica de los sólidos suspendidos. 
2. Estudiar la acetogénesis y metanogénesis termofílica de los ácidos grasos volátiles (AGV) formados en la etapa mesofílica.

3. Estudiar la destrucción de sólidos solubles y suspendidos en las dos etapas.

4. Estudiar la destrucción de patógenos y huevos de helminto en cada etapa.

\subsection{Antecedentes}

\subsubsection{Clasificación de lodos residuales en plantas de tratamiento de aguas residuales (PTAR)}

Las PTAR generan dos tipos de lodos, los obtenidos en el sedimentador primario y los obtenidos en el clarificador secundario.

1.4.1.1. Lodo primario (LP), es aquel que se produce en el sedimentador primario que remueve entre el 50 y $65 \%$ de los sólidos totales (ST) del efluente, alcanzando en promedio una concentración de 5 a $6 \%$ de ST dependiendo de la carga hidráulica superficial (CHS) y del tiempo de residencia hidráulica (TRH). Un lodo primario con un contenido inferior al 70\% de ST normalmente indica: presencia de agua pluvial, corrientes colaterales del procesado de lodos, presencia de arena, desechos industriales con bajo contenido de sólidos volátiles (SV) y puede ser deshidratado mecánicamente (Metcalf y Eddy, 2004). Son de color gris oscuro con un peso seco de los sólidos primarios (SP) del orden del $50 \%$ del total de los sólidos generados en la PTAR de lodos activados, presenta un alto contenido de materia orgánica fácilmente biodegradable constituida por proteínas, carbohidratos y lípidos que al ser hidrolizados resulta en una reducción de sólidos volátiles e incremento de la demanda química de oxígeno en la fase soluble (DQOs) con la consecuente formación de componentes orgánicos solubles que por fermentación da lugar a la formación de ácidos grasos volátiles (AGV) de cadena corta como ácido acético, propiónico, butírico e isobutírico necesarios para la remoción de nutrientes en los procesos biológicos (Turovskiy y Mathai, 2006).

1.4.1.2. Lodo secundario (LS) se produce en procesos de tratamiento biológicos que convierten residuos o sustratos solubles en biomasa. Son flóculos compuestos por bacterias y sustancias exopoliméricas (SEP), en las que se encuentran inmovilizadas casi 
todas las enzimas extracelulares (Yu, 2003). Además de cationes multivalentes, como silicatos, óxido de hierro y fosfato de calcio (Salhi, 2003). Están formados principalmente de proteínas, polisacáridos y ácidos húmicos (Frohlund y col., 1996). Las SEP son moléculas producidas por el metabolismo de las bacterias, estas sustancias constituyen del 80 a 90\% de la fracción orgánica de los LS y el resto son células (Wingender y col., 1999). Los porcentajes de SEP y biomasa dependen de los tiempos de retención de sólidos en el reactor y de las características del agua residual (Frohlund y col., 1996). Wilén y col., (2003) reportaron que las SEP contienen de un 44 a un 55\% de proteínas, de un 30 a un $33 \%$ de ácidos húmicos y un $10 \%$ de carbohidratos. El ácido desoxirribonucleico (ADN) es muy variable y constituye entre el 2 y el $15 \%$ del contenido de las SEP en el lodo (Raszka y col., 2006). Los sólidos suspendidos (SS) de los LS están constituidos por sólidos suspendidos volátiles (SSV), que representan entre el 60 y $85 \%$ de los SS y al mismo tiempo representa la materia orgánica, en tanto que los sólidos suspendidos fijos (SSF), representan el material inorgánico. Los SSV están constituidos entre el 30 y $54 \%$ por proteínas, entre 7.7 y 12\% de lípidos y entre 9 y $22 \%$ de carbohidratos (Bougrier y col., 2008). La DQO de los LS está constituida por $41 \%$ de proteínas, $25 \%$ de lípidos y $14 \%$ de carbohidratos y un $20 \%$ son compuestos no identificados (Tanaka y col., 1997). Los LS contienen entre un 3 y un $4 \%$ de materia orgánica medido como sólidos suspendidos volátiles (SSV), con rendimientos de 0.5 a 1.2 $\mathrm{kg} \mathrm{SSV/kg} \mathrm{DQO}$ Removida. La composición y producción de los LS depende del grado de tratamiento secundario; composición de la carga orgánica (Bv), tiempo de residencia de sólidos (TRS), temperatura y naturaleza de las descargas. Su aplicación directa al suelo,

por el contenido de materia orgánica y otros compuestos aportados, pueden modificar la distribución y movilidad de metales pesados afectando la asimilación de $\mathrm{Cu}$ y $\mathrm{Zn}$ (Ahumada y col., 2004). Contienen elementos como; $\mathrm{Ca}, \mathrm{Cd}, \mathrm{Cu}, \mathrm{Ag}, \mathrm{Hg}, \mathrm{Mo}, \mathrm{Na}, \mathrm{P}, \mathrm{S}$, Se y Zn. Algunos presentan una elevada concentración de Cr, Ni, Si, K y Mg.

\subsubsection{Características de los lodos residuales (LR)}

1.4.2.1. Biológicas: Por ser un subproducto del tratamiento de aguas residuales, contienen microorganismos patógenos y parásitos (Bitton, 1999). Los coliformes son indicativos de contaminación fecal de humanos y animales de sangre caliente y pueden dividirse en 
totales y fecales. Su principal diferencia, es la capacidad de los fecales de crecer a mayor temperatura en condiciones de laboratorio y de producir gas a partir de lactosa (Madigan y col., 2000; Pelczar, 2006). Moeller y Ferat (2000) confirmaron la presencia de cantidades elevadas de los géneros Salmonella y Shigella, protozoarios patógenos al hombre como E. hystolitica y G. lamblia y parásitos más persistentes como: Ascaris y Strongyloides Cuadro 1.1. La Salmonella spp es el género de mayor incidencia de salmonelosis con tiempos de duplicación de 23 minutos para Salmonella typhi y de 150 minutos para Salmonella pollorus. Con tiempos de sobrevivencia de 2 meses en aguas residuales y hasta 8 meses en suelo. Los Ascaris lumbricoides pueden conservarse viables durante 22 meses en aguas superficiales y profundas, y de 1 a 2 meses en cultivos.

Cuadro 1.1. Características microbiológicas en aguas y lodos residuales (USEPA, 2000).

\begin{tabular}{|c|c|c|c|c|c|c|}
\hline \multirow{2}{*}{ Microorganismo } & \multicolumn{5}{|c|}{ NMP/100 mL } & \multicolumn{2}{c|}{ NMP/gSS lodo } \\
\cline { 2 - 7 } & Alcantarilla & Trat. Prim. & Trat. Sec. & Trat. Terc $^{\text {a }}$ & Crudo $^{\text {Digerido }}{ }^{\text {b }}$ \\
\hline Colif. Fecales & $1 \times 10^{9}$ & $1 \times 10^{7}$ & $1 \times 10^{6}$ & $<2$ & $1 \times 10^{7}$ & $1 \times 10^{6}$ \\
\hline Salmonella spp & $8 \times 10^{3}$ & $8 \times 10^{2}$ & $8 \times 10^{3}$ & $<2$ & $1.8 \times 10^{3}$ & 18 \\
\hline Shigella & $1 \times 10^{3}$ & $1 \times 10^{2}$ & $1 \times 10^{3}$ & $<2$ & 220 & 3 \\
\hline Virus entérico & $5 \times 10^{4}$ & $1.5 \times 10^{4}$ & $1.5 \times 10^{3}$ & $2 \times 10^{-3}$ & $1.4 \times 10^{3}$ & 210 \\
\hline Huevos de Helminto & $8 \times 10^{2}$ & $8 \times 10^{1}$ & $8 \times 10^{2}$ & $<8 \times 10^{2}$ & $3 \times 10^{1}$ & 10 \\
\hline Quistes de Giardia & $1 \times 10^{4}$ & $5 \times 10^{3}$ & $2.5 \times 10^{3}$ & 3 & $1.4 \times 10^{2}$ & 43 \\
\hline
\end{tabular}

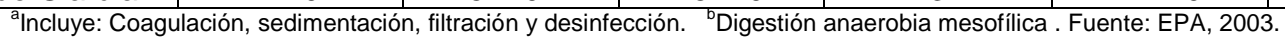

1.4.2.2. Físicas: Los lodos activados (LA) presentan un contenido de ST menor al 1\%, los provenientes de filtros percoladores de 0.5 a $2 \%$ y los del tratamiento primario hasta un $5 \%$. La proporción de materia orgánica en los LS está entre 70 y $80 \%$ de los ST (Winkler, 1994). El tamaño de partícula es variable y es un factor que incide inversamente en la facilidad para desaguar el lodo y directamente en la estabilización (Dimock y Morgenroth, 2006). Con tamaño de partícula entre 1 y 10 micras, el secado se favorece. La sedimentabilidad o velocidad de sedimentación, depende de la concentración de sólidos suspendidos (SS), viscosidad del líquido, tamaño y forma del sedimentador, propiedades químicas, físicas y electrostáticas de la materia en suspensión.

1.4.2.3. Químicas: (1) que se refiere a la materia orgánica de origen animal, vegetal y compuestos tóxicos orgánicos e inorgánicos (compuestos organoclorados, surfactantes, pesticidas, derivados del petróleo y metales pesados; $\mathrm{As}, \mathrm{Cd}, \mathrm{Cu}, \mathrm{Ni}, \mathrm{Hg}, \mathrm{Pb}, \mathrm{Se}$ y $\mathrm{Zn}$ (Anise y Darwin, 1995). Tanto los pesticidas como los metales pesados son altamente 
acumulables en tejidos celulares y difíciles de eliminar por acción microbiana, causan daño a cultivos y a ecosistemas (suelo y agua) (Ros y col., 2006). Al disponer el lodo en el suelo, estos compuestos se dispersan por a) volatilización, que depende de la temperatura ambiental, del método de aplicación y de la velocidad del viento; b) por fotodescomposición, que se da por incidencia de la radiación solar en el lodo, o c) por lixiviación y (2) que se refiere a los inorgánicos como metales pesados y nutrientes. Durante la digestión anaerobia, los metales como arsénico, cadmio y mercurio ejercen un efecto tóxico al interferir en la membrana celular de los microorganismos, lo que disminuye el potencial energético de la cadena de transporte de electrones; destruyen el metabolismo enzimático e inactivan a las enzimas al reaccionar los metales con los grupos HS $^{-}$de los aminoácidos y afectan más a las bacterias metanógenas que a las acetógenas (Montalvo y Guerrero, 2003).

\subsubsection{Producción de biosólidos}

La estabilización busca romper bioquímicamente los sólidos orgánicos para que sean más estables (menos pestíferos y menos putrescibles) y más deshidratables, reducir la masa y volumen del lodo hasta que los sólidos no reaccionen entre ellos ni con su entorno y reducir razonablemente la densidad de patógenos que puedan estar en forma directamente infecciosas para los humanos, o en sus formas más resistentes (quistes y huevos) (Jiménez y col, 2001). La estabilización, depende del grado de destrucción de la fracción volátil u orgánica de los sólidos, por ello, es necesario someter a los lodos residuales a tratamientos de desinfección, que garanticen la eliminación de microorganismos patógenos y la estabilidad de materia orgánica putrecible para utilizar el biosólido en tierras agrícolas y aprovechar su contenido de materia orgánica carbonada, nitrogenada y de nutrientes ( $\mathrm{Ca}, \mathrm{Cd}, \mathrm{Mo}, \mathrm{Na}, \mathrm{P}, \mathrm{S}$, etc.). Las bacterias al incorporarse al suelo, juegan un papel importante en el ciclo del carbono, el nitrógeno y el azufre; debido a que diversos grupos microbianos poseen la habilidad de usar diferentes tipos de aceptores de electrones: nitrato, sulfato y carbonato durante la degradación de contaminantes orgánicos en ecosistemas contaminados por hidrocarburos y en la biotransformación de metales pesados (Balagurusamy, 2005). Además, favorecen el acondicionamiento de suelos arcillosos (Dumontet y col., 2001). Los lodos líquidos que provienen del tratamiento primario y secundario, contienen del 1 al $6.5 \%$ de nitrógeno y 
del 0.6 al 2.5\% de fósforo. Digeridos y secos por acción del aire, el contenido de nitrógeno se reduce al $2 \%$ y el fósforo hasta en un 1.5\%. La materia orgánica varía del 40 al $80 \%$ de la materia seca (MS) (Keller y col., 2004). Su aplicación en suelos agrícolas en países de Europa representa del 45 al 56\% (Lue-Hing y col., 1996; Bastian, 1997). Los métodos utilizados en la estabilización, se basan en: reducción biológica del contenido de materia volátil, oxidación química de matera volátil, elevación de $\mathrm{pH}$, aumento en la temperatura, aplicación de calor con el objetivo de desinfectar o esterilizar el lodo. La intensidad y los tiempos de exposición del lodo residual a estos mecanismos son determinantes para una eficiente desinfección (Souza y col., 2006). La reducción de patógenos y estabilización del biosólido, se logra por combinación de mecanismos: 1) elevación de pH (> a 12) por un periodo de 72 horas y 2 ) elevación de temperatura $\left(T>52^{\circ} \mathrm{C}\right)$ por un periodo de 12 horas (Ingallinella y col., 2001; EPA, 2003). En México la NOM-004-SEMARNAT-2002 define la calidad del biosólido para su aprovechamiento de acuerdo a lo señalado en los Cuadros $1.2,1.3$ y 1.4 .

Cuadro 1.2. Límites máximos permisibles de metales pesados en biosólidos.

\begin{tabular}{|c|c|c|}
\hline Contaminante & $\begin{array}{c}\text { Tipo excelente } \\
\text { (mg/kg en base seca) }\end{array}$ & $\begin{array}{c}\text { Tipo bueno } \\
\text { (mg/kg en base seca) }\end{array}$ \\
\hline Arsénico & 41 & 75 \\
\hline Cadmio & 39 & 85 \\
\hline Cromo & 1,200 & 3,000 \\
\hline Cobre & 1,500 & 4,300 \\
\hline Plomo & 300 & 840 \\
\hline Mercurio & 17 & 57 \\
\hline Níquel & 420 & 420 \\
\hline Zinc & 2,800 & 7,500 \\
\hline
\end{tabular}

Cuadro 1.3. Límites máximos permisibles de patógenos y parásitos en lodos y biosólidos.

\begin{tabular}{|c|c|c|c|}
\hline \multirow{2}{*}{ Clase } & \multicolumn{2}{|c|}{ Patógenos } & Parásitos \\
\cline { 2 - 4 } & $\begin{array}{c}\text { Coliformes fecales } \\
\text { NMP/g ST }\end{array}$ & $\begin{array}{c}\text { Salmonella Sp } \\
\text { NMP/g ST }\end{array}$ & HH/g ST \\
\hline \hline A & $<1,000$ & $<3$ & $<1^{(a)}$ \\
B & $<1,000$ & $<3$ & $<10^{(a)}$ \\
C & $<2 \times 10^{6}$ & $<300$ & $<35^{(a)}$ \\
\hline
\end{tabular}

(a) Huevos de Helminto viables

Cuadro 1.4. Aprovechamiento de biosólidos.

\begin{tabular}{|c|c|c|c|}
\hline Tipo & Clase & \multicolumn{1}{c|}{ Aprovechamiento } \\
\hline Excelente & A & $\begin{array}{l}\text { - Usos urbanos con contacto público directo durante su aplicación } \\
\text { - Los establecidos para la clase B yC }\end{array}$ \\
\hline Excelente o bueno & B & $\begin{array}{l}\text { - Usos urbanos sin contacto público directo durante su aplicación } \\
\text { - Los establecidos para la clase C }\end{array}$ \\
\hline Excelente o bueno & C & $\begin{array}{l}\text { - Usos forestales } \\
\text { - Mejoramiento de suelos } \\
\text { - Usos agrícolas }\end{array}$ \\
\hline
\end{tabular}




\subsubsection{Tratamiento de lodos}

Con el tratamiento se busca reducir su masa y volumen, para facilitar su manejo, y aumentar su estabilidad biológica. Un tren convencional de tratamiento de lodos, consiste de: espesamiento, estabilización química (cal) o biológica (digestión anaerobia, aerobia o compostaje), acondicionamiento, exprimido y secado.

1.4.4.1. Espesamiento.- Esta etapa reduce el volumen del lodo, aumentando la concentración de sólidos y puede realizarse mediante procedimientos físicos por; flotación, gravedad y centrifugación (Winkler, 1994). En los lodos a estabilizar por digestión anaerobia, su espesamiento no debe pasar del $7 \%(70 \mathrm{~g} / \mathrm{L})$, considerándose como óptima una concentración entre el 3 y el $6 \%$, con el objeto de no afectar las propiedades reológicas del lodo y sus consecuencias en bombas, tuberías y mezcladores (Noyola, 1998).

1.4.4.2. Estabilización.- En esta parte del tren de tratamiento se eliminan, en su variante biológica, los sólidos volátiles para reducir el volumen del lodo para su disposición así como la estabilización de la biomasa para limitar los patógenos y proporcionar un producto menos oloroso reduciendo el potencial de atracción de vectores. Los procesos de estabilización pueden dividirse en químicos y biológicos (Metcalf y Eddy, 2004).

1.4.4.2.1. Estabilización química.- Consiste en la aplicación de productos químicos que inhiben la actividad biológica y oxidan la materia orgánica; como la cal (Cuadro 1.5) que al mezclarse con el sólido, eleva su pH a más de 12, propiciando condiciones para que los microorganismos patógenos y virus no sobrevivan eliminando la mayor parte de ellos (Andreoli y col., 2001; Metcalf y Eddy, 2004). Puede emplearse cal viva (CaO) que al reaccionar con el agua forma cal hidratada $\left(\mathrm{Ca}(\mathrm{OH})_{2}\right)$, llevándose a cabo una reacción exotérmica de 64 kJ/gmol (Metcalf y Eddy, 2004, Williford y col., 2007). Físicamente en el sólido se forma una capa más dura y blanca al ser expuestos al aire libre. Químicamente, puede haber fijación de metales pesados e insolubilización de fósforo, a causa de la reacción con ortofosfatos que provocan la formación de precipitados de fosfato de calcio. También se pierde nitrógeno por volatilización de amonio (Andreoli y col, 2001; Méndez y 
col, 2002). La estabilización alcalina del lodo implica una serie de reacciones químicas que alteran su composición, como se muestra a continuación:

$$
\begin{aligned}
& \text { Calcio: } \mathrm{Ca}^{2+}+2 \mathrm{HCO}_{3}{ }^{-}+\mathrm{CaO} \rightarrow 2 \mathrm{CaCO}_{3}+\mathrm{H}_{2} \mathrm{O} \\
& \text { Fósforo: } 2 \mathrm{PO}_{4}{ }^{3-}+6 \mathrm{H}^{+}+3 \mathrm{CaO} \rightarrow \mathrm{Ca}_{3}\left(\mathrm{PO}_{4}\right)_{2}+3 \mathrm{H}_{2} \mathrm{O} \\
& \text { Dióxido de carbono: } \mathrm{CO}_{2}+\mathrm{CaO} \rightarrow \mathrm{CaCO}_{3}
\end{aligned}
$$

Reacciones con contaminantes orgánicos:

$$
\begin{aligned}
& \text { Ácidos: } \mathrm{RCOOH}+\mathrm{CaO} \longrightarrow \mathrm{RCOOCaOH} \\
& \text { Grasas: Grasa }+\mathrm{Ca}(\mathrm{OH})_{2} \longrightarrow \text { Glicerol + Ácidos grasos }
\end{aligned}
$$

\begin{tabular}{|c|c|c|c|c|}
\hline \multicolumn{2}{|c|}{ Concentración de sólidos } & \multicolumn{2}{|c|}{${ }^{*}$ Cantidad de cal } & \\
\hline \multirow[b]{2}{*}{ Tipo de lodo } & \multicolumn{2}{|c|}{$\%$} & \multicolumn{2}{|c|}{ g Ca(OH $)_{2} / \mathrm{kg}$ de sólidos secos } \\
\hline & Rango & Promedio & Rango & Promedio \\
\hline Primario & 3.6 & 4.3 & $60-170$ & 120 \\
\hline Activado & $1-1.5$ & 1.3 & $210-430$ & 300 \\
\hline Digerido anaeróbicamente & $6-7$ & 5.5 & $140-250$ & 190 \\
\hline Septico & $1-4.5$ & 2.7 & $90-510$ & 200 \\
\hline
\end{tabular}

Cuadro 1.5. Dosis de cal en la estabilización de lodos residuales.

${ }^{*}$ Cantidad de $\mathrm{Ca}(\mathrm{OH})_{2}$ para mantener el pH a 12 por 30 minutos.

1.4.4.2.2. Estabilización biológica.- consiste en la conversión de la fracción volátil a metano o dióxido de carbono, según la via aplicada, por medio de la acción de microorganismos, principalmente bacterias y puede llevarse a cabo por: 1) digestión anaerobia, 2) digestión aerobia y 3) por composteo.

1) Digestión anaerobia.- Proceso que se lleva a cabo a través de una serie de reacciones bioquímicas bajo acción bacteriana en ausencia de oxígeno molecular con la subsecuente conversión de materia orgánica en biogás, Figura 1.1 (Flotats y col., 2005). Durante el desarrollo del proceso, las bacterias establecen de cierta forma el equilibrio en el sistema y su control requiere de un balance entre poblaciones; es decir, entre las bacterias formadoras de ácido y las bacterias productoras de metano. En la primera fase, participan bacterias hidrolíticas, encargadas de romper los polímeros orgánicos (polisacáridos, proteínas, y lípidos) en monómeros (triglicéridos, aminoácidos, azúcares, ácidos grasos 
volátiles de cadena larga, alcoholes, $\mathrm{H}_{2}$ y $\mathrm{CO}_{2}$ ). Seguida por bacterias fermentativas $\mathrm{o}$ acidogénicas que transforman los productos formados durante la hidrólisis en compuestos orgánicos simples (ácidos grasos volátiles de cadena corta: ácido acético y compuestos intermedios como etanol, ácido láctico, ácido propiónico, ácido fórmico y ácido butírico, nuevas células bacterianas además de $\mathrm{H}_{2}$ y $\mathrm{CO}_{2}$ ). Estos compuestos son convertidos en acetato, $\mathrm{H}_{2}$ y $\mathrm{CO}_{2}$ por las bacterias acetogénicas. Finalmente, las bacterias metanogénicas producen metano a partir de sus sustratos: la mezcla de $\mathrm{H}_{2} / \mathrm{CO}_{2}$, el formiato, el acetato, el metanol y las metilaminas. Algunas pueden utilizar el etanol, el ciclopentanol y el 2-propanol como donadores de electrones para producir el $\mathrm{CO}_{2}$. Los principales sustratos de los digestores anaerobios son; la mezcla de $\mathrm{H}_{2} / \mathrm{CO}_{2}$, el formiato y el acetato. Este último da origen al 73\% del metano producido (Griffin y col., 1998; Díaz y col., 2002; Bouallagui y col., 2005).

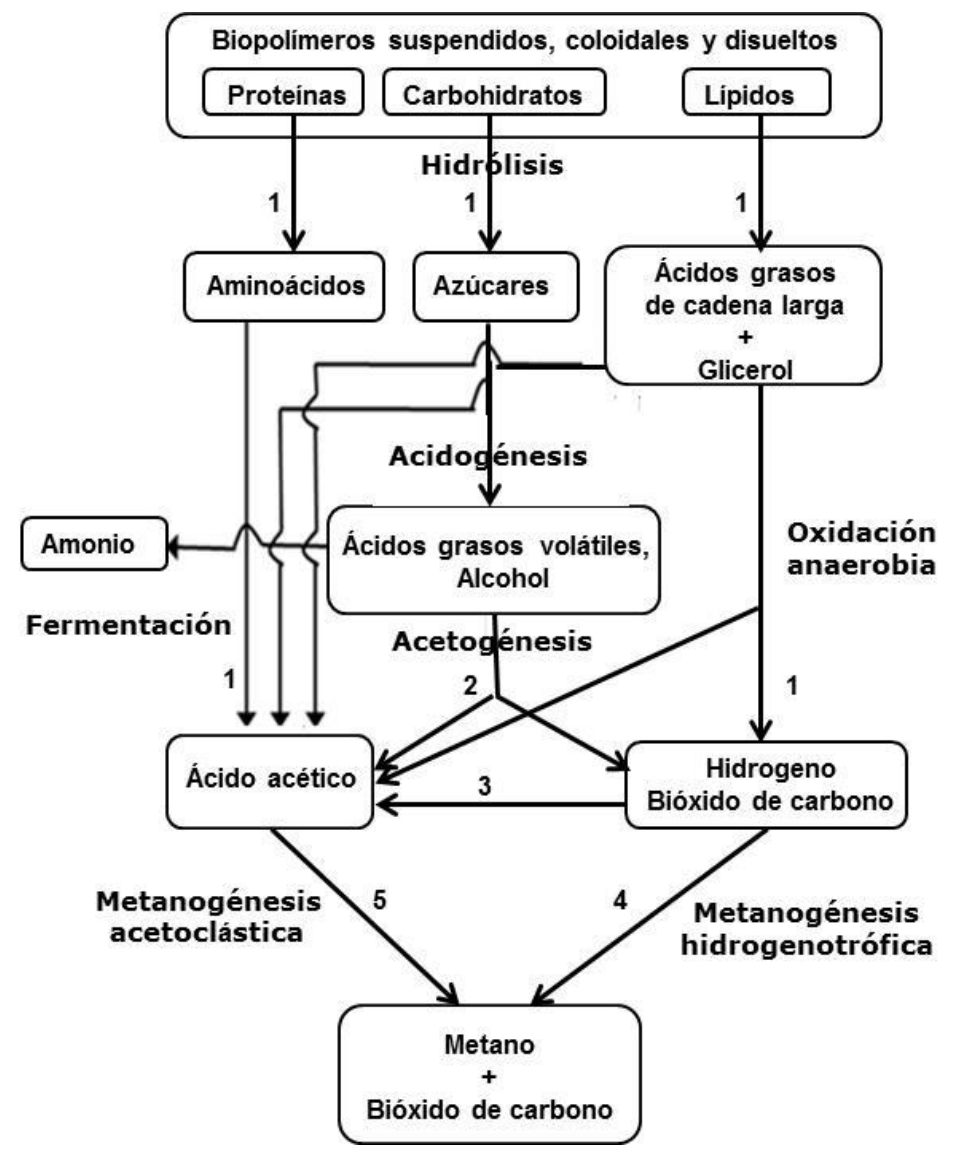

Figura 1.1 Esquema de la digestión anaerobia de lodos residuales (Sanders, 2001). Los números indican la población bacteriana responsable del proceso: 1: bacterias fermentativas; 2: bacterias acetogénicas que producen hidrógeno; 3: bacterias homoacetogénicas; 4: bacterias metanogénicas hidrogenotróficas; 5 : bacterias metanogénicas acetoclásticas. 
El biogás producido presenta una composición volumétrica del 65 al $70 \%$ de $\mathrm{CH}_{4}$, del 25 al $30 \%$ de $\mathrm{CO}_{2}$, pequeñas cantidades de $\mathrm{N}_{2}, \mathrm{H}_{2}$ y $\mathrm{H}_{2} \mathrm{~S}$ (Aguilar y Álvarez, 2007). Cuando su contenido de metano es superior al $45 \%$ es inflamable.

Cuadro 1.6. Características generales del biogás

\begin{tabular}{|l|l|}
\hline Composición & $\begin{array}{l}55-70 \% \text { metano }\left(\mathrm{CH}_{4}\right) \\
30-45 \% \text { dióxido de carbono }\left(\mathrm{CO}_{2}\right) \\
\\
\text { Trazas de otros gases }\end{array}$ \\
\hline Contenido energético & $6.0-6.5 \mathrm{kWh} / \mathrm{m}^{3}$ \\
\hline Equivalente de combustible & $0.60-0.65 \mathrm{~L}$ petróleo $/ \mathrm{m}^{3}$ biogás \\
\hline Límite de explosión & $6-12 \%$ de biogás en el aire \\
\hline Temperatura de ignición & $650-750^{\circ} \mathrm{C}$ (con el contenido de $\mathrm{CH}_{4}$ mencionado) \\
\hline Presión crítica & $74-88 \mathrm{~atm}$ \\
\hline Temperatura crítica & $-82.5^{\circ} \mathrm{C}$ \\
\hline Densidad normal & $1.2 \mathrm{~kg} \mathrm{~m} \mathrm{~m}^{3}$ \\
\hline Olor & Huevo podrido (el olor del biogás desulfurado es imperceptible) \\
\hline Masa molar & $16.043 \mathrm{~kg} / \mathrm{kmol}$ \\
\hline
\end{tabular}

Fuente: Deublein y Steinhauser (2008)

El volumen y la composición del biogás dependen del material digerido, del funcionamiento del proceso y de la carga alimentada y a la temperatura debido a su influencia en la velocidad de descomposición (Cuadro 1.7). A los sólidos que no se degradan se les denomina sólidos inertes y son una fracción del lodo digerido. La calidad del biosólido producido está en función de: la temperatura de exposición, pH y tiempo de retención del lodo en el digestor (Noyola, 1998; Qin y Herbert, 2003; Nidal y col., 2004). Se requiere de tiempos de residencia y temperaturas entre 60 días a $20^{\circ} \mathrm{C}$ y 15 días a temperaturas entre 35 y $55^{\circ} \mathrm{C}$ para disminuir los sólidos volátiles en un $38 \%$ (Miron y col., 2000; Sanchez y col., 2012). Con concentraciones entre 6 y 7\% de ST y $10.5 \%$ de SV se logra mejorar la reducción de sólidos (Nidal y col., 2004). Residuos con alto contenido de nitrógeno y azufre, pueden producir altas concentraciones de compuestos tóxicos (amonio y súlfuro de hidrógeno) que son inhibidores para la digestión anaerobia. A mayor concentración de sólidos, mayor producción de compuestos tóxicos (Bouallagui y col., 2005).

Cuadro 1.7. Componentes del biogás en función del sustrato

\begin{tabular}{|lcccc|}
\hline Componente & $\begin{array}{c}\text { Residuos } \\
\text { agrícolas }\end{array}$ & $\begin{array}{c}\text { Lodos de } \\
\text { PTAR }\end{array}$ & $\begin{array}{c}\text { Residuos } \\
\text { industriales }\end{array}$ & Gas \\
\hline Metano & $50-80 \%$ & $50-80 \%$ & $50-70 \%$ & $45-65 \%$ \\
Dióxido de carbono & $30-50 \%$ & $20-50 \%$ & $30-50 \%$ & $34-55 \%$ \\
Agua & Saturado & Saturado & Saturado & Saturado \\
Hidrógeno & $0-2 \%$ & $0-5 \%$ & $0-2 \%$ & $0-1 \%$ \\
Súlfuro de hidrógeno & $100-700$ ppm & $0-1 \%$ & $0-8 \%$ & $0.5-100$ ppm \\
Amoniaco & Trazas & Trazas & Trazas & Trazas \\
Monoxido de carbono & $0-1 \%$ & $0-1 \%$ & $0-1 \%$ & Trazas \\
Nitrógeno & $0-1 \%$ & $0-3 \%$ & $0-1 \%$ & $0-20 \%$ \\
Oxígeno & $0-1 \%$ & $0-1 \%$ & $0-1 \%$ & $0-5 \%$ \\
Compuestos orgánicos & Trazas & Trazas & Trazas & 5 ppm* \\
\hline
\end{tabular}

*terpernos, esteres,... 
Modelo cinético de la digestión anaerobia (DA).

Las reacciones de la DA, se expresan con un modelo de reacción consecutiva de primer orden como sigue:

$$
\begin{aligned}
& \mathrm{SS} \stackrel{\mathrm{k}_{1}}{\longrightarrow} \mathrm{SD} \stackrel{\mathrm{k}_{2}}{\longrightarrow} \mathrm{B}^{-} \stackrel{\mathrm{k}_{3}}{\longrightarrow} \mathrm{CH}_{4} \\
& V_{\mathrm{SS}}=\mathrm{k}_{1} \mathrm{SS} \\
& V_{\mathrm{SD}}=\mathrm{k}_{1} \mathrm{SS}-\mathrm{k}_{2} \mathrm{~S} \\
& V_{\mathrm{B}}^{-}=\mathrm{k}_{2} \mathrm{~S}-\mathrm{k}_{3} \mathrm{~B}^{-} \\
& V_{\mathrm{CH} 4}=\mathrm{k}_{3} \mathrm{~B}^{-}
\end{aligned}
$$

Donde $k_{i}=$ constante de velocidad de reacción $\left(d^{-1}\right), S S=$ concentración de sólidos suspendidos $(g / L)$ y SD = concentración de sólidos disueltos en la fase soluble $(\mathrm{g} / \mathrm{L}), \mathrm{B}^{-}=\mathrm{AGV}$ producidos $(\mathrm{g} / \mathrm{L})$ yVCH${ }_{4}=$ metano producido (L/d).

La estabilización de lodos residuales puede llevarse a cabo en reactores con alimentación continua o intermitente (Figura 1.2).

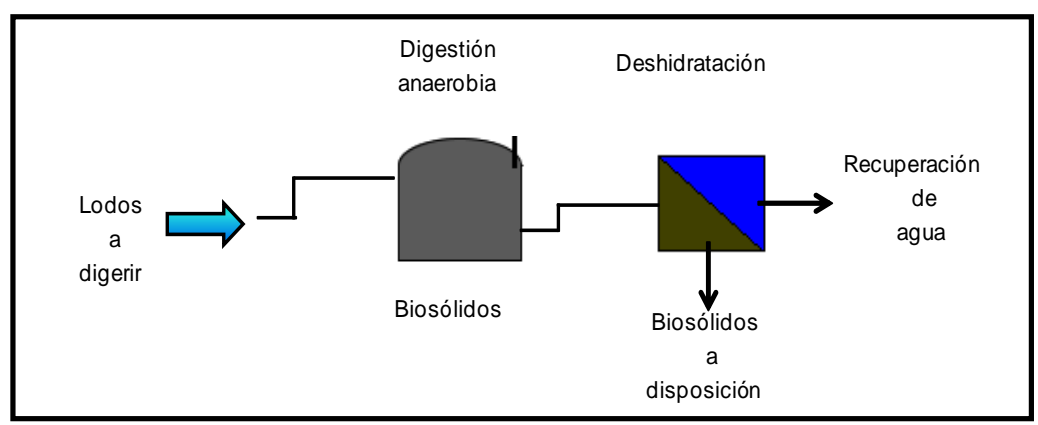

Figura 1.2. Esquema de la estabilización de lodos residuales.

La eficiencia del proceso, puede evaluarse con base en la destrucción de la materia orgánica (SSV O DQO), volumen y composición del biogás que se produjo. Como controladores de la DA se tiene: el aumento en la concentración de $\mathrm{H}_{2}$ y $\mathrm{CO}_{2}$, acumulación de AGV y consumo de la alcalinidad. Las variables que influyen en el arranque, la estabilidad y el control del proceso de digestión anaerobia de lodos residuales (Montalvo y Guerrero, 2003) son: composición del sustrato, parámetros ambientales y operacionales, como:

Nutrientes.- Entre los nutrientes minerales del sistema anaerobio destacan carbono, 
nitrógeno, fósforo y pequeñas cantidades de azufre (Cuadro 1.8), vitaminas (riboflavina y vitamina B12) y una serie de elementos minerales como $\mathrm{Na}, \mathrm{K}, \mathrm{Ca}, \mathrm{Mg}$ y $\mathrm{Fe}$ en muy bajas concentraciones, además de cobalto, níquel, molibdeno y selenio (Speece, 1987). Los requerimientos de nitrógeno y fósforo dependen de la concentración de carbono en la alimentación, considerándose una relación óptima de C/N/P del orden de 250/7/1, aunque puede variar dependiendo del tipo de residuo o de C/N entre 15-30:1, y la C/P de 75-113/1 (Speece, 1987; Forbes y col., 2002).

Cuadro 1.8. Nutrientes para el desarrollo de bacterias anaerobias (Speece, 1987 y Forbes, 2002).

\begin{tabular}{|lcc|}
\hline & $\mathbf{g} / \mathbf{k g}$ SSV & $\mathbf{g} / \mathbf{k g}$ DQO \\
\hline Nitrógeno & $80-120$ & $95-55$ \\
Fósforo & $10-25$ & $7-18$ \\
Azufre & $10-25$ & $7-18$ \\
Hierro & $5-15$ & $4-11$ \\
\hline
\end{tabular}

pH.- Variaciones en el pH afecta la actividad enzimática de los microorganismos por cambios de estado de los grupos ionizables, provoca alteración de los componentes no ionizables del sistema como la desnaturalización de la estructura proteíca de las enzimas (Clark y Speece, 1989). Altos valores de pH favorece la formación de amoníaco libre, inhibidor de la fase metanogénica lo que provoca desequilibrio entre la producción y el consumo de ácidos grasos volátiles por acumulación de éstos (Iza, 1995) acidificando el reactor (Zeeman y Sanders, 2001). Por su parte niveles alcalinos, afecta las bacterias metanogénicas acetoclásticas (Malina y Pohland, 1992). La DA puede llevarse a cabo en un intervalo de $\mathrm{pH}$ entre 6.2 y 7.8 , con un óptimo entre 7 y 7.2 (Noyola, 1998).

Alcalinidad.- La capacidad amortiguadora durante la DA se debe a la presencia de carbonatos, en particular a la capacidad tampón del bicarbonato $\mathrm{HCO}_{3}{ }^{-}$. En el digestor los bicarbonatos de calcio, magnesio y amonio son sustancias que actúan como amortiguadores para mantener el $\mathrm{pH}$ constante. Un digestor estable presenta una alcalinidad total de 2,000 a 5,000 mg/L (WEF, 1996), el principal reductor de alcalinidad es el dióxido de carbono, y no los ácidos grasos volátiles (Speece, 1987). El dióxido de carbono se produce en las fases de fermentación y metanogénesis de la digestión y, debido a la presión parcial del gas en el digestor, se solubiliza y forma ácido carbónico que reduce la alcalinidad. La concentración de $\mathrm{CO}_{2}$ se ve reflejada en los requerimientos de alcalinidad. Un criterio para verificar si la carga orgánica suministrada al digestor es 
adecuada, es mediante la relación $\alpha$ de la alcalinidad debida a los bicarbonatos entre la alcalinidad total. La relación AGV/alcalinidad, también es indicadora de estabilidad; una relación inferior a 0.4 indica fallo inmediato (WPCF, 1995).

Toxicidad e inhibición. Puede presentarse debido a concentraciones elevadas de metales pesados y metales alcalinotérreos (Hayes y Theis, 1982), ácidos grasos volátiles (Hickey y Switzenbaum, 1991; Hwu y col., 1997), nitrógeno amoniacal (Angelidaki y Ahring, 1997) y sulfuros (Hulshoff Pol y col., 1998).

Temperatura. Define el crecimiento de las especies predominantes en los biodigestores dentro de cada rango, la velocidad de crecimiento aumenta con la temperatura hasta alcanzar un máximo, y a partir del cual empieza a disminuir. Por lo tanto, ésta es una de las variables que dicta los límites de viabilidad del proceso. Los incrementos de temperatura generan dos efectos importantes en los organismos (Peterson y col., 2006); a) Por un lado, se favorece la reacción catalítica $\left(k_{\mathrm{cs}} \mathrm{f}\right)$ como lo propuso por primera vez Arrhenius en 1889 al cuantificar el efecto de la temperatura sobre la capacidad enzimática en la hidrólisis del azúcar (Thomas y Scopes, 1998). En lodos residuales, a medida que la temperatura se incrementa, el crecimiento bacteriano y la hidrólisis de sólidos ocurre más rápidamente de acuerdo a la siguiente ecuación para la catálisis enzimática (Sanders, 2001):

Donde:

$$
k=A e^{-E_{a} / R T}
$$

$\mathrm{K}$ representa la constante cinética o constante de hidrólisis $\left(\mathrm{en}^{-1}{ }^{-1}\right.$.

A es la constante de Arrhenius que toma en cuenta la frecuencia y orientación de las colisiones moleculares.

$E_{a}$ es la energía mínima necesaria para llevar a cabo la transformación (la cual es llamada energía de activación $(\mathrm{J} / \mathrm{mol})$.

$R$ es la constante de los gases $(\mathrm{J} / \mathrm{Kmol})$.

$\mathrm{T}$ es la temperatura absoluta en $\mathrm{K}$.

Los valores normalmente observados en la energía de activación para los sistemas biológicos se encuentran en el rango de 4 a $20 \mathrm{kcal} / \mathrm{mol}$, medidos a $25^{\circ} \mathrm{C}$, y un aumento de $10^{\circ} \mathrm{C}$, favorece su actividad de 1.2 a 3.0 veces. Por otro lado cuando se sobrepasa el umbral de cierta temperatura se propicia el daño irreversible de los componentes de la biomasa (proteínas, ácidos nucleícos y otros componentes celulares), afecta constantes 
de equilibrio químico, provoca desplazamientos en parámetros, como alcalinidad, $\mathrm{pH}$, precipitación o redisolución de compuestos inorgánicos, cambios en la composición del gas por efecto de solubilidad, disolución de compuestos orgánicos volátiles como el amonio y el sulfuro de hidrógeno. Por tanto, la temperatura debe ser controlada adecuadamente, un cambio en ella, podría afectar el proceso de digestión anaerobia de sólidos (Sanders, 2001; Mahmoud y col., 2004). En digestores anaerobios mesofílicos algunos problemas de operación son: baja reducción de SSV y lenta velocidad de destrucción de microorganismos patógenos. En lodos primarios a TRH de 15 a 30 días, la remoción de sólidos volátiles es del 55 al 60\% con una producción de biogás de 500 a $600 \mathrm{~L} / \mathrm{kg}_{\mathrm{sv}} \mathrm{d}$; en lodos secundarios la remoción de SV es del 32 al $40 \%$ con una producción de biogás de 250 a $350 \mathrm{~L} / \mathrm{kg}_{\text {sv }}$ d y en mezclas de ellos con TRH menores a 10 d, la remoción de SV es del 40 al 50\% con una produccion de biogás de 450 a 550 $\mathrm{L} / \mathrm{kg}_{\mathrm{sv}}$ d. Los reactores mesofílicos son eficientes en la eliminación de enterovirus (Gavala y col., 2003), pero ineficientes en la eliminación de huevos viables de nematodos y sólo se logra un biosólido clase B (Monpoeho y col., 2004). Entre las ventajas que presentan los reactores mesofílicos cabe mencionar el control y eliminación del mal olor asociado al lodo, mejoramiento de la solubilidad de $\mathrm{N}$ y $\mathrm{P}$ para su acción fertilizante y alta remoción de AGV. Tienden a ser más robustos y tolerantes que los termofílicos.

En los digestores termofílicos se favorece la hidrólisis de SV, no tienen problemas de formación de espuma, pero presentan baja remoción de AGV lo que provoca desestabilización por acumulación de propionato, generan malos olores y menores eficiencias de remoción de proteínas y lípidos (Carrozzi y Steinle, 1994). Por el aumento en la temperatura se producen biosólidos clase (Puchajda y Oleszkiewicz, 2004), además presentan ventajas como: separación de la fase sólida de la líquida e incremento en el grado de destrucción de sólidos orgánicos hasta en un 56\% (Zitomer y col., 2005). Los digestores termofílicos son de 1.5 a 2.5 veces más eficiente que los mesofílicos pero mucho más sensibles a altas concentraciones de amonio debido a que al incrementar la temperatura, se favorece la forma molécular, que es más tóxica que la iónizada (Koster, 1989) predominando el amonio libre según el balance entre la forma molécular y la iónizada del amonio. A pesar de que las bacterias patógenas son destruidas más rápidamente a temperaturas mayores de $53^{\circ} \mathrm{C}$ (Cuadro 1.9) que a $35^{\circ} \mathrm{C}$, algunas bacterias 
con endosporas como Clostridium perfringens, Bacillus cereus y Bacillus anthracis pueden sobrevivir a $53^{\circ} \mathrm{C}$ transmitiendose a través de los biosólidos (Couturier y Galtier, 2000; Gale, 2002).

Cuadro 1.9. Eliminación de patógenos y huevos de helminto (Couturier y Galtier, 2000; Gale, 2002).

\begin{tabular}{l} 
Organismo \\
\hline Salmonella typhosa \\
Salmonella sp. \\
Shigella sp. \\
Escherichia coli. \\
Entamoeba histolytica \\
Taenia saginata \\
Trichinella spiralis \\
Brucella abortus o Br. Suis. \\
Mycrococcus pyogenes var. Aureus \\
Streptococcus pyogenes \\
Mycobacterium tuberculosis var. Homini \\
Corynebacterium diptheria
\end{tabular}

Huevos en aparato gastro Intestinal de bovinos

Huevos en excremento de cerdos

Huevos de Ascaris lumbricoides

Necator americanus en intestino delgado

de humanos, cerdos, perros y gatos.

\section{Temperatura y tiempo de exposición}

Sin crecimiento por encima de $46^{\circ} \mathrm{C}$, eliminación en 30 minutos a $55-60^{\circ} \mathrm{C}$ y en 20 minutos a $60^{\circ} \mathrm{C}$.

Eliminación en 1 hora a $55^{\circ} \mathrm{C}$ y en $15-20$ minutos a $60^{\circ} \mathrm{C}$.

Eliminación en 1 hora a $55^{\circ} \mathrm{C}$.

Eliminación en 1 hora a $55^{\circ} \mathrm{C}$ y en $15-20$ minutos a $60^{\circ} \mathrm{C}$.

Eliminación en pocos minutos a $45^{\circ} \mathrm{C}$ y en pocos segundos a $55^{\circ} \mathrm{C}$.

Eliminación en pocos minutos a $55^{\circ} \mathrm{C}$.

Eliminación rápida a $55^{\circ} \mathrm{C}$ e instantánea a $60^{\circ} \mathrm{C}$.

Eliminación en 1 hora a $55^{\circ} \mathrm{C}$ y en 3 minutos a $62-63^{\circ} \mathrm{C}$.

Eliminación en 10 minutos a $50^{\circ} \mathrm{C}$.

Eliminación en 10 minutos a $54^{\circ} \mathrm{C}$.

Eliminación en $15-20$ minutos a $66^{\circ} \mathrm{C}$.

Eliminación en 45 minutos a $55^{\circ} \mathrm{C}$.

$\begin{array}{cc}\text { Inactivacion a } 35^{\circ} \mathrm{C} & \frac{\text { Inactivacion a } 53^{\circ} \mathrm{C}}{2 \text { días }} \\ 6-8 \text { días } & 1-4 \text { horas } \\ 1-4 \text { horas }\end{array}$

Eliminación en menos de 1 hora a temperaturas mayores de $50^{\circ} \mathrm{C}$

Eliminación en 50 minutos a $45^{\circ} \mathrm{C}$.

Tiempo de retención de sólidos (TRS). Se define como el tiempo medio que el sustrato alimentado permanece en el digestor antes de ser eliminado como lodo digerido. En un reactor de mezcla completa, sin recirculación de sólidos, el TRH coincide con el TRS. Si existe recirculación de sólidos el TRS es mayor que el TRH. El tiempo de retención afecta a la velocidad de producción de gas. A igualdad del resto de las condiciones, la eficacia del proceso (\% de sustrato alimentado convertido en biogás) aumenta con el tiempo de retención hasta un valor asintótico. Existe un TRS mínimo donde la destrucción de sólidos es menor al 30\% (Figura 1.3) con TRS entre 15 y 20 días, la producción de biogás mejora a $35^{\circ} \mathrm{C}$.

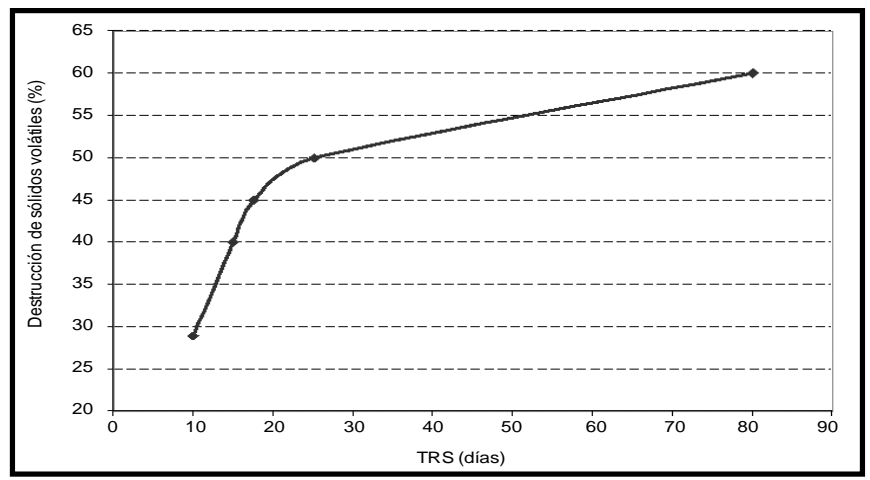

Figura 1.3. Destrucción de sólidos en función del TRS (Yuan y col., 2009). 
Tiempo de retención hidráulica. El tiempo medio de retención hidráulico $(T R H)$ se calcula como el cociente entre el volumen del digestor y el caudal alimentado. Es importante para establecer la carga orgánica, el tiempo de crecimiento bacteriano y la subsecuente conversión de materiales orgánicos solubles en biogás producto de la destrucción de los SV.

2) Digestión aerobia.- Esta tecnología hace uso de oxígeno para la estabilización de lodos residuales para obtener como productos finales dióxido de carbono, agua y amoniaco, que puede oxidarse, si las condiciones lo permiten, hasta nitrato.

3) Compostaje.- Es un método de estabilización de lodo (40-60\% de sólidos). Conforme se degrada la materia orgánica, la pila se va calentando hasta alcanzar temperaturas entre 50 y $70^{\circ} \mathrm{C}$ con una conversión del 20 al $30 \%$ de sólidos volátiles en dióxido de carbono y agua y, destrucción de microorganismos patógenos (Metcalf y Eddy, 2004).

1.4.4.3. Acondicionamiento.- Se emplea para concentrar el lodo y alcanzar una buena deshidratación. Puede ser: 1) Químico: utilizando iones inorgánicos polivalentes o polielectrolitos para reducir la humedad hasta niveles del 65\% y 2) Térmico a altas temperaturas $\left(180-200^{\circ} \mathrm{C}\right)$ y presiones $(10-20 \mathrm{~atm})$ por periodos cortos de tiempo.

1.4.4.4. Exprimido.- Permite la remoción de agua de los lodos hasta adquirir características casí sólidas. Lo que permite disminuir el costo de transporte (reducción de masa y volúmen del lodo), facilita los procesos subsecuentes (incineración o composteo), reduce el potencial de putrefacción y disminuye los lixiviados si el lodo es dispuesto en rellenos sanitarios. Puede realizarse por; filtración al vacío con tambor rotatorio, filtros banda, filtros prensa, lechos de secado y centrifugado (Winkler, 1994).

1.4.4.5. Secado.- Involucra la reducción del contenido de agua por vaporización hasta alcanzar un contenido de humedad en el lodo menor al 10\%. Pueden utilizarse lechos de secado donde la evaporación a la atmósfera se produce por diferencia en la presión de vapor y por secado mecánico donde el calor externo aumenta la capacidad de retención de vapor en el aire ambiental. 


\subsection{Procesos anaerobios en la estabilización de lodos residuales}

En este apartado se hace una revisión bibliográfica de los procesos anaerobios empleados en la estabilización de lodos residuales. La digestión anaerobia (DA) comúnmente es el método más utilizado en la estabilización de lodos residuales de las PTAR, cuyo objetivo principal es: 1) estabilización de la materia orgánica, 2) eliminación de olores, 3) reducción de microorganismos patógenos y, 4) reducción sólidos orgánicos, con la subsecuente producción de metano. Metcalf y Eddy (2004) citan las siguientes configuraciones; digestión ácido-gas, digestión mesofílica y termofílica en una sola etapa y digestión termofílica-mesofílica en dos etapas:

1.5.1. Digestión Ácido-Gas.- Pohland y Ghosh (1971) propusieron la fase ácido-gas variando los TRS para seleccionar la cinética de las bacterias formadoras de ácido y la de los microorganismos formadores de metano debido a que estos presentan una tasa de crecimiento baja. A TRS cortos y altas cargas orgánicas se puede provocar la acumulación de ácidos orgánicos intermediarios en el primer digestor. El pH crea las condiciones favorables para el crecimiento de las bacterias formadoras de ácidos y presentan un crecimiento óptimo a pH 6 (Dichtl, 1997). Un primer digestor es operado a TRS cortos (12 horas-1.5 días) para promover el crecimiento de microorganismos formadores de ácidos, el segundo digestor es operado a TRS largos ( $\geq 18$ días) para establecer la biomasa formadora de metano.

1.5.2. Digestión mesofílica en una etapa. - Es el método comúnmente utilizado en la estabilización de lodos residuales operado de $30-38^{\circ} \mathrm{C}$. En décadas pasadas era considerada como una alternativa tecnológica para la digestión de lodos residuales y la destrucción de patógenos y reducir los SV. Sin embargo, no se logra reducir los patógenos hasta niveles permisibles en la norma. Con tiempos de retención hidráulicos (TRH) mayores a 10 días, la producción específica media de biogás referida a los SSV eliminados varía entre 200 y $600 \mathrm{~L}$ biogás $/ \mathrm{kg} \mathrm{SSV}_{\text {eliminado }}$ (Cuadro 1.10). Para TRH entre 5 y 55 días la concentración volumétrica de metano varía entre el 62 y el 66\%. En cuanto a la reducción de sólidos volátiles (SV), a TRH de 15 a 30 días, la reducción es del 55 al $60 \%$ para lodos residuales primarios y del 32 al $40 \%$ para lodos residuales secundarios 
con una producción de biogás de 500 a 600 L/kg SV eliminado. En mezclas de LP:LS la remoción de SV es del 40 al 50\% a TRH menores a 10 días con una producción de biogás de 450 a 550 L/kg SV eliminado (Kyung-Yub y col., 1997; Roberts y col., 1999).

Cuadro 1.10. Eficiencia de remoción de sólidos suspendidos y producción de metano en la digestión anaerobia mesofílica de lodos residuales primario y secundario.

\begin{tabular}{|c|c|c|c|c|c|c|c|}
\hline $\begin{array}{l}\text { Tipo de } \\
\text { reactor }\end{array}$ & $\mathrm{T}^{\circ} \mathrm{C}$ & Tipo de lodo & $\begin{array}{l}\text { TRS } \\
\text { dias }\end{array}$ & $\begin{array}{c}\mathrm{Bv} \\
\mathrm{kgSV} / \mathrm{m}^{3} \cdot \mathrm{d}\end{array}$ & $\begin{array}{l}\text { Eficiencia } \\
\text { de remoción } \\
\text { de SV }(\%)\end{array}$ & $\begin{array}{l}\text { Produccion } \\
\text { de metano } \\
\mathrm{LCH}_{4} / \mathrm{m}^{3} \mathrm{~d}\end{array}$ & Referencia \\
\hline RCTA & 37 & $\begin{array}{c}\text { LP } \\
\text { LS } \\
\text { LS:LP }\end{array}$ & $15-30$ & 2 & $\begin{array}{l}55-60 \\
32-40 \\
40-50\end{array}$ & $\begin{array}{l}0.785 \\
0.392 \\
0.714 \\
\end{array}$ & $\begin{array}{c}\text { Carrozzi y Steinle., } \\
\text { (1994). }\end{array}$ \\
\hline RCTA & 35 & LP:LS & 20 & $1.5-3$ & 49 & 0.588 & $\begin{array}{c}\text { Metzner y Lemmer., } \\
\text { (1997) }\end{array}$ \\
\hline RCTA & 35 & LS & 20 & 1.75 & 48 & 0.962 & Killilea y col., (2000) \\
\hline Batch & 35 & $\begin{array}{c}\text { LS } \\
\text { LP } \\
\text { LP:LS }(1: 1)\end{array}$ & 27 & $\begin{array}{l}0.54 \\
1.21 \\
0.87\end{array}$ & $\begin{array}{l}50 \\
70 \\
60\end{array}$ & NR & Arnaiz y col., (2006) \\
\hline
\end{tabular}

RCTA: Reactores continuos en tanque agitado; NR: No reportado.

1.5.3. Digestión termofílica en una etapa.- Esta tecnología es interesante debido a su potencial en la reducción de microorganismos patógenos, aumento en la tasa de destrucción de materia orgánica en suspensión, destrucción de SV, producción de biosólidos clase A, producción de metano, incremento en las velocidades de las reacciones bioquímicas de los microorganismos, mejoramiento en las propiedades de secado del lodo estabilizado lo que reduce el tamaño de los digestores (Kim y Speece, 2002). Se lleva a temperaturas de 50 a $60^{\circ} \mathrm{C}$, pero presenta inestabilidad debido a que las bacterias termofílicas son muy sensibles a las fluctuaciones de $\mathrm{pH}$ y temperatura lo que hace díficil su control (Appels y col., 2008). Presenta problemas de olor en sus efluentes debido a la baja remoción de los ácidos grasos volátiles (altos niveles AGV), así como menores eficiencias de remoción de proteínas y lípidos (Carrozzi y Steinle, 1994), sin embargo bajo condiciones controladas pueden minimizarse estos problemas (WEF, 1996). 
Cuadro 1.11. Eficiencia de remoción de sólidos suspendidos y producción de metano en la digestión anaerobia termofílica de lodos residuales primario y secundario.

\begin{tabular}{|c|c|c|c|c|c|c|c|}
\hline $\begin{array}{l}\text { Tipo de } \\
\text { reactor }\end{array}$ & $\mathbf{T}^{\circ} \mathbf{C}$ & $\begin{array}{l}\text { Tipo de } \\
\text { lodo }\end{array}$ & $\begin{array}{l}\text { TRS } \\
\text { dias }\end{array}$ & $\mathrm{Bv} \mathrm{kgSV} / \mathrm{m}^{3} \mathrm{~d}$ & $\begin{array}{l}\text { Eficiencia } \\
\text { de remoción } \\
\text { de SV (\%) }\end{array}$ & $\begin{array}{l}\text { Produccion } \\
\text { de metano } \\
\mathrm{LCH}_{4} / \mathrm{m}^{3} \cdot \mathrm{d}\end{array}$ & Referencia \\
\hline RCTA & $\begin{array}{l}35 \\
55\end{array}$ & LP:LS & 27 & $1-3$ & $\begin{array}{l}53 \\
53\end{array}$ & $\begin{array}{l}0.178 \\
0.143\end{array}$ & De la Rubia y col., (2002). \\
\hline RCTA & 55 & LP:LS & $\begin{array}{l}15 \\
20 \\
27 \\
40\end{array}$ & $\begin{array}{l}2.3 \\
2.0 \\
1.5 \\
1.0\end{array}$ & $\begin{array}{l}75 \\
55 \\
45 \\
45\end{array}$ & $\begin{array}{l}0.279 \\
0.195 \\
0.150 \\
0.121\end{array}$ & De la Rubia y col., (2006). \\
\hline
\end{tabular}

RCTA: Reactores continuos en tanque agitado.

1.5.4. Digestión anaerobia en 2 etapas. Con este arreglo se utiliza un reactor termofílico seguido de un digestor mesofílico para incrementar la estabilidad del primer reactor y reducir el potencial de olores en los biosólidos termofílicamente digeridos (Han y Dague, 1997). En los digestores termofílicos no hay condiciones óptimas de $\mathrm{pH}$ para que se desarrollen las bacterias formadoras de ácidos. Sin embargo a TRS entre 3 y 5 días puede existir un balance entre las bacterias formadoras de ácido y las bacterias formadoras de metano (Dichtl, 1997). Con la separación física de las etapas: aumenta la estabilidad del proceso, hay un mejor control de la etapa subsiguiente, soporte de mayores tasas de carga orgánica, incremento de la actividad específica de las bacterias metanogénicas e incremento en la producción de metano, eliminación de compuestos tóxicos que inhiban a las bacterias metanogénicas y previsión de un sustrato constante para estas bacterias. Los Cuadros 1.12 y 1.13 muestran la destrucción de sólidos volátiles y de microorganismos patógenos citados en la literatura.

Cuadro 1.12. Investigaciones realizadas en la estabilización de lodos residuales.

\begin{tabular}{|c|c|c|}
\hline Autor & Sistema estudiado & $\begin{array}{l}\text { Destrucción } \\
\text { de SV (\%) }\end{array}$ \\
\hline Garcia y col., (1999) & $\begin{array}{l}\text { En un RCTA en dos etapas a } 55 \text { y } 35^{\circ} \mathrm{C} \text { con LS a } 2 \text { y } 10 \text { días de TRS y } \\
\text { carga orgánica de } 2.6 \text { y } 3 \mathrm{~kg} \mathrm{SSV} / \mathrm{m}^{3} \mathrm{~d} \text {. }\end{array}$ & 38 \\
\hline Huyard y col., (2000) & $\begin{array}{l}\text { En un RCTA AT; alimentado con mezcla de LP:LS, contenido del } 2.5 \text { al } \\
5 \% \text { de ST a } 2 \text { días de TRH, seguido de un reactor MM a } 10.5 \text { días de } \\
\text { TRH con recirculación de lodo. }\end{array}$ & 61 \\
\hline Tsakou y col., (2000) & $\begin{array}{l}\text { Sistema acidogénico-termofílico a } 56^{\circ} \mathrm{C} \text { y } 10 \text { días de tiempo de } \\
\text { retención de sólidos (TRS). }\end{array}$ & 27.9 \\
\hline Vandenburgh y Ellis., (2002) & Sistema MM con LP y ST del $4.9 \%$ a un TRH de 20 días. & 61.5 \\
\hline Shana y Assadi., (2003) & $\begin{array}{l}\text { En un RCTA a } 35^{\circ} \mathrm{C} \text { con mezcla de LP:LS de } 70: 30 \text { y un contenido del } \\
5.5 \text { al } 6 \% \text { de sólidos. }\end{array}$ & 29 \\
\hline Mahmoud y col., (2004) & En un RCTA con LP y TRS de 10 a 15 días a $25^{\circ} \mathrm{C}$. & 60 \\
\hline Watts y col., 2005 & En un sistema de dos etapas M-T a $60^{\circ} \mathrm{C}$ y 2 días de TRH con LS. & 34.5 \\
\hline Young y Richard, 2006 & En un reactor FAFD con LP a $35^{\circ} \mathrm{C}$ y 5 días de $\mathrm{TRH}$ & 50 \\
\hline Arnaiz y col., (2006) & En reactores de $250 \mathrm{~mL}$ alimentados con LP, LS en lote. & 87.2 con LP y \\
\hline
\end{tabular}




\begin{tabular}{|c|c|c|}
\hline & & 42.6 con LS \\
\hline Bolzonella y col., 2007 & En un RCTA con LS a $70^{\circ} \mathrm{C}$ y TRH de 2 días & 25.3 \\
\hline Rincón y col., (2010) & En un RCTA a 37 y $55^{\circ} \mathrm{C}$ de $3,5 \mathrm{~L}$ y $\mathrm{TRH}$ de 30,25 y 15 días & $\begin{array}{c}\text { A TRH de } 30 d: \\
29 \text { a } 37^{\circ} \mathrm{C} \text { y } 43 \\
\text { a } 55^{\circ} \mathrm{C} .\end{array}$ \\
\hline Rubio y col., (2010) & $\begin{array}{l}\text { En un RCTA de } 2 \text { etapas; acidogénico termofílico (AT) a TRH de } 3 \text { y } 2 \\
\text { días, MM y MT a } 13 \text { y } 10 \text { días de TRH. }\end{array}$ & $\begin{array}{c}31 \text { y } 32 \text { en AT- } \\
\text { MM y } 28 \text { en } \\
\text { AT-MT. }\end{array}$ \\
\hline Gomez y col., (2011) & $\begin{array}{l}\text { En un RCTA de } 4 \mathrm{~L} \text { operados en semi-continuo a } 36 \pm 1^{\circ} \mathrm{C} \text { y } \mathrm{COV} \text { de } 3.4 \\
\text { a } 5.0 \mathrm{gSV} / \mathrm{d}\end{array}$ & 54 \\
\hline
\end{tabular}

RCTA: Reactores continuos en tanque agitado, FAFD: Filtro anaerobio de flujo descendente AT: acidogénico termofílico, MM: metanogénico mesofílico, MT: metanogénico termofílico, M: mesofílico y T: termofílico.

Cuadro 1.13. Eliminación de patógenos y de parásitos en lodos residuales.

\begin{tabular}{|c|c|c|c|c|c|c|c|}
\hline $\begin{array}{l}\text { Lodo } \\
\text { Sistema }\end{array}$ & $\begin{array}{r}\text { Trata } \\
\text { TRH(días) }\end{array}$ & $\begin{array}{l}\text { miento } \\
\text { TRS (días) }\end{array}$ & $\begin{array}{l}\text { Colif. Fec. } \\
\text { reducción. }\end{array}$ & $\begin{array}{l}\text { Salmonella spp } \\
\text { reducción }\end{array}$ & $\begin{array}{l}\text { H. Helminto } \\
\% \text { de dest. }\end{array}$ & Clase & Referencia \\
\hline LP/M-T & 15 & ---- & $3.1 \times 10^{2} \mathrm{NMP} / \mathrm{gST}$ & ---- & ---- & $A$ & Han y Dague (1997) \\
\hline $\begin{array}{l}\text { LP/LS: } 60: 40 \\
\text { T-M }\end{array}$ & 02 & ---- & $3.16 \times 10^{5} \mathrm{NMP} / \mathrm{gST}$ & $3.9 \times 10^{2} \mathrm{NMP} / \mathrm{gST}$ & ---- & C & Huyard y col., 2000 \\
\hline LS/T-M & ---- & ---- & $1 \times 10^{2} \mathrm{NMP} / \mathrm{gST}$ & ---- & ---- & $A$ & Cheunbarn y col., 2000 \\
\hline $\mathrm{LS} / \mathrm{T}$ & ---- & ---- & $2.3 \times 10^{1} \mathrm{NMP} / \mathrm{gST}$ & ---- & ----- & A & Gantzer y col., 2001 \\
\hline LS/M-T & 15 & 35 & $2 \times 10^{6} \mathrm{NMP} / \mathrm{gST}$ & ---- & 97 & B & Rojas y col., 2001 \\
\hline & 15 & 20 & $1 \times 10^{2} \mathrm{NMP} / \mathrm{gST}$ & ---- & 98.4 & $A$ & \\
\hline LP/LS, DA & 2.6 & ---- & $2.29 \log _{10}$ & ---- & ---- & C & Shana y Assadi., 2003 \\
\hline 70/30, DM & 12.4 & ----- & $2.8 \log _{10}$ & ----- & ----- & C & \\
\hline T-M & Global & ---- & $1 \times 10^{3} \mathrm{NMP} / \mathrm{gST}$ & ---- & 96 & $A$ & \\
\hline $\mathrm{LS} / \mathrm{T}$ & ----- & ----- & $9.7 \times 10^{1} \mathrm{NMP} / \mathrm{gST}$ & ----- & ---- & A & Song y col., 2004 \\
\hline
\end{tabular}

M: Mesofílico, T: Termofílico, LP: Lodo primario, LS: Lodo secundario, DA: Digestor acidogénico, DM: Digestor metanogénico.

\subsection{Reactores anaerobios de lodos}

El arreglo y diseño de los reactores anaerobios son importantes en el tratamiento de lodos para alcanzar mayores efiencias de degradación y pueden clasificarse en:

1.6.1 Reactores de baja tasa (Figura 1.4), son aquellos en los que el proceso se lleva a cabo sin calentamiento ni mezclado, lo que favorece la estratificación del fluido, formando tres zonas distintas; una capa flotante de natas, un nivel intermedio de sobrenadante y una capa inferior de lodo. Debido a la estratificación y a la ausencia de contacto entre los microorganismos y el sustrato, el volumen del digestor sin mezcla se utiliza en no más del $50 \%$ de forma efectiva y toda la descomposición se restringe en la zona inferior, la alimentación y salida del lodo son discontinuas. Poco después de haber sido alimentado, se generan burbujas de gas y la acción de éstas al aumentar de volumen tienden a subir a la superficie, lo que genera un mezclado. Los TRH se encuentran entre 30 y 90 días, con 
cargas recomendadas entre 0.5 y $1.6 \mathrm{kgSSV} / \mathrm{m}^{3} \cdot \mathrm{d}$. Poseen bajas eficiencias de remoción de contaminantes; remoción de sólidos suspendidos en un $60 \%$ y un $30 \%$ de $\mathrm{DBO}_{5}$ (Metcalf y Eddy, 2004). Sin embargo, con la introducción de un mezclador mecánico se favorece la transferencia de masa en el reactor lo que permite aprovechar todo el volumen del líquido en la reacción y de alimentar cargas orgánicas hasta de $2 \mathrm{kgSSV} / \mathrm{m}^{3} \cdot \mathrm{d}$.

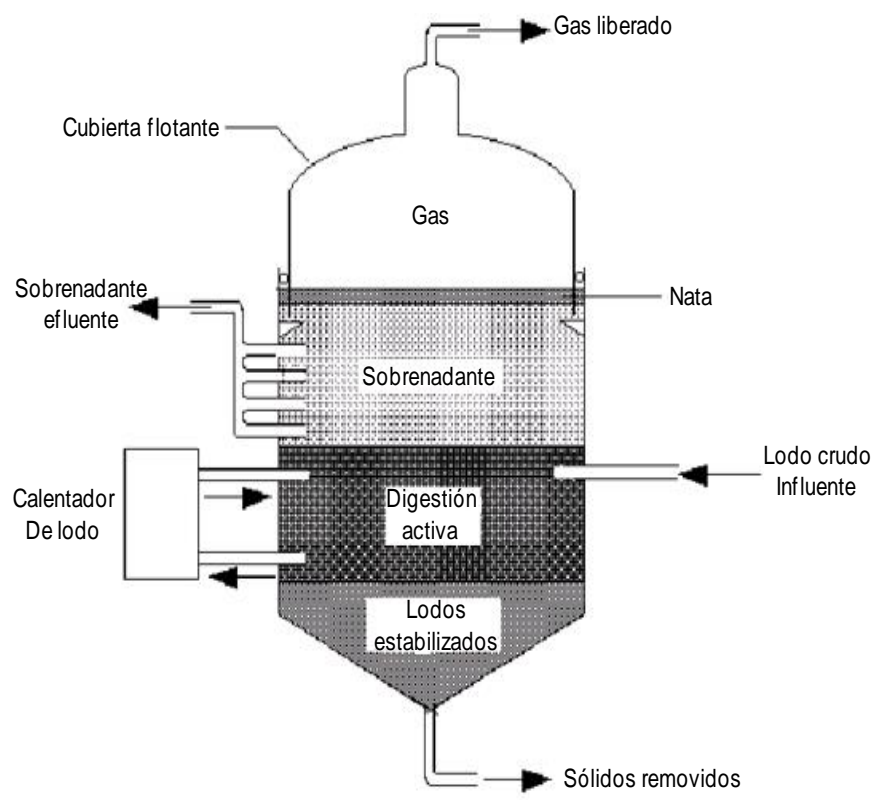

Figura 1.4. Digestor anaerobio de baja tasa.

El lodo estabilizado, que se acumula y se espesa en el fondo del digestor, es extraído periódicamente desde el centro del piso, el sobrenadante es removido del costado del tanque y se recircula en la alimentación. El gas que se acumula arriba de la superficie líquida es extraído por medio de una toma en la cubierta. La aplicación de este tipo de reactores es principalmente en plantas pequeñas.

1.6.2 Reactores de alta tasa (Figura 1.5), se caracterizan por un mezclado al medio de reacción, ya sea mediante agitación mecánica, por recirculación de gas o de líquido o combinación de ambos. Las cargas orgánicas van de 2 a $3.6 \mathrm{kgSSV} / \mathrm{m}^{3} \cdot \mathrm{d}$. Son operados a temperatura constante entre 30 y $40^{\circ} \mathrm{C}\left( \pm 0.6^{\circ} \mathrm{C}\right)$ de la temperatura de diseño con TRH de 10 a 20 días (Metcalf y Eddy, 2004). El lodo se mezcla continuamente para crear un ambiente homogéneo en todo el reactor y evitar la estratificación estando todo el digestor 
disponible para una activa descomposición de la materia orgánica. El espesamiento del lodo a una concentración de 30 a $60 \mathrm{~g} / \mathrm{L}$, permite la reducción del volumen del digestor en un $75 \%$ del equivalente de la digestión sin espesamiento. Este sistema difiere con el de baja tasa, por su capacidad de soportar mayores cargas orgánicas, por la temperatura de operación y TRH menores (Metcalf y Eddy, 2004).

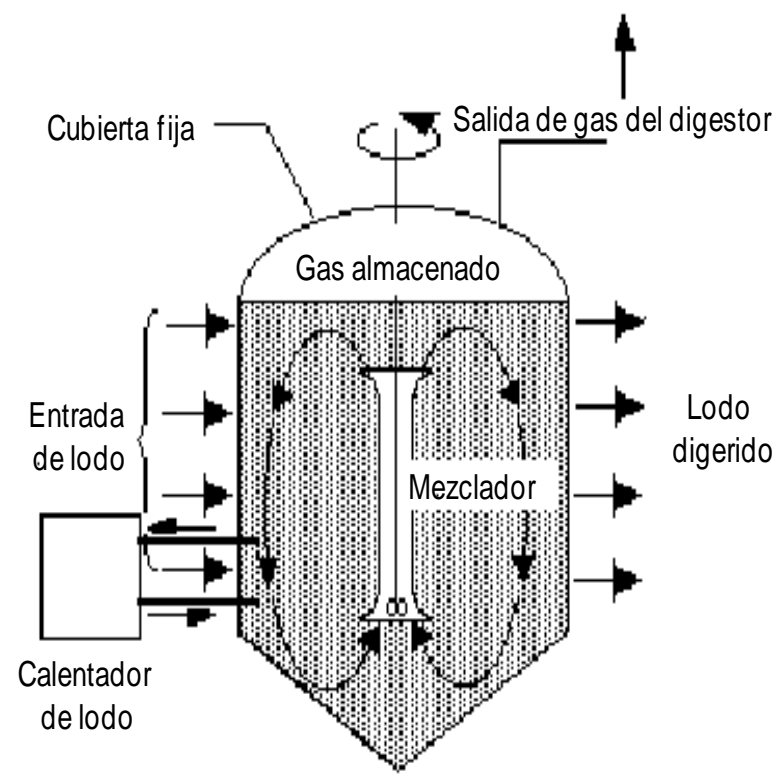

Figura 1.5. Digestor anaerobio de alta tasa.

1.6.3 Digestor anaerobio de flujo ascendente.

En este tipo de digestores las fases de la DA; hidrólisis-acidogénesis y metanogénesis se llevan a cabo de manera simultánea en el mismo reactor (Lettinga y col., 1980). Mancebo del Castillo (2001), Pérez (2004) y, Barrios y col., (2005) reportaron problemas de operación por formación de espumas y natas.

La separación en dos etapas, permite que en la primera etapa (fase hidrolíticaacidogénica) se formen AGV dejando al lodo predigerido, para que en una segunda etapa, Ios AGV sean convertidos en metano. Con el uso de reactores termofílicos en la segunda etapa se reducen de manera notable la cantidad de patógenos (coliformes fecales y Salmonella, principalmente) así como de parásitos (huevos de helminto) (Huyard y col 2000). Combinando las ventajas de la mesofília (menor concentración de ácidos grasos volátiles, AGV) con las de la termofília (mayor destrucción de patógenos) se puede evitar las desventajas de cada una (Cheunbarn y Pagilla, 2000). 


\subsection{Conclusiones}

> La digestión de sólidos requiere de un paso de concentración directa entre el 3 y el $6 \%$, que normalmente se hace por decantación o con equipos como centrifugas o tanques de consolidación.

> Con la separación de la DA en dos etapas es posible lograr la estabilidad del sistema para producir biosólidos de calidad con TRH menore a los reportados en la literatura.

> La reacción de hidrólisis y acidogénesis en un reactor en mesofilia resulta ser más rápida, porque se generan productos menos inhibitorios que en reactores termofílicos.

> La combinación de los sistemas mesofílico y termofílico, favorece la remoción de la materia orgánica y la eliminación de patógenos. 


\section{CAPÍTULO 2}

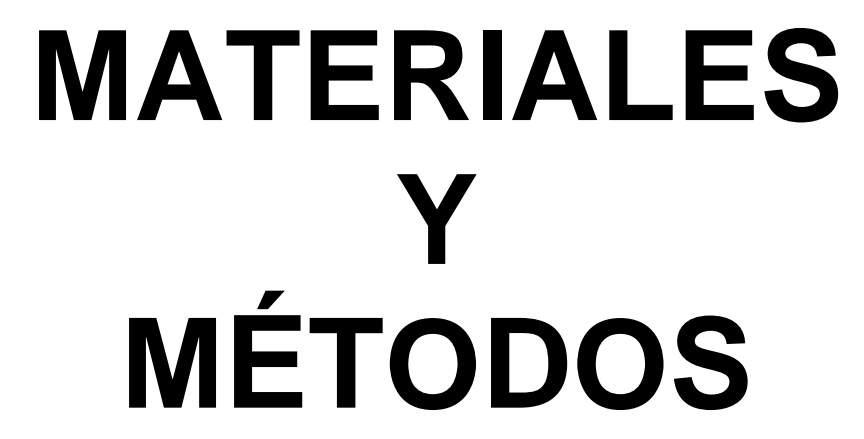

En este capítulo se describe la metodología utilizada en el estudio. Se indican las características de los reactores y la temperatura a la que fueron operados, se da el origen del inóculo durante su arranque, para alcanzar las condiciones de hidrólisis y acidogénesis en el reactor acidogénico mesofílico (rAM) y las de metanogénesis en el reactor metanogénico termofílico (rMT).

Se presentan los puntos de muestreo de los lodos residuales en la PTAR "Cerro de la Estrella", el tamizado al que fueron sujetos los lodos antes de preparar las mezclas de LP:LS y el diseño experimental utilizado.

Se detallan las técnicas analíticas para evaluar los parámetros a la entrada y salida de cada reactor $(\mathrm{pH}, \mathrm{DQO}$ total y soluble, azúcares totales y solubles, proteína total y soluble, ácidos grasos volátiles, sólidos suspendidos totales y volátiles, composición de biogás, coliformes fecales, Salmonella spp y huevos de helminto). 


\subsection{Metodología}

Se emplearon dos reactores tubulares de vidrio con chaqueta; volumen de diseño $10 \mathrm{~L}$ y volumen útil de $8.6 \mathrm{~L}$ (Figura 2.1).

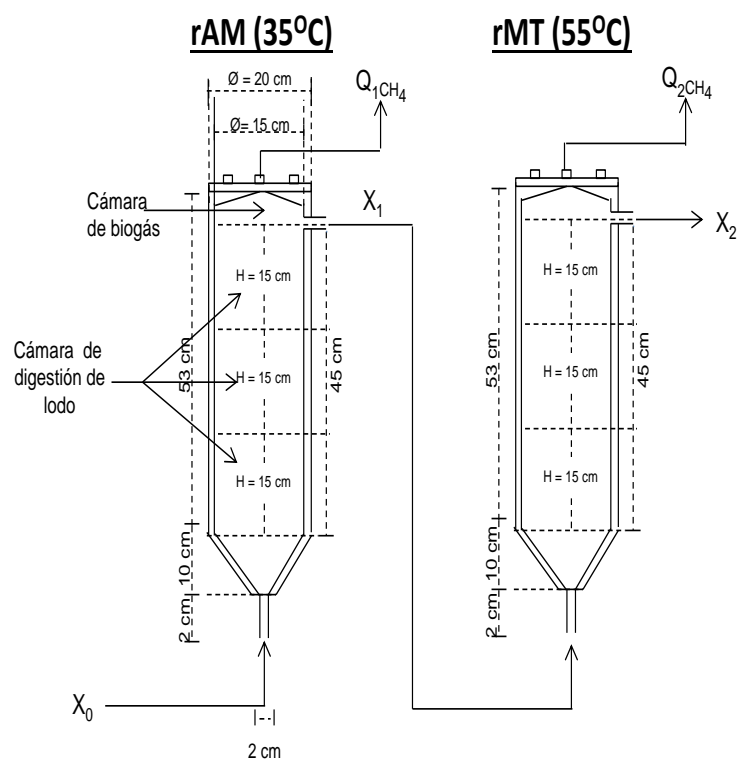

Figura 2.1. Esquema de los dos reactores de flujo ascendente en serie para la digestion anaerobia de lodos residuales.

\subsection{Inóculo}

La biomasa utilizada como inóculo se colectó de un reactor UASB que trata aguas domésticas en la delegación Xochimilco, presentó una concentración de 27 g/L de SV. Durante el periodo de arranque y estabilización, se empleó medio mineral RAMM (Shelton y Tiedje, 1984), con glucosa como fuente de carbono para lograr condiciones de acidogénesis en el reactor acidogénico mesofílico ( $\mathrm{rAM}$ ) y acetato de sodio para el desarrollo de las condiciones metanogénicas en el reactor metanogénico termofílico (rMT).

\subsection{Obtención de lodos}

El lodo primario se colectó de la línea de purga del sedimentador primario y el lodo secundario de la línea de recirculación de lodos activados de la planta de tratamiento de aguas residuales municipales Cerro de la Estrella, en la Ciudad de México. El lodo secundario, por presentar un alto contenido de agua, fue necesario concentrarlo in situ drenando por varias ocasiones el sobrenadante hasta lograr la mayor concentración de sólidos. 


\subsection{Tamizado del lodo primario}

El lodo primario fue tamizado para retirar la basura (colillas de cigarro, desechos de cocina, etc., Se utilizó un tamiz de acero inoxidable de abertura de $3.36 \mathrm{~mm}$, diámetro 203 $\mathrm{mm}$ y altura total de $66.6 \mathrm{~mm}$.

\subsection{Contenido de sólidos suspendidos totales en los lodos residuales}

El lodo primario presentó un valor promedio en la concentración de SST de $19.37 \mathrm{~g} / \mathrm{L}$ (desv. std. 9.8) y el lodo secundario un valor promedio de SST de $8.7 \mathrm{~g} / \mathrm{L}$ (desv. std. 4.92) después de su espesamiento in situ.

\subsection{Preparación de la mezcla de lodos residuales}

A partir de la ecuación $C_{1} V_{1}=C_{2} V_{2}$ se calculó el volumen a tomar de lodo concentrado (primario y secundario) según la proporción de LP:LS a probar en el rAM.

\subsection{Diseño experimental}

El reactor acidogénico mesofílico ( $\mathrm{rAM}$ ), fue operado a una temperatura de $35 \pm 3^{\circ} \mathrm{C}$, sin control de $\mathrm{pH}$, agitación ni recirculación. Alimentado con 3 diferentes proporciones de LP:LS (volumen/volumen): 30:70, 70:30 y 50:50 a fin de evaluar el efecto de la carga orgánica volumétrica $(\mathrm{Bv})$ y el TRH de 1, 2 y 3 días en la destrucción de los sólidos suspendidos. El cambio en la segunda proporción de LP:LS en la mezcla de lodos residuales (corrida IV) fue para probar que debido a la mayor fracción volátil del lodo primario se favorecería la formación de productos solubles. Solo una fracción del lodo predigerido por el rAM fue alimentado al reactor metanogénico termofílico (rMT) a $55 \pm 1^{\circ} \mathrm{C}$ a 1, 2, 4 y 6 días de TRH (Figura 2.2).

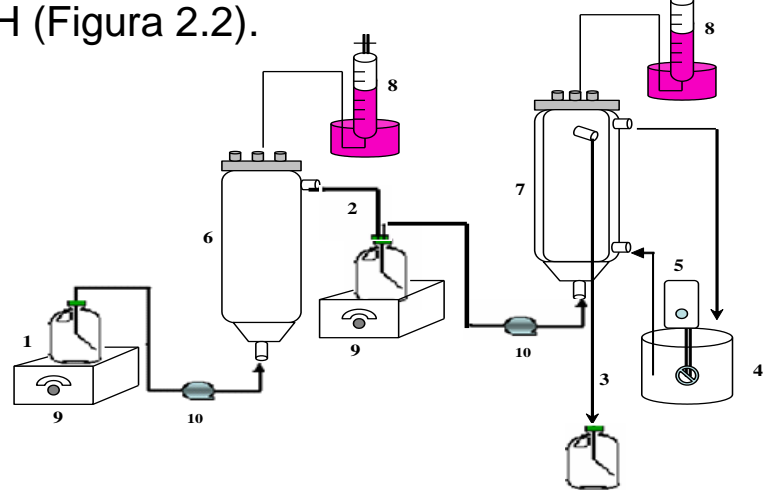

Figura 2.2. Descripción del proceso. 1) Lodo crudo, 2) Lodo predigerido, 3) Lodo estabilizado, 4) Termorecirculador, 5) Recirculacion de agua $\left.\left(55 \pm 1^{\circ} \mathrm{C}\right), 6\right) \operatorname{rAM}$ a $\left.35 \pm 1^{\circ} \mathrm{C}, 7\right) \operatorname{rMT}$ a $\left.55 \pm 1^{\circ} \mathrm{C}, 8\right)$ Columna colectora de biogás con solución salina, 9) Parrilla de agitación y 10) Bomba peristáltica. 


\subsection{Condiciones de operación de los reactores}

Los cuadros 2.1 y 2.2 muestran las condiciones de operación de cada reactor en las distintas corridas en que se efectuó el experimento.

Cuadro 2.1. Condiciones de operación del rAM.

\begin{tabular}{|c|c|c|c|c|c|c|c|}
\hline Corrida & I & II & III & IV & V & VI & VII \\
\hline Periodo (d) & $71-113$ & $124-167$ & $174-184$ & $237-293$ & $316-426$ & $470-525$ & $533-736$ \\
\hline Proporción (LP:LS) & $30: 70$ & $30: 70$ & $30: 70$ & $70: 30$ & $50: 50$ & $50: 50$ & $50: 50$ \\
\hline Bv (g DQO/L'd) & 5.5 & 3.9 & 7.5 & 14.2 & 7.3 & 3.6 & 2.4 \\
\hline Bv (g SSV/L'd) & 2.4 & 2.8 & 5.3 & 10.1 & 4.3 & 2.15 & 1.2 \\
\hline TRH (d) & 1.0 & 1.0 & 1.0 & 1.0 & 1.0 & 2.0 & 3.0 \\
\hline TRS (d) & 34.2 & 32.6 & 11.3 & 12.5 & 11.1 & 9.2 & 17.2 \\
\hline
\end{tabular}

Cuadro 2.2. Condiciones de operación del rMT.

\begin{tabular}{|c|c|c|c|c|c|c|c|}
\hline Corrida & I & II & III & IV & V & VI & VII \\
\hline Periodo (d) & $71-113$ & $124-167$ & $174-184$ & $237-293$ & $316-426$ & $470-525$ & $533-736$ \\
\hline $\mathrm{Bv}(\mathrm{g} \mathrm{DQO} / \mathrm{L} \cdot \mathrm{d})$ & 3.3 & 3.2 & 4.9 & 9.3 & 2.2 & 0.8 & 0.3 \\
\hline $\mathrm{Bv}(\mathrm{g} \mathrm{SSV/L} \cdot \mathrm{d})$ & 1.7 & 2.0 & 3.5 & 7.2 & 1.5 & 0.4 & 0.2 \\
\hline $\mathrm{TRH}(\mathrm{d})$ & 1.0 & 1.0 & 1.0 & 1.0 & 2.0 & 4.0 & 6.0 \\
\hline $\mathrm{TRS}(\mathrm{d})$ & 19.6 & 22.9 & 7.4 & 15.9 & 8.01 & 16.9 & 14.08 \\
\hline
\end{tabular}

Las Bv se calcularon a partir de la siguiente ecuación:

Donde:

$$
\mathrm{Bv}=\frac{(F * S o)}{V}
$$

$$
\begin{aligned}
& \mathrm{F}=\text { flujo }(\mathrm{L} / \mathrm{d}) \\
& \mathrm{S}=\text { concentración de sustrato }(\mathrm{gSST} / \mathrm{L}) \\
& \mathrm{V}=\text { volumen del reactor }(\mathrm{L})
\end{aligned}
$$

\subsection{Caracterización de los lodos del rAM y del rMT}

Para la caracterización de los lodos crudos (entrada del rAM), predigeridos por el rAM y los tratados por el rMT (en ambos casos la muestra de lodo predigerida y tratada fue tomada a la salida de cada reactor), se determinaron los siguientes parámetros: $\mathrm{pH}$, demanda química de oxígeno (DQO), sólidos suspendidos totales (SST), sólidos suspendidos volátiles (SSV), $\mathrm{CHO}_{s}$, proteína, Salmonella spp, coliformes fecales y huevos de helminto. 


\subsection{Técnicas analíticas}

La evaluación de los principales parámetros de lodo primario (LP), lodo secundario (LS), mezcla de LP:LS alimentada al rAM (influente), lodo predigerido por el rAM a $35 \pm 3^{\circ} \mathrm{C}$ (efluente) y lodo digerido por el $\mathrm{rMT}$ a $55^{\circ} \mathrm{C}$ (efluente) para el control del proceso (análisis de la diferencia de parámetros) entre la mezcla de lodo tratado y la mezcla de lodo crudo sin tratamiento se realizó de la siguiente manera: para el análisis de la fracción soluble, las muestras se centrifugaron a 5,000 rpm en una centrifuga con un diámetro de $200 \mathrm{~mm}$ durante 10 minutos y posteriormente se filtraron con filtros de microfibra de vidrio de 55 $\mathrm{mm}$ de diámetro y $1.2 \mu \mathrm{m}$ de porosidad. El análisis de ácidos grasos volátiles (AGV), se determinó por cromatografía de gases (Hewlett Packard serie II modelo 5890) con un detector de ionización de flama (FID) y columna capilar Superox FA, AT 1000, empleando un volumen de inyección de $0.2 \mu \mathrm{L}$, a partir de una muestra preparada (volumen del filtrado: $950 \mu \mathrm{L}$ y $50 \mu \mathrm{L}$ de $\mathrm{HCl}$ al $50 \%$ ). El equipo se trabajó bajo las siguientes condiciones de operación: temperatura de columna $\left(120\right.$ a $\left.140^{\circ} \mathrm{C}\right)$ con incremento de $10^{\circ} \mathrm{C}$ /minuto, temperatura del inyector $130^{\circ} \mathrm{C}$, temperatura del detector $150^{\circ} \mathrm{C}, \mathrm{N}_{2}$ como gas acarreador a $3 \mathrm{~mL} / \mathrm{min}$. La composición del biogás $\left(\mathrm{CH}_{4}\right.$ y $\left.\mathrm{CO}_{2}\right)$ se evaluó por cromatografía de gases con un detector de conductividad térmica (Gow-Mac Instruments Co. Serie 550) con columna de Carbosphere 80/100, las condiciones de operación fueron: temperatura de la columna, $140^{\circ} \mathrm{C}$; temperatura del detector, $190^{\circ} \mathrm{C}$; temperatura del inyector, $170^{\circ} \mathrm{C}$; corriente de los filamentos de $120 \mathrm{~mA}$, presión del helio de $40 \mathrm{psi}$; flujo del helio de $25 \mathrm{~mL} / \mathrm{min}$. El valor de $\mathrm{pH}$ se determinó con un potenciómetro de mesa (Corning pH/ion Analyzer modelo 455). La demanda química de oxígeno (DQO), los sólidos suspendidos totales (SST) y los sólidos suspendidos volátiles (SSV) se analizaron de acuerdo al método estándar (APHA, AWWA, WPFC, 2005). Los carbohidratos totales y solubles, mediante la técnica del fenol sulfúrico (Dubois y col., 1956). El contenido de proteína, por Lowry y col. (1951), el análisis microbiológico (coliformes fecales y Salmonella spp), de acuerdo a la NOM-004-SEMARNAT-2002 y los huevos de helminto, por la técnica de Ritchie modificada (Aguilar y Llaguno, 2003). 
2.11. Cálculo de variables respuesta en los reactores rAM y rMT, de acuerdo a la Figura 2.3:

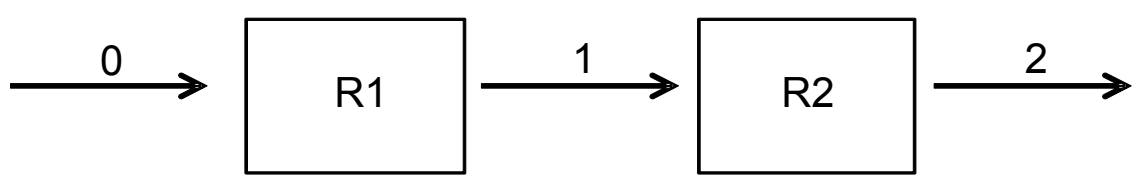

Figura 2.3. Velocidades de reacción de la digestión anaerobia (DA).

a) Eficiencia de hidrólisis:

$$
\eta_{c}=\frac{C_{i-1}-C_{i}}{C_{i-1}}
$$

b) Velocidad de hidrólisis:

$$
U_{c}=\frac{C_{i}-\left(C_{i+1}\right)}{T R H}
$$

c) Velocidad de formación de producto:

$$
\mathrm{U}_{\mathrm{p}}=\frac{P}{T R H}
$$

d) Velocidad de hidrólisis de proteína:

$$
U_{\text {Proteína }}=\frac{P s-P o}{T R H}=k p P S S
$$

e) Velocidad de formación de AGV:

$$
\mathrm{U}_{\mathrm{AGV}}=\frac{A-A o}{T R H}
$$

f) Tiempo de retención de sólidos:

$$
\mathrm{TRS}=\frac{(V r * S S T o)}{F(S S T o-S S T)}
$$

g) Eficiencia y velocidad de eliminación de coliformes fecales:

$$
\eta_{\mathrm{Cf}}=\frac{\mathrm{Cf}_{\mathrm{i}}-\mathrm{Cf}_{\mathrm{i}+1}}{\mathrm{Cf}_{\mathrm{i}}} \quad, \quad \mathrm{U}_{\mathrm{Cf}}=\frac{\mathrm{Cf}_{\mathrm{i}}-\mathrm{Cf}_{\mathrm{i}+1}}{\mathrm{TRH}}
$$


h) Eficiencia y velocidad de eliminación de Salmonella spp

$$
\eta_{\mathrm{spp}}=\frac{S s p_{\mathrm{i}}-S s p_{\mathrm{i}+1}}{S s p_{\mathrm{i}}} \quad, \quad \mathrm{U}_{\mathrm{Ssp}}=\frac{S s p_{\mathrm{i}}-S s p_{\mathrm{i}+1}}{\mathrm{TRH}}
$$

i) Eficiencia y velocidad de eliminación de huevos de helminto:

$$
\eta_{\text {Ssp }}=\frac{H_{i}-H_{i+1}}{H H_{i}}, \quad U_{\text {Ssp }}=\frac{H H_{i}-H H_{i+1}}{T R H}
$$

NOMENCLATURA:

$\mathrm{C}_{\mathrm{i}}=$ concentración del indicador $(\mathrm{g} / \mathrm{L})$.

$\mathrm{S}_{\mathrm{i}+1}=\mathrm{DQO}$ soluble $(\mathrm{g} / \mathrm{L})$.

$\mathrm{SS}_{\mathrm{i}}=\mathrm{St}_{\mathrm{t}_{+1}}-\mathrm{S}_{\mathrm{i}+1}=$ Sólidos suspendidos $(\mathrm{g} / \mathrm{L})$.

$\mathrm{P}=$ concentración de proteína soluble $(\mathrm{g} / \mathrm{L})$.

$\mathrm{P} t=$ concentración de proteína total $(\mathrm{g} / \mathrm{L})$.

$P S=P_{t_{i+1}}-P_{i+1}=$ proteína suspendida $(g / L)$.

$P_{i}=$ proteína soluble en el influente $(g / L)$

Ao $=$ AGV $(g / L)$

$\mathrm{TRH}=$ Tiempo de retención hidráulica $(\mathrm{d})$

TRS $=$ Tiempo de retención de sólidos $(\mathrm{d})$

$\mathrm{V}_{\mathrm{r}}=$ Volumen del reactor $(\mathrm{L})$

SST = Sólidos suspendidos totales en el reactor $(\mathrm{g} / \mathrm{L})$.

$\mathrm{F}=$ Flujo $(\mathrm{L} / \mathrm{d})$.

$A=A G V(g / L)$.

$\mathrm{Q}_{\mathrm{CH} 4}=$ metano

$\mathrm{C} f=$ Coliformes fecales

Ssp $=$ Salmonella

$\mathrm{HH}=$ Huevos de helmintos

$\mathrm{i}=$ condiciones inicilaes de operación

$\mathrm{Bv}=$ Carga orgánica $\left(\mathrm{kg} / \mathrm{m}^{3} \cdot \mathrm{d}\right)$ 


\subsection{Análisis de los reactores rAM y rMT}

A partir del modelo de reacciones secuenciales para la metanización de los lodos mediante la secuencia de reacciones de las ecuaciones 1 a 4 de la sección 1.4.4.2.2 se hacen los respectivos balances alrededor del rAM y rMT.

a. balance de DQO y de sólidos suspendidos (SS) en el reactor acidogénico:

$$
\frac{d S}{d t}=F S_{i-1}-F S_{i}-V k_{1} S_{i} \quad \frac{d S S}{d t}=D\left(S S_{i}-S S_{i+1}\right)-k_{1} S S_{i+1}
$$

Tomando puntos semiestacionarios se puede obtener un valor de la constante de velocidad de hidrólisis (k).

$$
D\left(S S_{i-1}-S S_{i}\right)=k_{1} S S_{i}
$$

b. balance de sustrato soluble en estado semiestacionario

$$
\mathrm{V} \frac{\mathrm{dSD}}{\mathrm{dt}}=\mathrm{F}\left(\mathrm{SS}_{\mathrm{o}}-\mathrm{SS}\right)+\left(\mathrm{Vk}_{1} S \mathrm{~S}-\mathrm{Vk}_{2} \mathrm{~S}\right)=0
$$

Considerando las ecuaciones 2.12 y 2.13 :

$$
\mathrm{D}(\Delta \mathrm{SD}+\Delta \mathrm{SS})=\mathrm{k}_{2} \mathrm{SD}
$$

c. Balance de AGV $\left(B^{-}\right)$

$$
\begin{aligned}
& V \frac{\mathrm{dB}-}{\mathrm{dt}}=\mathrm{F}\left(\mathrm{B}_{\mathrm{i}-1}^{-}-\mathrm{B}_{\mathrm{i}}^{-}\right)+\mathrm{V}_{\mathrm{B}_{\mathrm{B}}^{-}}=0 \\
& \mathrm{DF}\left(\mathrm{B}_{\mathrm{i}-1}^{-}{ }_{-1}^{0} \mathrm{~B}\right)+\mathrm{k}_{2 i} \mathrm{SD}_{\mathrm{i}}^{-} \mathrm{k}_{3}\left[\mathrm{~B}_{\mathrm{i}}^{-}\right]=0 \\
& -\mathrm{DB}^{-}+\mathrm{k}_{2 i} \mathrm{SD}_{\mathrm{i}}-\mathrm{k}_{3} \mathrm{~B}_{\mathrm{i}}^{-}=0 \\
& \mathrm{k}_{2} \mathrm{SD}=\mathrm{k}_{3} \mathrm{~B}^{-}+\mathrm{DB}^{-}=\left(\mathrm{k}_{3 i}+\mathrm{D}_{\mathrm{i}}\right) \mathrm{B}_{\mathrm{i}}^{-}
\end{aligned}
$$


d. Balance de metano, que puede explicarse partiendo de la fracción de $A G V\left(B^{-}\right)$de la DQO soluble:

$$
\begin{aligned}
& {\left[\mathrm{B}_{\mathrm{i}}^{-}\right]_{\mathrm{i}}=\frac{\mathrm{k} 2 \mathrm{i}}{\mathrm{k} 3 \mathrm{i}+\mathrm{Di}} \mathrm{SDi}} \\
& \mathrm{v} \frac{\mathrm{d}\left[\mathrm{CH}_{4}\right]}{\mathrm{dt}}-\mathrm{Q}_{\mathrm{CH}_{4}}+\mathrm{r}_{\mathrm{CH}_{4}}=0 \\
& \mathrm{r}_{\mathrm{CH}_{4}}=\mathrm{Q}_{\mathrm{CH}_{4}} \\
& \mathrm{~K}_{3}\left[\mathrm{~B}^{-}\right]=\mathrm{Q}_{\mathrm{CH} 4}
\end{aligned}
$$




\section{CAPÍTULO 3}

\section{REACTOR ACIDOGÉNICO MESOFÍLICO (rAM)}

En este capítulo se presentan los resultados de hidrólisis de los sólidos suspendidos de mezclas de lodos primarios (LP) y lodos secundarios (LS) en un reactor $A M$ a $35^{\circ} \mathrm{C}$ sin control de: $\mathrm{pH}$, agitación ni recirculación. El reactor AM de flujo ascendente actuó como sedimentador-reactor, llegando a tener concentraciones de 15 a $56 \mathrm{~g} \mathrm{SST/L} \mathrm{propiciando}$ TRS de 11 a 34 d. La destrucción de sólidos en este reactor siguió una cinética de primer orden con una constante de hidrólisis ( $k$ ) de $0.0681 d^{-1}$ (figura 3.8). Se logró la mejor destrucción de sólidos a un TRH de 1 d, TRS de $12.5 \mathrm{~d}$, Bv de $14.2 \mathrm{~kg} \mathrm{SSV} / \mathrm{m}^{3} \cdot \mathrm{d}$ en un $29 \%$ y una tasa de producción de metano de $0.009 \mathrm{~L}_{\mathrm{CH}_{4}} / \mathrm{L}_{\mathrm{R}} \cdot \mathrm{d}$. Debido a que no se controló el $\mathrm{pH}$, la hidrólisis y la acidogénesis no dependieron del $\mathrm{pH}$, sino más bien el pH dependio de la hidrólisis y la acidogénesis y por lo tanto, del TRH. Se concluye que el desarrollo de la hidrólisis y acidificación de la mezcla de LP:LS fueron influenciadas por la carga orgánica (Bv) y por el tiempo de retención de sólidos (TRS). En consecuencia se observa que no hay influencia de la proporción de LP:LS sobre la tasa de reacción, pero sí de la carga orgánica ya que a mayor carga orgánica, mayor tasa de destrucción de sólidos. 


\subsection{Caracterización de los lodos primarios y secundarios}

Antes de abordar el análisis de los resultados, se presenta el cuadro 3.1, donde se muestran los promedios de los principales parámetros evaluados a 16 lotes de lodo primario (LP) y lodo secundario (LS). Se observa una dispersión significativa en los datos, debido a la variabilidad que presentan los lodos a lo largo de las diferentes épocas del año.

\begin{tabular}{lccc} 
& \multicolumn{3}{c}{ Cuadro 3.1 Caracterízación del lodo primario y secundario $(\mathrm{n}=16)$} \\
\hline \multicolumn{1}{c}{ Parámetro } & Unidades & LP & LS \\
\hline pH & & $6.24 \pm 0.65$ & $6.85 \pm 0.44$ \\
ST & $(\mathrm{g} / \mathrm{L})$ & $9.59 \pm 4.86$ & $9.6 \pm 5.31$ \\
SV & $(\mathrm{g} / \mathrm{L})$ & $5.73 \pm 2.81$ & $7.35 \pm 4.16$ \\
SST & $(\mathrm{g} / \mathrm{L})$ & $9.13 \pm 4.63$ & $8.7 \pm 4.92$ \\
SSV & $(\mathrm{g} / \mathrm{L})$ & $5.48 \pm 2.56$ & $6.91 \pm 3.93$ \\
DQO & $(\mathrm{g} / \mathrm{L})$ & $9.34 \pm 4.64$ & $8.59 \pm 4.77$ \\
DQOS & $(\mathrm{g} / \mathrm{L})$ & $0.53 \pm 0.26$ & $0.31 \pm 0.18$ \\
CHOT & $(\mathrm{g} / \mathrm{L})$ & $0.15 \pm 0.08$ & $0.054 \pm 0.029$ \\
CHOS & $(\mathrm{g} / \mathrm{L})$ & $0.009 \pm 0.005$ & $0.002 \pm 0.0009$ \\
ProteínaS & $(\mathrm{g} / \mathrm{L})$ & $6.54 \pm 3.35$ & $8.51 \pm 4.6$ \\
Proteínasol. & $(\mathrm{g} / \mathrm{L})$ & $0.89 \pm 0.45$ & $0.015 \pm 0.008$ \\
\hline
\end{tabular}

Resultados expresados como la media \pm desviación estándar.

El cuadro 3.2 muestra las características de la mezcla del lodo primario (LP) y lodo secundario (LS) que se alimentó al reactor acidogénico mesofílico (rAM), preparado de acuerdo a la sección 2.6.

Cuadro 3.2. Caracterización y corrientes de alimentación del rAM.

\begin{tabular}{|c|c|c|c|c|c|c|c|}
\hline $\begin{array}{l}\text { Corrida } \\
\text { TRH (d) } \\
\text { TRS (d) } \\
\text { Bv (g/L'd) } \\
\text { LP:LS }\end{array}$ & $\begin{array}{c}\text { I } \\
1 \\
34.2 \\
5.5 \\
30: 70\end{array}$ & $\begin{array}{c}\text { II } \\
1 \\
32.6 \\
3.9 \\
30: 70\end{array}$ & $\begin{array}{c}\text { III } \\
1 \\
11.3 \\
7.5 \\
30: 70\end{array}$ & $\begin{array}{c}\text { IV } \\
1 \\
12.5 \\
14.2 \\
70: 30\end{array}$ & $\begin{array}{c}V \\
1 \\
11.1 \\
7.3 \\
50: 50\end{array}$ & $\begin{array}{c}\text { VI } \\
2 \\
9.2 \\
3.6 \\
50: 50\end{array}$ & $\begin{array}{c}\text { VII } \\
3 \\
17.2 \\
2.4 \\
50: 50\end{array}$ \\
\hline $\mathrm{pH}$ & $6.5 \pm 0.2$ & $6.5 \pm 0.5$ & $6.7 \pm 0.6$ & $6.8 \pm 0.5$ & $6.5 \pm 0.2$ & $6.5 \pm 0.2$ & $6.5 \pm 0.3$ \\
\hline $\mathrm{ST}(\mathrm{g} / \mathrm{L})$ & $4.5 \pm 0.7$ & $4.6 \pm 0.3$ & $8.7 \pm 0.3$ & $16.3 \pm 0.7$ & $8.5 \pm 0.8$ & $8.8 \pm 0.8$ & $8.4 \pm 0.4$ \\
\hline $\operatorname{SST}(\mathrm{g} / \mathrm{L})$ & $3.7 \pm 0.6$ & $4.0 \pm 0.5$ & $8.3 \pm 1.0$ & $14.6 \pm 0.9$ & $7.5 \pm 0.9$ & $7.4 \pm 0.7$ & $7.6 \pm 0.5$ \\
\hline $\mathrm{SSV}(\mathrm{g} / \mathrm{L})$ & $2.4 \pm 0.5$ & $2.8 \pm 0.6$ & $5.3 \pm 1.2$ & $10.1 \pm 1.3$ & $4.3 \pm 0.7$ & $4.3 \pm 0.8$ & $3.7 \pm 0.3$ \\
\hline $\mathrm{DQO}_{\text {total }}(\mathrm{g} / \mathrm{L})$ & $5.5 \pm 0.1$ & $3.9 \pm 0.4$ & $7.5 \pm 0.1$ & $14.2 \pm 0.6$ & $7.3 \pm 0.1$ & $7.3 \pm 0.1$ & $7.3 \pm 0.2$ \\
\hline $\mathrm{DQO}_{\text {soluble }}(\mathrm{g} / \mathrm{L})$ & ND & $0.2 \pm 0.01$ & $0.3 \pm 0.04$ & $1.0 \pm 0.2$ & $0.5 \pm 0.01$ & $0.45 \pm 0.03$ & $0.5 \pm 0.1$ \\
\hline $\operatorname{AGV}(g / L)$ & $0.07 \pm 0.01$ & $0.07 \pm 0.01$ & $0.1 \pm 0.03$ & $0.2 \pm 0.1$ & $0.12 \pm 0.08$ & $0.12 \pm 0.03$ & $0.09 \pm 0.065$ \\
\hline Acetato $(\mathrm{g} / \mathrm{L})$ & $0.03 \pm 0.002$ & $0.03 \pm 0.005$ & $0.05 \pm 0.005$ & $0.12 \pm 0.07$ & $0.07 \pm 0.002$ & $0.06 \pm 0.02$ & $0.05 \pm 0.045$ \\
\hline Propiónato $(\mathrm{g} / \mathrm{L})$ & $0.02 \pm 0.005$ & $0.02 \pm 0.003$ & $0.02 \pm 0.003$ & $0.03 \pm 0.01$ & $0.02 \pm 0.001$ & $0.02 \pm 0.008$ & $0.02 \pm 0.01$ \\
\hline Isobutírato (g/L) & $0.01 \pm 0.001$ & $0.014 \pm 0.004$ & $0.02 \pm 0.002$ & $0.02 \pm 0.01$ & $0.02 \pm 0.001$ & $0.03 \pm 0.004$ & $0.01 \pm 0.006$ \\
\hline Butírato (g/L) & $0.007 \pm 0.006$ & $0.007 \pm 0.001$ & $0.01 \pm 0.02$ & $0.03 \pm 0.03$ & $0.01 \pm 0.006$ & $0.01 \pm 0.001$ & $0.009 \pm 0.004$ \\
\hline Proteínas $_{\text {totales }}(\mathrm{g} / \mathrm{L})$ & $3.1 \pm 0.2$ & $3.1 \pm 0.1$ & $6.1 \pm 0.2$ & $12.4 \pm 0.5$ & $5.9 \pm 0.7$ & $5.9 \pm 0.3$ & $4.6 \pm 1.2$ \\
\hline Proteínas $_{\text {solubles }}(\mathrm{g} / \mathrm{L})$ & $0.08 \pm 0.03$ & $0.08 \pm 0.008$ & $0.2 \pm 0.003$ & $0.76 \pm 0.04$ & $0.3 \pm 0.09$ & $0.3 \pm 0.05$ & $0.2 \pm 0.1$ \\
\hline${ }^{\mathrm{a}}$ Coliformes fecales & ND & $5.3 \times 10^{8}$ & $4.5 \times 10^{8}$ & $7.0 \times 10^{8}$ & $5.13 \times 10^{8}$ & $4.0 \times 10^{8}$ & $4.2 \times 10^{8}$ \\
\hline${ }^{b}$ Salmonella spp & ND & $5.3 \times 10^{8}$ & $5.3 \times 10^{8}$ & $6.5 \times 10^{7}$ & $5.0 \times 10^{8}$ & $4.5 \times 10^{8}$ & $4.82 \times 10^{8}$ \\
\hline${ }^{\mathrm{c}} \mathrm{HH}$ & ND & 32 & 23 & 24 & 24 & 23 & 26 \\
\hline
\end{tabular}

ND: no determinado; AGV: Ácidos grasos volátiles; a y b: NMP/g ST; c: Número de H de H/g ST.

Resultados expresados como la media \pm desviación estándar. 


\subsection{Comportamiento del reactor acidogénico mesofílico}

\subsubsection{Reactor de lodos de flujo ascendente como sedimentador}

La figura 3.1 muestra la concentración de sólidos a distintas alturas en el reactor. La cama de lodo ubicada en los primeros $15 \mathrm{~cm}$ de altura (22\% del volumen útil), presenta mayor contenido de sólidos y se aprecia que mientras la altura aumenta a 30 y $45 \mathrm{~cm}$, que corresponden al $44 \%$ y $66 \%$ del volumen útil, la concentración de sólidos disminuye.

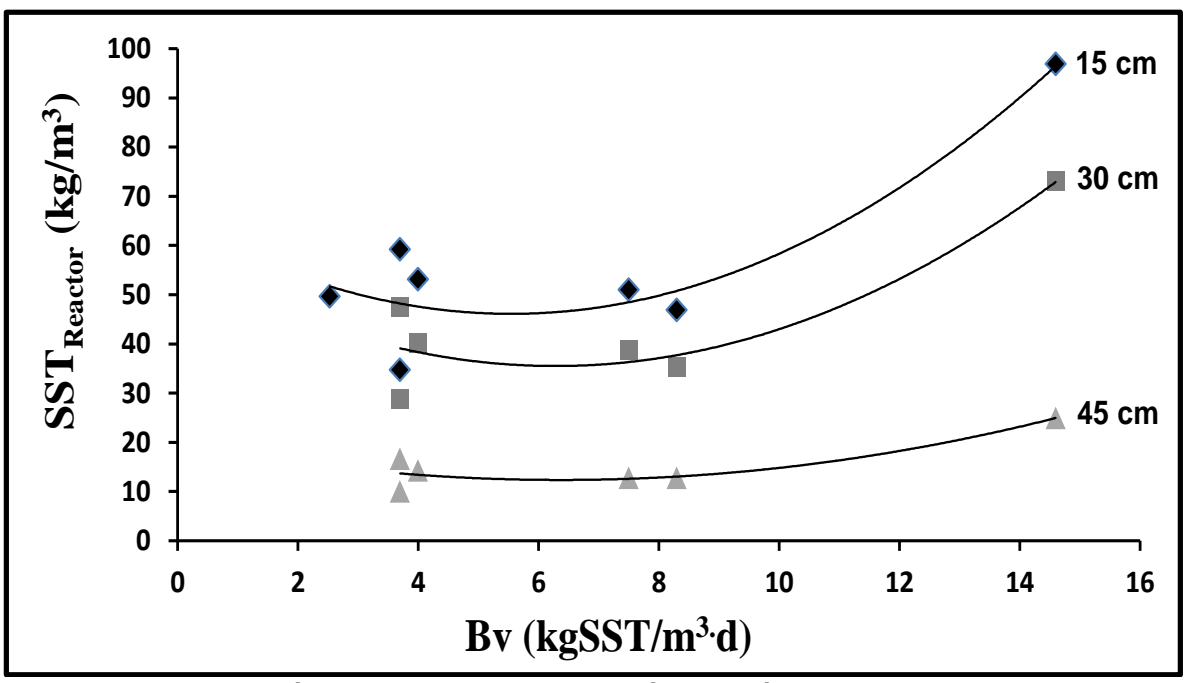

Figura 3.1. Efecto de la carga orgánica en la concentración de sólidos a distinta altura de la cama de lodos.

A partir de la figura 3.1 , se construye la figura 3.1 a que muestra el promedio de la concentración de SST en el reactor rAM a distintas alturas; $15 \mathrm{~cm}(55.91 \pm 19.55 \mathrm{~g} / \mathrm{L}), 30$ cm (42.88 \pm 14.44$)$ y $45 \mathrm{~cm}(14.99 \pm 4.82)$ lo que justifica el comportamiento del rAM como sedimentador-reactor.

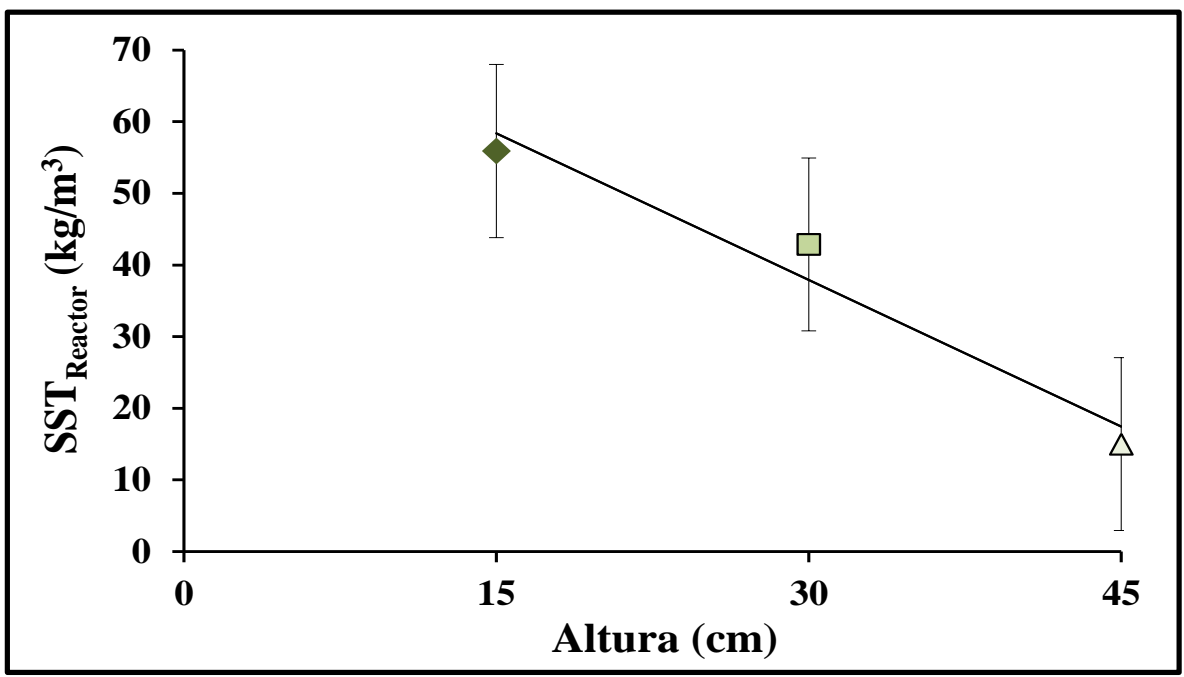

Figura 3.1a. Promedio de la concentración de SST a distinta altura (\% del volumen útil del rAM); $22 \%(\diamond), 44 \%(\square)$ y $66 \%(\triangle)$ y $r^{2}=0.9579$. 


\subsubsection{Hidrólisis de sólidos suspendidos volátiles (SSV) y formación de $\mathrm{DQO}_{\text {soluble }}$}

La figura 3.2 muestra la formación de $\mathrm{DQO}_{S}$ a partir de la destrucción de los SSV; los rombos representan los SSV en el influente y los cuadros los SSV en el efluente. Los tríangulos representan la $\mathrm{DQO}_{\mathrm{s}}$ en el influente y los círculos la $\mathrm{DQO}_{\mathrm{s}}$ en el efluente que se formó a partir de la destrucción de los sólidos suspendidos. Se observa mayor producción de $\mathrm{DQO}_{\mathrm{S}}(1.4 \pm 0.2$ y $1.75 \pm 0.2 \mathrm{~g} / \mathrm{L})$ y destrucción de SSV del 33.9 y $28.6 \%$ durante las corridas III y IV con proporciones de LP:LS de 30:70 y 70:30 y carga de sólidos de 5.3 y $10.1 \mathrm{gSSV} / \mathrm{L}$ d respectivamente a un día de TRH comparativamente con la de la entrada, en relación a las demás corridas (I, II, V, VI y VII) con proporción de LP:LS de 30:70 y 50:50, menor carga de sólidos y TRH de 1, 2 y 3 días. Estos resultados son similares a los reportados por Donoso y col. (2009) y menores a los reportados por Cheunbarn y Pagilla (2000) quienes reportan un $71.3 \%$ de reducción de SSV en un sistema mesofílico/mesofílico a TRH de 3.1 días en la primera fase y de 9.1 días para la segunda fase. Miron y col. (2000) lograron un incremento del $33 \%$ en la hidrólisis de materia orgánica de lodos residuales primarios, al variar el TRS entre 3 y 15 días en reactores completamente agitados a $25^{\circ} \mathrm{C}$. Pero menores a los reportados en la literatura en mezclas de lodos primarios y secundarios (LP:LS) digeridos donde se alcanzan eficiencias de reducción de sólidos suspendidos volátiles del 50 al $60 \%$ en sistemas mesofílicos (Killilea y col., 2000; Arnaiz y col., 2006). Las posibles razones por las cuales la reducción de sólidos no fue satisfactoria son: 1) disponibilidad de sólidos biodegradables en la mezcla de lodos residuales (biodegradabilidad de lodo primario mayor al de lodo secundario) (87\% versus 43\%) (Arnaiz y col., 2006), 2) TRH al que fue operado el rAM, en la literatura se reporta para digestores anaerobios mesofílicos TRH mayores a 20 días para lograr una reducción de SV de un 40\%,3) temperatura de operación ya que la tasa de hidrólisis de los sólidos suspendidos está reportado que aumenta conforme ésta se incrementa (Veeken y Hamelers, 1999; Yu y col., 2003; Mahmoud y col., 2004). Con el aumento de la temperatura, se mejora la hidrólisis y la acidificación de lodo primario (Ferreiro y col., 2003; Ahn y col., 2006; Cokgor y col., 2009). y 4) al pH debido al efecto sobre la hidrólisis y acidificación de lodo secundario de acuerdo al siguiente orden: alcalino>ácido>neutro. Se observa a pH alcalinos un incremento en la tasa de hidrólisis de los sólidos y en consecuencia la formación de AGV (Yinguang y col., 2007). Zhang y col. (2009) observaron el mismo resultado en la fermentación de lodos 
activados. Mahmoud y col. (2004), en su estudio del efecto del TRS y la temperatura sobre la hidrólisis, acidificación y metanogénesis de lodo primario en reactores RCTA, encontraron la mayor estabilización a 30 días de TRS a $35^{\circ} \mathrm{C}$ y de 10 a 15 días a $55^{\circ} \mathrm{C}$ logrando de un 39 a un $60 \%$ de degradación de materia orgánica. Por lo que la tasa de hidrólisis de los sólidos es mayor a $55^{\circ} \mathrm{C}$, que a 20 y $35^{\circ} \mathrm{C}$ durante la fermentación del lodo primario (Ahn y col., 2006).

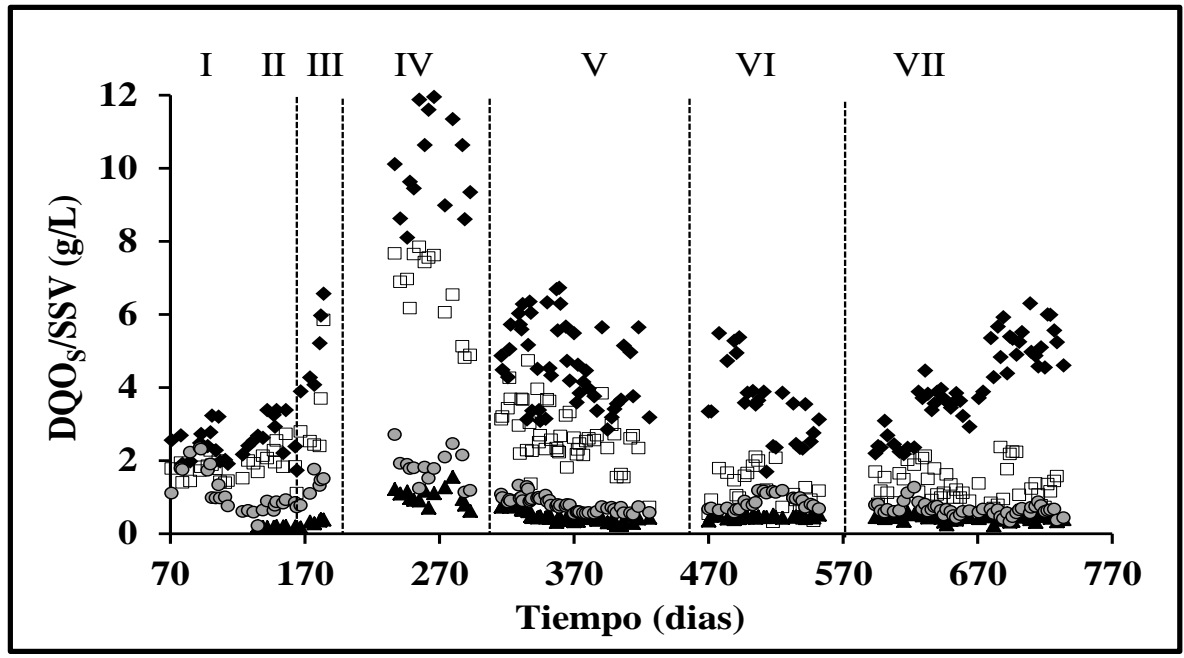

Figura 3.2. Concentración de SSV y formación de $\mathrm{DQO}_{S}$ en el reactor rAM.

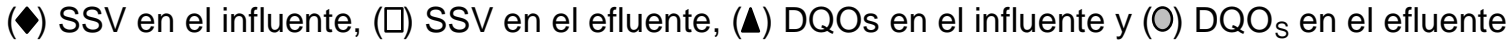

A partir de la figura 3.2 se construye la figura 3.2a, que muestra el efecto de la variación de la carga orgánica $(\mathrm{Bv})$ en la destrucción de sólidos con una $U_{S}$ de 1.8 y 2.93 $\mathrm{kgSSV} / \mathrm{m}^{3} \mathrm{~d}$ (corridas III y IV) y $\eta=33.9$ y $28.6 \%$. Por lo que se concluye que la velocidad de reacción $\left(U_{S}\right)$ es directamente proporcional a la carga de sólidos alimentados.

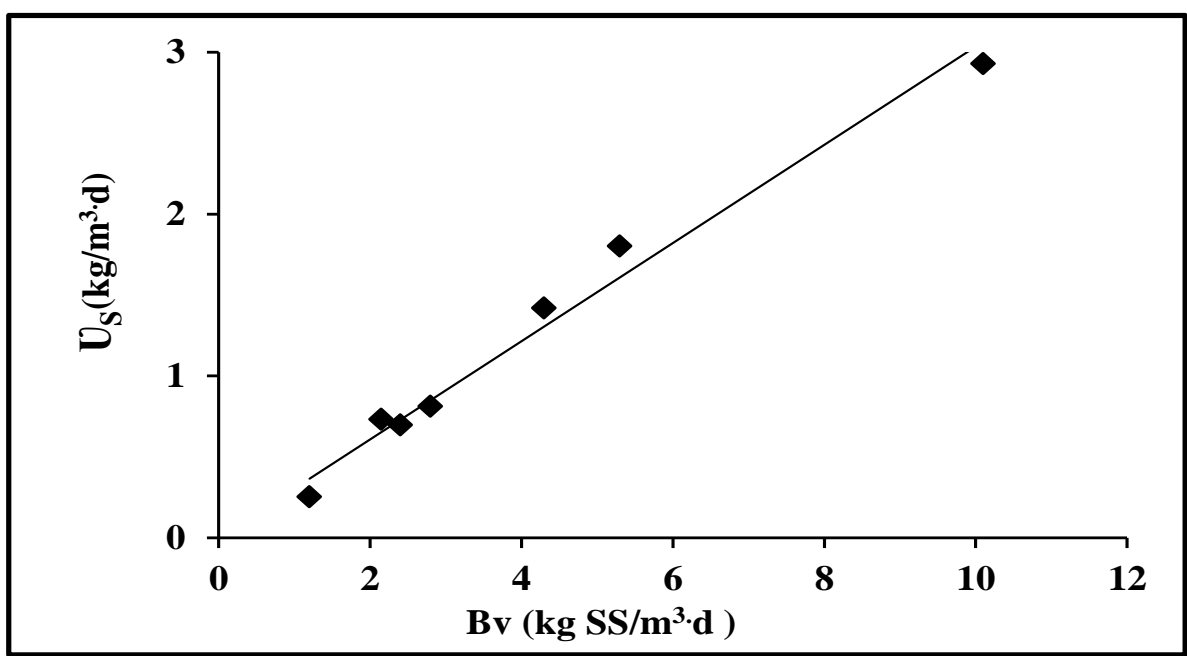

Figura 3.2a. Efecto de la carga orgánica (Bv) en la velocidad de destrucción de sólidos con $n=33.9$ y $28.6 \%, r^{2}=0.9816$. 


\subsubsection{Efecto de la proporción de LP:LS en la velocidad de destrucción de sólidos}

También se observa en la figura 3.3, que la mezcla con la mayor carga orgánica con una proporción de LP:LS de 70:30 influye en la tasa de remoción de sólidos a una tasa de 2.9 $\mathrm{kg} / \mathrm{m}^{3} \cdot \mathrm{d}$. A partir de esta figura se construye la $3.3 a$ donde se muestra que no hay ningún efecto de la proporción de LP:LS sobre la velocidad de destrucción de sólidos, pero sí influye la carga orgánica, coincidiendo con lo reportado por Metzner y Lemmer. (1997).

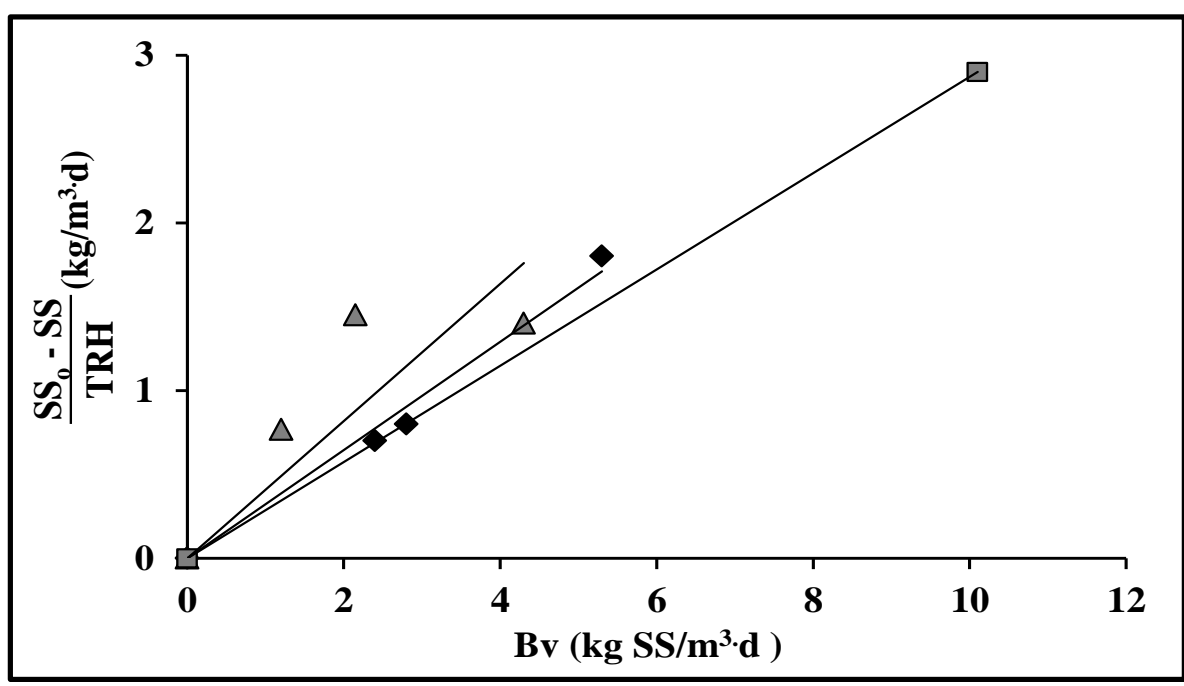

Figura 3.3. Efecto de la carga orgánica en la destrucción de sólidos con distinta proporción de LP:LS; $30: 70$ $(\diamond) \eta=32.3 \% y^{2}=0.9852,50: 50(\Delta) \eta=40.96 \%$ y $r^{2}=0.6157$ y $70: 30(\square) \eta=28.7 \%$ y $r^{2}=0.95$.

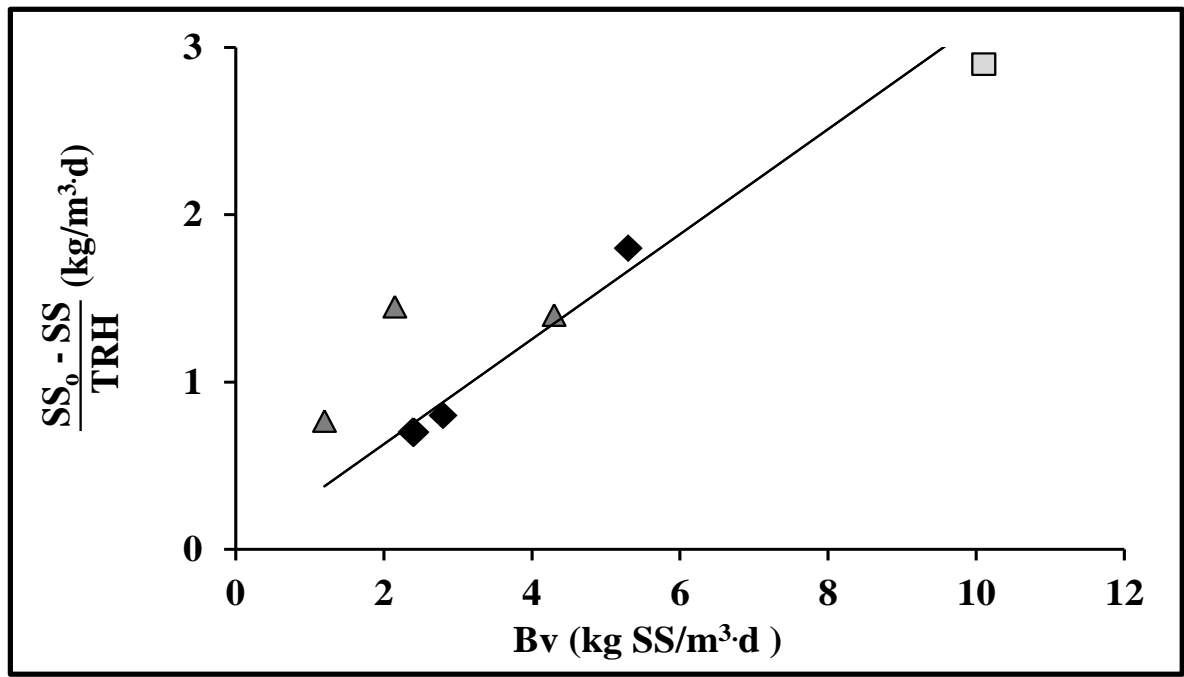

Figura 3.3a. Efecto de la carga de orgánica en la destrucción de sólidos en el rAM con LP:LS; 30:70 ( $), 50: 50(\Delta)$ y 70:30 $\square) \eta=31.4 \%$ y $r^{2}=0.77$.

La figura 3.4 muestra el efecto del TRS en la velocidad de destrucción de sólidos en mezclas de lodos residuales con proporciones de LP:LS; 30:70, 70:30 y 50:50 en el rAM. 
Se observa que a mayor carga de sólidos (Corrida $I V=10.1 \mathrm{kgSSV} / \mathrm{m}^{3} \cdot \mathrm{d}$ ), mayor velocidad de destrucción a TRS cortos (12.5 días) en comparación a las demás corridas (menor carga de sólidos), donde los TRS resultaron ser más largos (TRS>17 días). Debido a que no se mantuvo fijo uno de los dos parámetros (TRS o Bv) y variando uno de ellos, no se puede concluir sí el TRS tuvo algún efecto en la velocidad de destrucción de los sólidos, pero por los análisis antes hechos, la carga de sólidos juega un papel importante en la destrucción de sólidos orgánicos.

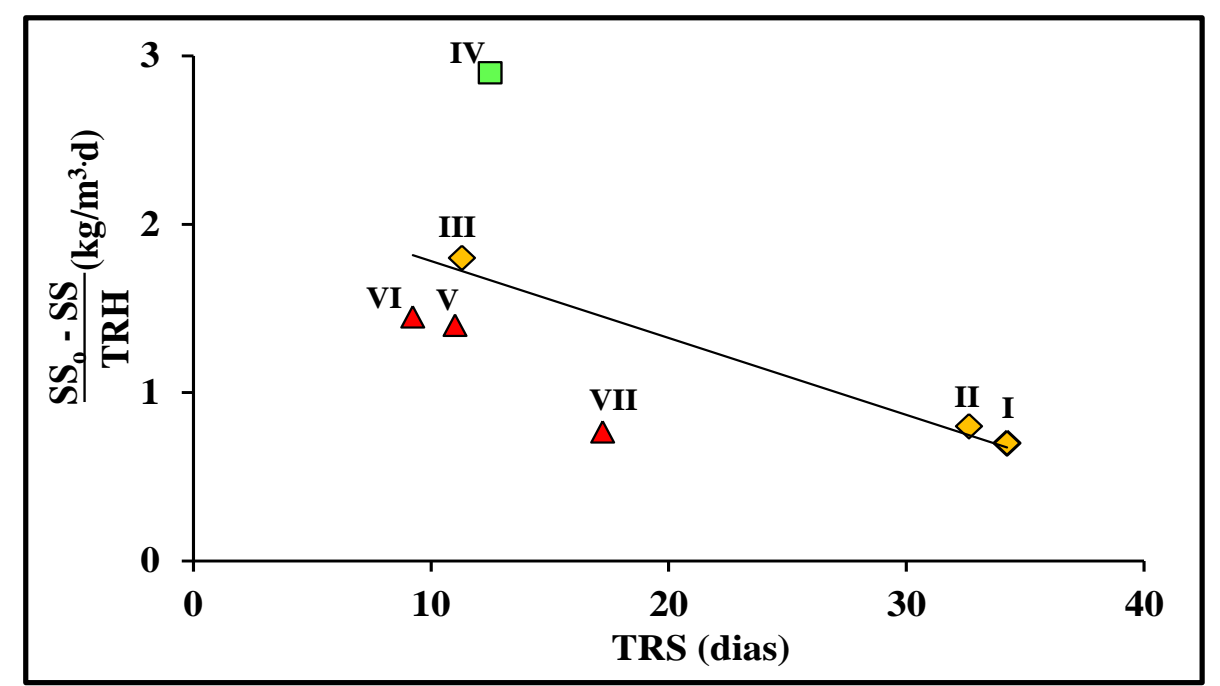

Figura 3.4. Efecto del TRS (d) en la velocidad destrucción de sólidos en mezclas de LP:LS; 30:70 $(\diamond)$ corridas I-III, 70:30 $\square$ ) corrida IV y 50:50 ( $\Delta$ ) corridas V-VII.

\subsubsection{Producción de AGV}

La figura 3.5 muestra la producción total de AGV en términos de la DQOs en el efluente del rAM. Se observa una baja producción de AGV durante las corridas I a la VI en 0.36, $0.22,0.25,0.23,0.28$ y $0.32 \mathrm{~g} / \mathrm{L}$ a valores de $\mathrm{pH}$ de $5.4,5.8,5.4,5.7,5.7$ y 5.1 respectivamente con un máximo en la corrida $\mathrm{VI}$ a 2 días de $\mathrm{TRH}$. Pero menor concentración $(0.2 \mathrm{~g} / \mathrm{L})$ durante la corrida $\mathrm{VII}$ a pH 7.2 y 3 días de $\mathrm{TRH}$ al tiempo en que se observa un cambio tanto en el volumen de biogás producido como en su composición (68.3\% de $\mathrm{CH}_{4}$ ) comparativamente al de corridas anteriores (figuras 3.6 y 3.9). La razón por la cual la producción de AGV fue baja se atribuye a que bajo estas condiciones no se incrementó la hidrólisis del lodo secundario y en consecuencia la producción de más sustratos solubles para la acidificación. En la literatura se menciona un valor óptimo de $\mathrm{pH}$ para la fase ácida durante la operación de bioreactores entre 5.0 y 6.0 (Eastman y 
Ferguson, 1981; Zoetemeyer y col., 1982). Carrozzi y Steinle (1994) observaron que la concentración de AGV varía con el TRH encontrando a TRH menores a 5 días y $\mathrm{pH}<6$ una concentración de AGV de 42 mM, con TRH entre 10 y 15 días una concentración 9 $\mathrm{mM}$ y para TRH>15 días, menor concentración de AGV de $2.5 \mathrm{mM}$; observando que el pH era menor a 6 a TRH menores a 5 días y que el $\mathrm{pH}$ se incrementaba a 7.7 a TRH mayores a 5 días a consecuencia del amoniaco producido por la hidrólisis de las proteínas. Elefsiniotis y Oldham (1994) observaron que la distribución de ácidos grasos volátiles (AGV) se ve afectada por el cambio en el TRS durante la DA de lodos residuales primarios. Miron y col. (2000) demostraron que la hidrólisis de lípidos y carbohidratos de lodos primarios se incrementa con el aumento del TRS y que la deficiente solubilización de material orgánico a concecuencia de la hidrólisis de los sólidos suspendidos afecta la acidogénesis (Maharaj y Elefsiniotis, 2001). El empleo de LP en la mezcla con LS es utilizado para favorecer la formación de productos solubles $\left(D O_{S}\right)$ y producción de AGV por fermentación (Thomas y col., 2003). Shana y Assadi., (2003) en reactores RCTA con cargas orgánicas de $21.4 \mathrm{~kg} \mathrm{DQO} / \mathrm{m}^{3} \cdot \mathrm{d}$, TRH de 2 a 4 días y proporción de LP:LS (70:30) a $35^{\circ} \mathrm{C}$, lograron un incremento del $373 \%$ de AGV en relación a los AGV iniciales en el lodo crudo con composición de; acético (38.3\%), propiónico (35.16\%), N-butírico (11.2\%), I-butírico (4.78\%), I-valérico (4.3\%) y $\mathrm{N}$-valérico (6.3\%). Y refieren que la producción de AGV está en función de la carga orgánica, del contenido de fracción volátil y del pH, ya que al incrementar los niveles de $\mathrm{pH}$ a 5.5 durante la fermentación del lodo primario aumenta significativamente el ácido acético en un $70 \%$, mientras que al disminuirlo, la producción de AGV también disminuye con predominio del ácido propiónico y ácidos de 4 y 5 átomos de carbono (Bouzas y col., 2007). Yinguang y col. (2007) reportan que a valores de $\mathrm{pH}(\mathrm{pH}=4.0,5.0)$ se favorece la acidogénesis mientras que a $\mathrm{pH}$ alcalinos $(\mathrm{pH}$ de 9-11) se favorece la hidrólisis. 


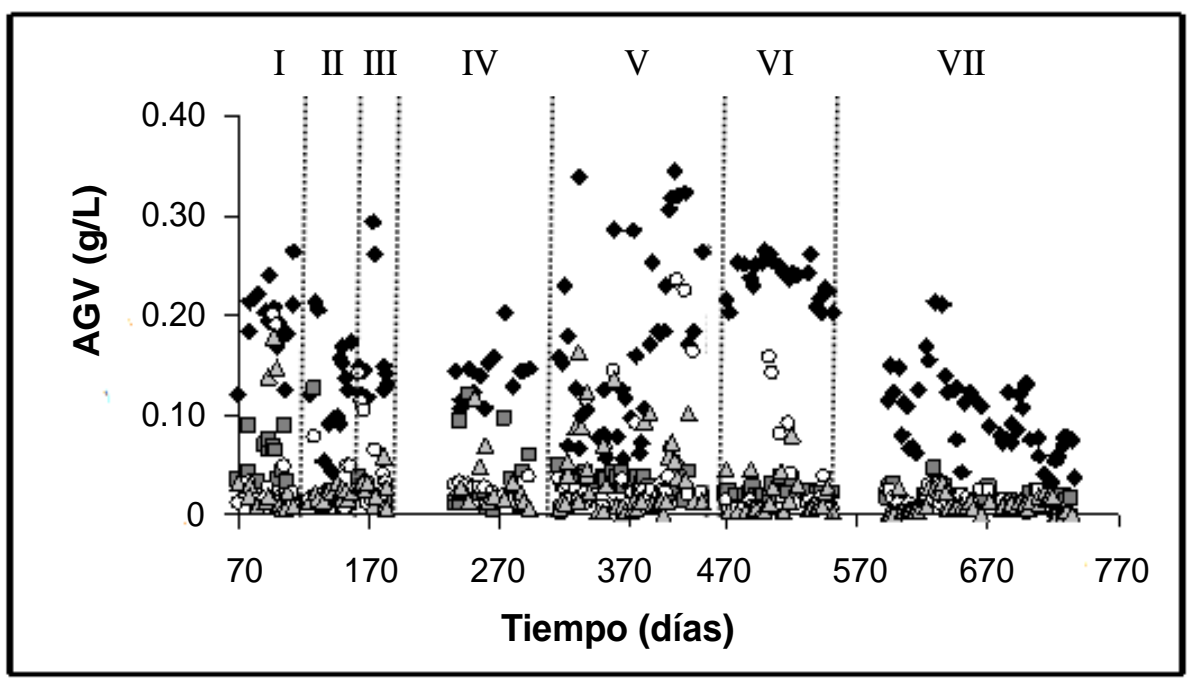

Figura 3.5. AGV formados en el reactor acidogénico mesofilico. Acetato $($ ), Propionato $(\square)$, Isobutirato $(\triangle)$ y Butirato $(O)$.

\subsubsection{Producción y composición de biogás en el rAM}

La figura 3.6 muestra la producción y composición de biogás a diferentes cargas de sólidos y TRH (Cuadro 3.2). Se observa durante las corridas I-V (TRH = 1 día) y corrida VI ( $\mathrm{TRH}=2$ días) una menor producción de biogás en promedio de $12.38 \mathrm{~mL} / \mathrm{L}_{\mathrm{R}} \cdot \mathrm{d}$ con una composición promedio de $\mathrm{CO}_{2}$ del $66.8 \%$ comparativamente al producido durante la corrida VII a 3 días de TRH (52 mL/ $\mathrm{L}_{\mathrm{R}}$ d) con una composición promedio del $68 \%$ de $\mathrm{CH}_{4} \mathrm{y}$

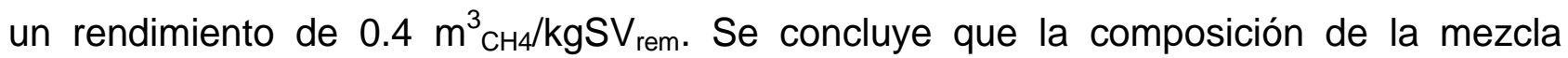
alimentada (50\% de LP y $50 \%$ de LS) influyó en el cambio de $\mathrm{pH}$ y a consecuencia de ello, la producción y composición del biogás. La influencia del pH sobre la producción de metano también fue reportada por Lay y col. (1997). Comparativamente la productividad de metano durante la DA de LP y LS es mayor cuando se estabiliza LP (Metzner y Lemmer, 1997).

El comportamiento del reactor en cuanto a la producción y composición de metano concuerda con lo que menciona Yinguang y col. (2007) quienes reportaron que la producción de metano se ve afectada tanto por el $\mathrm{pH}$ como por el $\mathrm{TRH}$, alcanzando la máxima producción a $\mathrm{pH}=6$ y TRH de 8 días. 


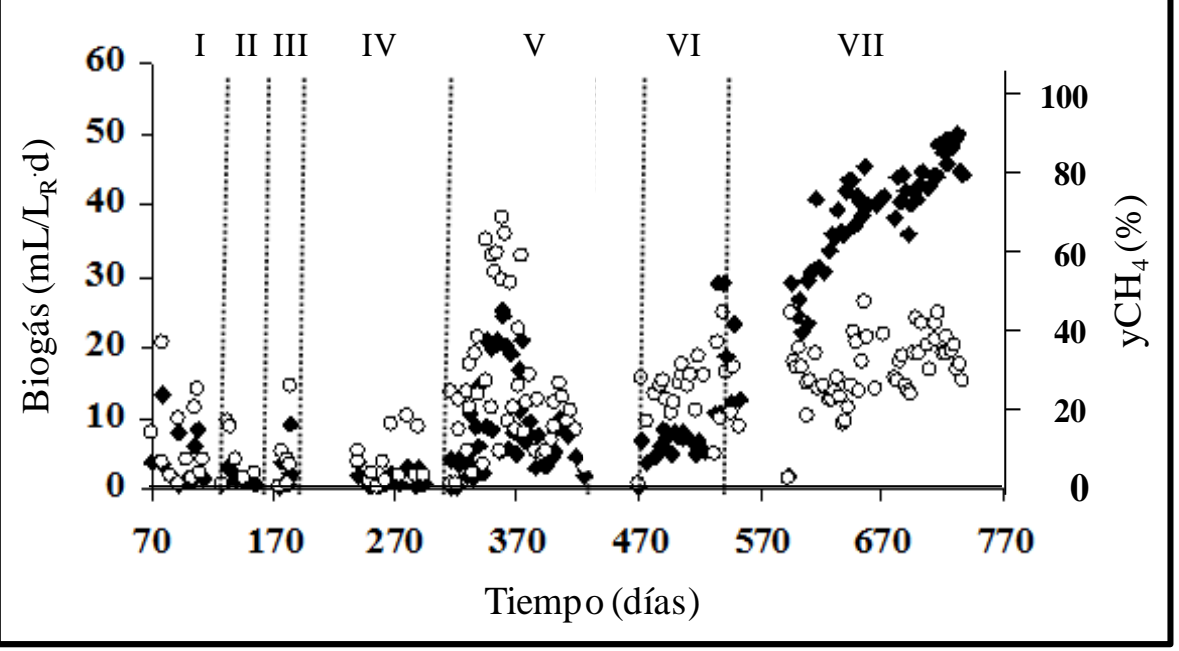

Figura 3.6. Producción $\bigcirc$ ) y composición del biogás ( en el reactor acidogénico.

A partir de las figuras 3.2, 3.5 y 3.6 se construye el cuadro 3.3 que representa el promedio de los días de operación cuando el reactor alcanzó la fase estacionaria en cada corrida.

Cuadro 3.3. Características del lodo hidrolizado y biogás del rAM.

\begin{tabular}{|c|c|c|c|c|c|c|c|}
\hline Corrida & I & II & III & IV & V & VI & VII \\
\hline $\mathrm{pH}$ & $5.4 \pm 0.4$ & $5.8 \pm 0.5$ & $5.4 \pm 0.3$ & $5.7 \pm 0.3$ & $5.7 \pm 0.2$ & $5.1 \pm 0.2$ & $7.2 \pm 0.4$ \\
\hline $\mathrm{ST}(\mathrm{g} / \mathrm{L})$ & $3.0 \pm 0.4$ & $3.3 \pm 0.3$ & $6.0 \pm 2.3$ & $10.9 \pm 1.8$ & $5.5 \pm 1.3$ & $3.6 \pm 1.2$ & $3.1 \pm 0.8$ \\
\hline $\operatorname{SST}(\mathrm{g} / \mathrm{L})$ & $2.5 \pm 0.4$ & $2.9 \pm 0.4$ & $5.5 \pm 2.0$ & $9.4 \pm 1.7$ & $4.4 \pm 1.2$ & $2.1 \pm 0.8$ & $1.8 \pm 0.5$ \\
\hline $\mathrm{SSV}(\mathrm{g} / \mathrm{L})$ & $1.7 \pm 0.3$ & $2.0 \pm 0.5$ & $3.5 \pm 1.4$ & $7.2 \pm 0.6$ & $2.9 \pm 0.7$ & $1.4 \pm 0.6$ & $1.4 \pm 0.4$ \\
\hline $\mathrm{DQO}_{\mathrm{T}}(\mathrm{g} / \mathrm{L})$ & $3.3 \pm 0.4$ & $3.2 \pm 0.3$ & $4.9 \pm 0.2$ & $9.3 \pm 1.01$ & $4.3 \pm 1.0$ & $3.1 \pm 0.5$ & $2 \pm 0.9$ \\
\hline $\mathrm{DQO}_{\mathrm{S}}(\mathrm{g} / \mathrm{L} \cdot \mathrm{d})$ & ND & $0.7 \pm 0.2$ & $1.4 \pm 0.2$ & $1.75 \pm 0.2$ & $0.8 \pm 0.07$ & $0.45 \pm 0.03$ & $0.2 \pm 0.02$ \\
\hline $\operatorname{AGV}(g / L)$ & $0.36 \pm 0.2$ & $0.22 \pm 0.09$ & $0.25 \pm 0.08$ & $0.23 \pm 0.1$ & $0.28 \pm 0.13$ & $0.32 \pm 0.07$ & $0.2 \pm 0.1$ \\
\hline Acetato $(\mathrm{g} / \mathrm{L})$ & $0.2 \pm 0.04$ & $0.14 \pm 0.05$ & $0.19 \pm 0.07$ & $0.14 \pm 0.03$ & $0.16 \pm 0.1$ & $0.25 \pm 0.03$ & $0.16 \pm 0.08$ \\
\hline Propionato (g/L) & $0.05 \pm 0.03$ & $0.02 \pm 0.03$ & $0.01 \pm 0.003$ & $0.04 \pm 0.03$ & $0.03 \pm 0.01$ & $0.02 \pm 0.008$ & $0.02 \pm 0.009$ \\
\hline Isobutirato (g/L) & $0.07 \pm 0.11$ & $0.04 \pm 0.04$ & $0.03 \pm 0.02$ & $0.02 \pm 0.01$ & $0.05 \pm 0.07$ & $0.04 \pm 0.05$ & $0.01 \pm 0.008$ \\
\hline Butirato $\quad(\mathrm{g} / \mathrm{L})$ & $0.04 \pm 0.06$ & $0.02 \pm 0.007$ & $0.02 \pm 0.02$ & $0.03 \pm 0.03$ & $0.04 \pm 0.04$ & $0.02 \pm 0.02$ & $0.01 \pm 0.008$ \\
\hline Proteínas $_{\mathrm{T}}(\mathrm{g} / \mathrm{L})$ & $2.3 \pm 0.2$ & $2.2 \pm 0.2$ & $3.9 \pm 0.22$ & $8.2 \pm 0.75$ & $4.03 \pm 0.49$ & $2.4 \pm 0.32$ & $0.9 \pm 0.39$ \\
\hline Proteínas $_{\mathrm{S}}(\mathrm{g} / \mathrm{L})$ & $0.19 \pm 0.06$ & $0.22 \pm 0.05$ & $0.5 \pm 0.03$ & $0.78 \pm 0.4$ & $0.36 \pm 0.1$ & $0.4 \pm 0.02$ & $0.32 \pm 0.1$ \\
\hline $\mathrm{Q}_{\text {BiogásTPS }}\left(\mathrm{mL} / \mathrm{L}_{\mathrm{R}} \cdot \mathrm{d}\right)$ & $11.2 \pm 9.8$ & $6.3 \pm 4.8$ & $7.7 \pm 8.4$ & $5.5 \pm 4.3$ & $24.0 \pm 17.1$ & $19.6 \pm 5.8$ & $52.6 \pm 14.3$ \\
\hline $\mathrm{CH}_{4}$ en el biogás $(\%)$ & 38.4 & 25.4 & 38.9 & 27.1 & 38.3 & 31.1 & 68.3 \\
\hline
\end{tabular}

Con el cuadro 3.3 se construye la figura 3.7 que muestra el efecto de la carga orgánica sobre la eliminación de la DQOT; se observa que la mejor eficiencia de eliminación ( $\eta=$ $41 \%$ ) se alcanza con una proporción de LP:LS de 50:50, TRH = 1 día y carga orgánica $\left(B v=7.3 \mathrm{~kg} / \mathrm{m}^{3} \cdot \mathrm{d}\right)$ con una velocidad $\left(\mathrm{U}=3 \mathrm{~kg} / \mathrm{m}^{3} \cdot \mathrm{d}\right)$ en relación a las demás mezclas de LP:LS a TRH de 1, 2 y 3 días. Se esperaría una mayor remoción de DQO a TRH largos (corrida VII), dado que en la literatura se reporta que para solubilizar del $30-50 \%$ de la 
DQO T ó de los sólidos volátiles (SV) se requieren más de 30 días de TRS (Parkin y Owen, 1986). Sin embargo esto no ocurre así debido a que la carga de sólidos es menor.

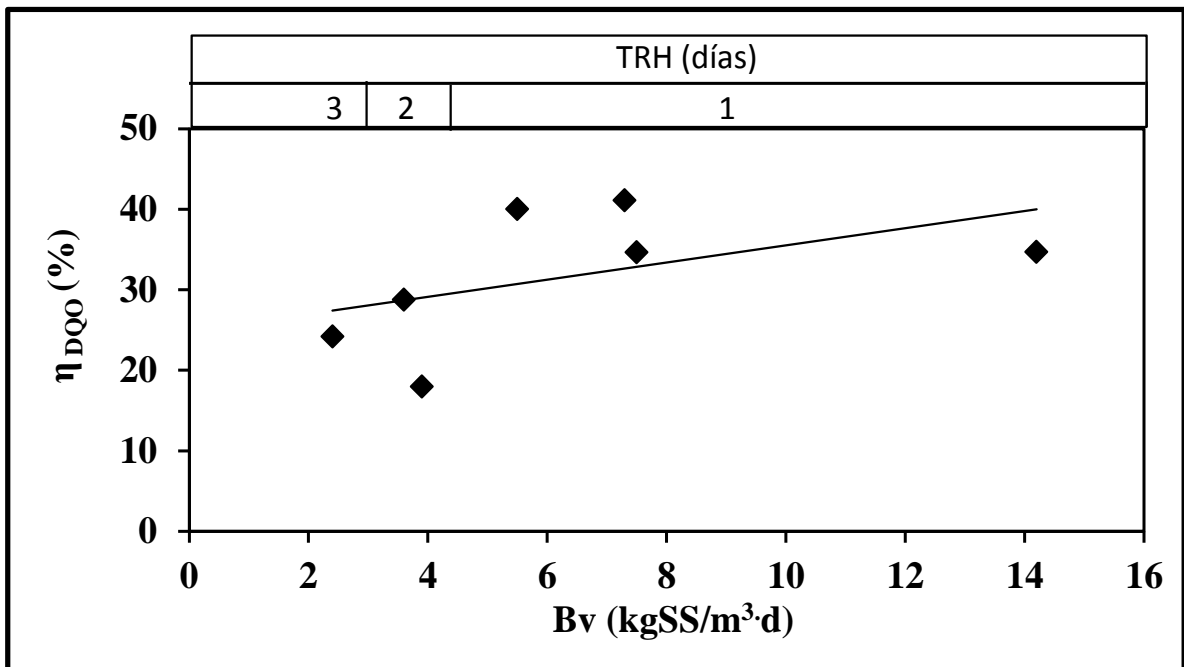

Figura 3.7. Efecto de la carga orgánica (Bv) en la eliminación de $\mathrm{DQO}_{\mathrm{T}}(\downarrow)$.

\subsubsection{Análisis cinético del reactor $\mathrm{rAM}$}

Las figuras 3.8 y 3.8 a muestran las ecuaciones 1.6 y 1.7 para calcular la tasa de hidrólisis de sólidos suspendidos $\left(k_{1}\right)$ y de acidogénesis $\left(k_{2}\right)$.

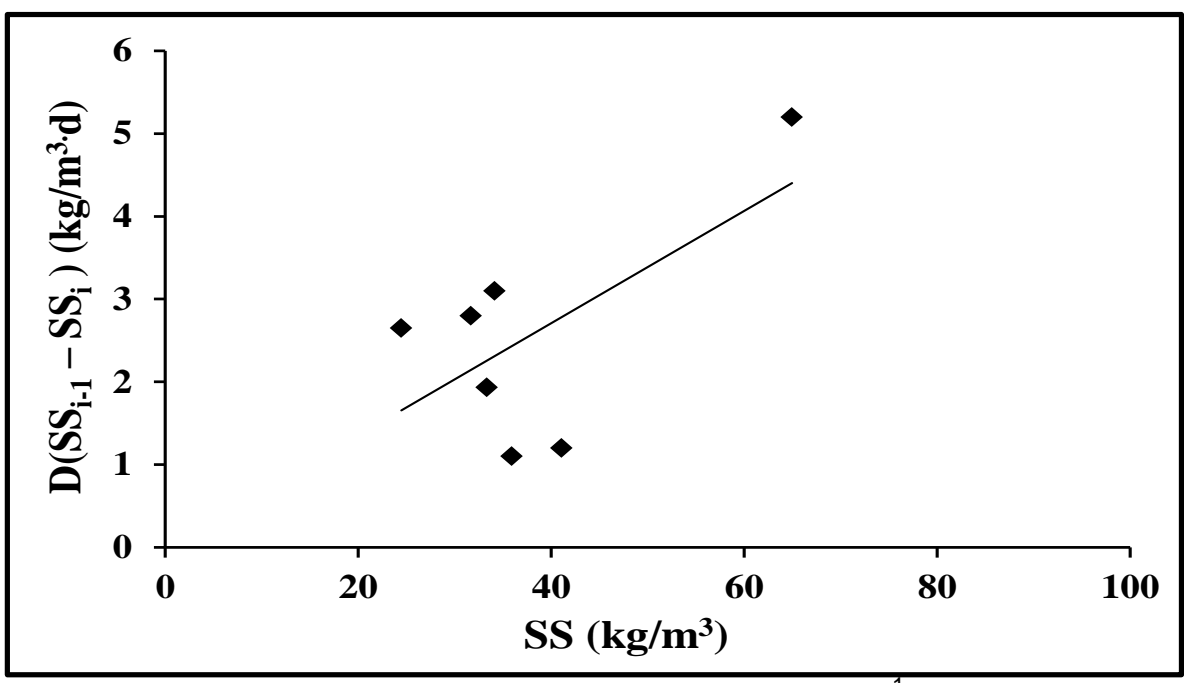

Figura 3.8. Estimación de $\mathrm{k}_{1}=0.0681 \mathrm{~d}^{-1}$. 


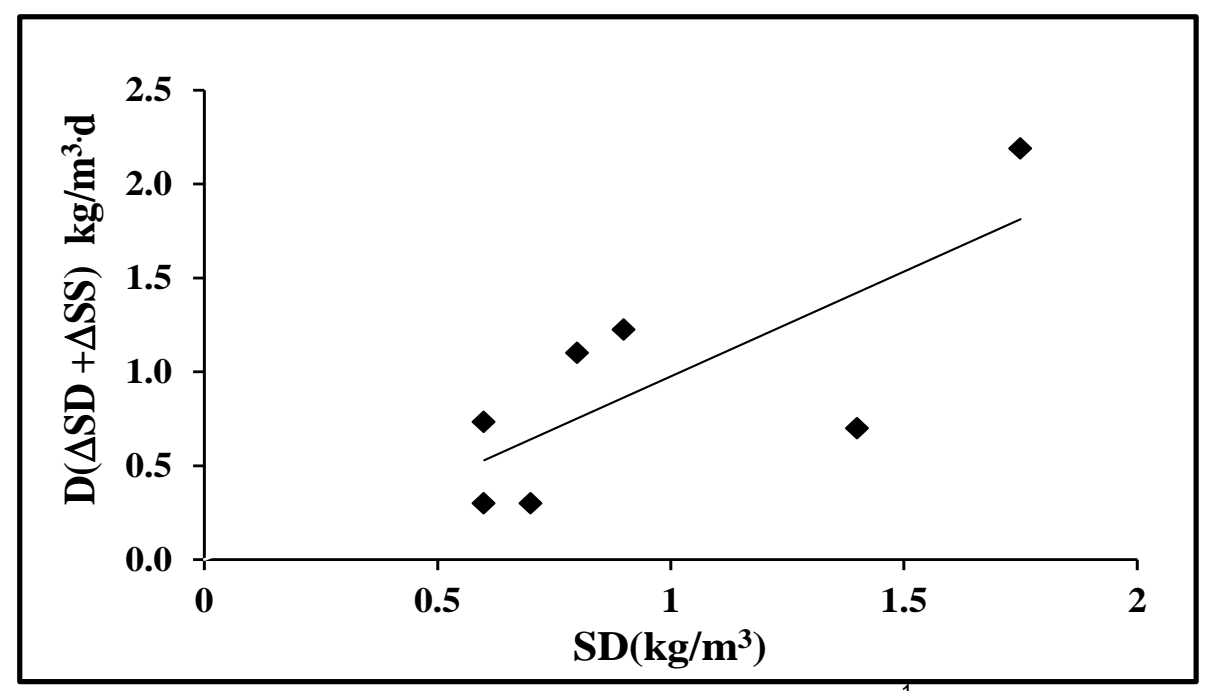

Figura 3.8a. Estimación de $\mathrm{k}_{2}=1.12 \mathrm{~d}^{-1}$

De las figuras anteriores se concluye que $k_{2}$ (tasa de acidogénesis) es 2 veces más grande que la tasa de hidrólisis de los sólidos suspendidos $\left(\mathrm{k}_{1}\right)$, lo que confirma que la hidrólisis de SS es la reacción limitante de la DA, provocando que haya poco material soluble fermentable y por consiguiente hace que la DA de los lodos residuales sea muy lenta.

\subsubsection{Evolución de pH}

La figura 3.9 muestra la evolución del pH. Se observa un pH promedio en el efluente de 5.5 con una tendencia a la alza en la última corrida $(\mathrm{pH}=7.2)$, debido a que parte del material fermentado se convirtió en metano.

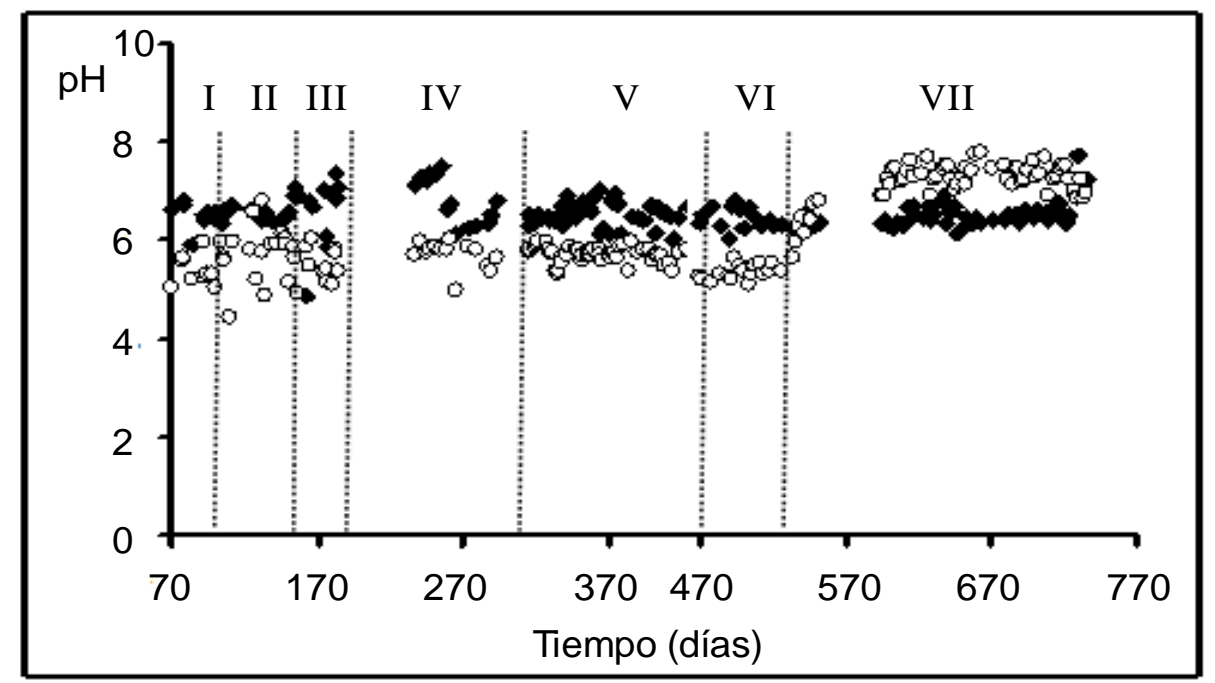

Figura 3.9. Evolución de pH en el reactor acidogénico; Influente $(\checkmark)$ y Efluente $(\bigcirc)$. 
Del inciso "c" del apartado 2.12 (Capitulo 2) para el análisis de los reactores, del total de AGV (ionizados y protonados) se estima la constante de producción de metano $\left(\mathrm{k}_{3}\right)$ sólo tomando en cuenta a los $\mathrm{AGV}$ ionizados $\left(\mathrm{B}^{-}\right)$en función del pH de cada corrida.

$$
\begin{gathered}
\mathrm{B}^{-}=f\left(\mathrm{pH}, \mathrm{A}_{\mathrm{t}}\right) \\
\mathrm{pH}=\mathrm{pka}+\log \frac{\mathrm{B}^{-}}{\mathrm{BH}}
\end{gathered}
$$

A partir de la ecuación de Henderson Hasselbach y de que

$$
\begin{aligned}
& B_{t}=B^{-}+H B \\
& B^{-}=B_{t} /(F i+1),
\end{aligned}
$$

Donde:

$$
\mathrm{Fi}=10^{(\mathrm{pKa}-\mathrm{pH})}
$$

Se obtiene la figura 3.10 que muestra la formación de AGV no ionizados a partir de la fermentación de la $\mathrm{DQO}_{\mathrm{s}}$.

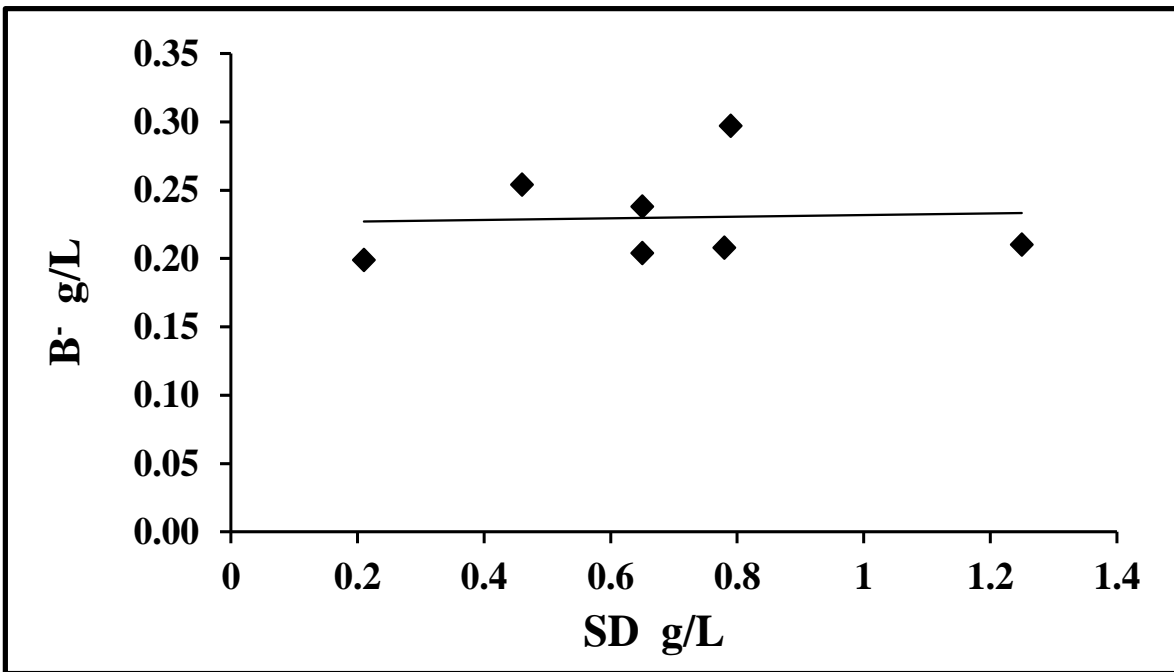

Figura 3.10. Estimación de la tasa de formación de AGV no ionizados $\left(\mathrm{B}^{-}\right)$ a partir de la $\mathrm{DQO}_{\text {Soluble }}(\mathrm{SD})$ con $\mathrm{k}=0.0058 \mathrm{~d}^{-1}$.

A partir de la figura 3.9 y 3.10 se construye la figura 3.11 que muestra la ecuación 1.9 (capitulo 1), para estimar $\mathrm{k}_{3}$. 


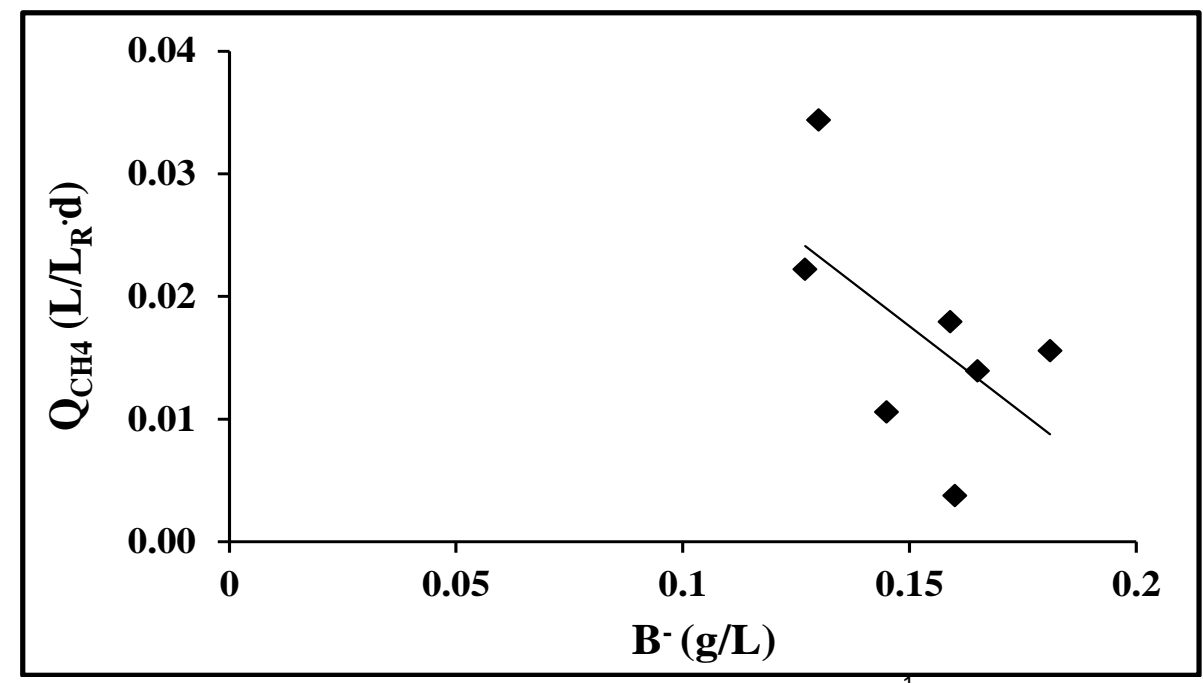

Figura 3.11. Estimación de $\mathrm{k}_{3}=0.35 \mathrm{~d}^{-1}$.

Se concluye en base a las $k$ estimadas (figuras 3.8, 3.8a, 3.10 y 3.11) que el valor obtenido para cada k es indicativo de la evolución del proceso de digestión anaerobia de lodos residuales y de la tasa de reacción del metabolismo entre las especies involucradas, por lo que se confirma que la etapa limitante es la hidrólisis de sólidos suspendidos y a consecuencia de ésto, la DA es muy lenta.

\subsubsection{Hidrólisis de proteínas}

La figura 3.12 muestra la concentración de proteína residual en el efluente del rAM y la figura 3.13 el efecto de la carga de sólidos sobre la hidrólisis de la proteína a distinto TRH. Se observa que durante los periodos de aclimatación de la biomasa del digestor al lodo residual como sustrato a distinta proporción de LP:LS, la concentración de proteína en el efluente es similar a la que entra (corridas I, II y V) comparativamente al de las demás corridas. Y que entre mayor sea la carga de sólidos en la alimentación (14 $\mathrm{kg} \mathrm{SS} / \mathrm{m}^{3} \cdot \mathrm{d}$ ) y menor el TRH, la hidrólisis de proteína es mejor (34\%) en relación a cuando se alimenta menos carga de sólidos $\left(\mathrm{Bv}<4 \mathrm{~kg} \mathrm{SS} / \mathrm{m}^{3} \cdot \mathrm{d}\right)$ a TRH mayores. La hidrólisis de proteínas del lodo secundario requiere de otras condiciones para lograr su disolución en un $40 \%$ y TRH que van de 1 a 5 días (Boehler y Siegri, 2006). La temperatura juega un papel importante en las velocidades de reacción, además de otras condiciones para logar su hidrólisis. Mahmoud y col. (2004) mencionan que la temperatura tiene una influencia significativa en la hidrólisis de proteínas, hidratos de carbono, y lípidos del lodo primario; en su estudio 
bajo condiciones mesofílicas en reactores CSTR. Miron y col. (2000) mencionan que se requiere más de 15 días de $\mathrm{TRH}$ a $25^{\circ} \mathrm{C}$ para lograr un $33 \%$ de hidrólisis de proteínas.. Debido a la fracción de SV de fácil biodegradación en los lodos primarios respecto al del lodo secundario ( $87 \%$ versus $43 \%$ ) hace que la hidrólisis de proteínas y de carbohidratos de los lodos primarios, favorezca la formación de la $\mathrm{DQO}_{\mathrm{S}}$, y su posterior conversión a AGV por fermentación (Arnaiz y col, 2006).

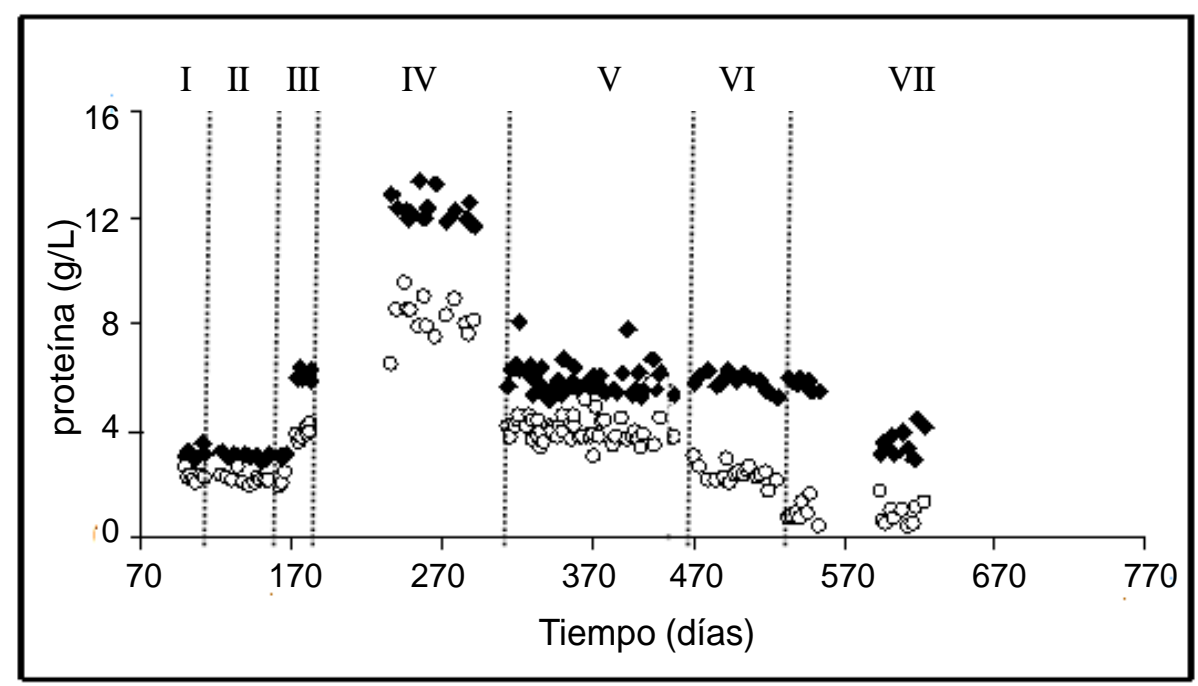

Figura 3.12. Hidrólisis de proteína en el reactor rAM: Influente $(\lambda)$ y Efluente $(O)$.

En la figura 3.13, se muestra que no hay un efecto significativo de la carga de sólidos en la hidrólisis de proteínas en mezclas a distinta proporción de LP:LS.

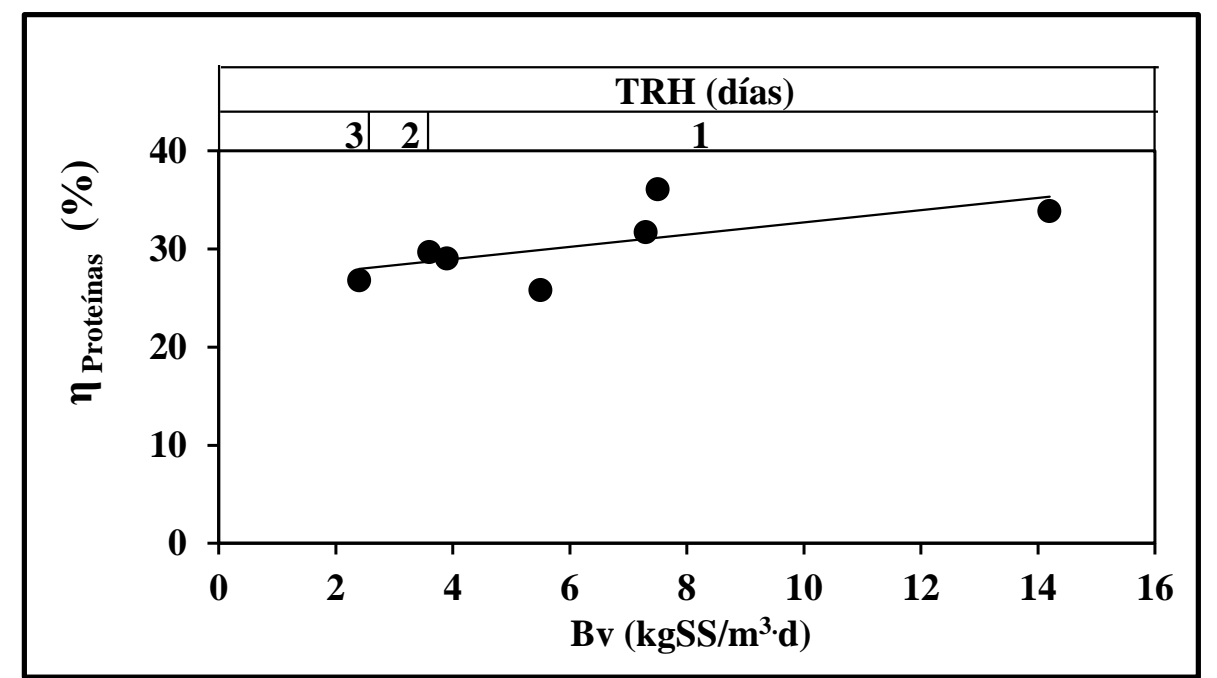

Figura 3.13. Efecto de la carga orgánica en la hidrólisis de proteína $(\eta=30 \%)$. 


\subsubsection{Estimación de constantes de velocidad de reacción $(\mathbf{k})$}

El cuadro 3.4 muestra los valores estimados de las constantes de velocidad de reacción que se llevan a cabo en el rAM de acuerdo al modelo cinético de la digestión anaerobia (DA) que se mencionó en el capítulo 1.

Cuadro 3.4. Constantes de velocidad de reacción (k) en el rAM.

\begin{tabular}{|c|c|c|}
\hline Reacción & Velocidad de reacción & $\mathrm{K}(1 / \mathrm{d})$ \\
\hline \multirow{3}{*}{$\begin{array}{c}\mathrm{SS} \rightarrow \mathrm{SD} \rightarrow \mathrm{AGV} \rightarrow \\
\mathrm{CH}_{4}\end{array}$} & $\mathrm{r}_{\mathrm{SS}}=\mathrm{k}_{1} \mathrm{SS}$ & $\mathrm{k}_{1}=0.0681$ \\
\cline { 2 - 3 } & $\mathrm{r}_{\mathrm{SD}}=\mathrm{k}_{1} \mathrm{SS}-\mathrm{k}_{2} \mathrm{SD}$ & $\mathrm{k}_{2}=1.12$ \\
\cline { 2 - 3 } & $\mathrm{r}_{\mathrm{AGV}}=\mathrm{k}_{2} \mathrm{SD}-\mathrm{k}_{3} \mathrm{AGV}\left(\mathrm{B}^{-}\right)$ & $\mathrm{k}_{\mathrm{AGV}}=0.058$ \\
\cline { 2 - 3 } & $\mathrm{r}_{\mathrm{CH} 4}=\mathrm{k}_{3} \mathrm{AGV}\left(\mathrm{B}^{-}\right)$ & $\mathrm{K}_{3}=0.35$ \\
\hline
\end{tabular}

El valor de $\mathrm{k}\left(\mathrm{d}^{-1}\right)$ en la velocidad de reacción $\left(\mathrm{r}_{\mathrm{SS}}=\mathrm{k}_{1} \mathrm{SS}\right.$ ) comparada con el valor de la costante cinética $\mathrm{k}\left(\mathrm{d}^{-1}\right)$ de reducción de SSV y estabilización de biomasa del la mezcla de LP:LS, fue mayor al reportado por Arnaiz y col. (2006) quienes reportan valores de reducción de SSV de $0.035,0.044$ y $0.022 \mathrm{~d}^{-1}$ para LP, LS y mezcla respectivamente. Pero menor a los valores de las constantes cinéticas $k_{1}, k_{2}$ y $k_{3}$ reportadas por Siegrist y col., 1992 para mezcla de LP:LS $\left(0.25,5.0\right.$ y $\left.0.5 \mathrm{~d}^{-1}\right)$ respectivamente.

\subsubsection{Conclusiones parciales:}

> El Reactor rAM de flujo ascendente actúa como sedimentador-reactor, ya que suspensiones de 3 a $14 \mathrm{~g} \mathrm{SST/L}$ se llegan a concentrar entre 15 y $56 \mathrm{~g} \mathrm{SST/L}$. Como resultado, la velocidad de reacción se sextuplica $\left(r_{S S T}=k^{*} S S T\right)$ en el reactor propiciando TRS de 11 a $34 \mathrm{~d}$.

> La mejor destrucción de sólidos (2.93 $\mathrm{kgSSV}_{\text {rem }} / \mathrm{m}^{3} \cdot \mathrm{d}$ ), se logró a TRS de $12.5 \mathrm{~d}$, con velocidades de producción de metano de $0.009 \mathrm{~L}_{\mathrm{CH}_{4}} / \mathrm{L}_{\mathrm{R}} \cdot \mathrm{d}$.

> La carga orgánica y el TRS influyen en la destrucción de sólidos. A mayor carga orgánica, mayor destrucción de sólidos y menor los TRS), por lo que a mayor concentración de sólidos, mayor velocidad de reacción $\left(U_{S}\right)$.

$>$ La formación de AGV y su posterior conversión a biogás son dependientes del pH y del TRH.

> Como $k_{2}$ es 2 veces más grande que $k_{1}$, se confirma que la hidrólisis de SS es la reacción limitante de la $D A, y$ que $k_{3}$ es mucho menor que $k_{2}$ debido al poco material soluble fermentable en AGV, por lo que la DA de los lodos residuales resulta muy lenta. 


\section{CAPÍTULO 4}

\section{REACTOR METANOGÉNICO TERMOFÍLICO (rMT)}

Se presentan los resultados obtenidos en el reactor rMT durante la estabilización de lodo predigerido por el reactor rAM. Se encuentra que: el reactor rMT de flujo ascendente también actuó como sedimentador-reactor dado que se observó una correlación entre la concentración de sólidos del reactor y la carga orgánica alimentada: con suspensiones de 1.8 a $9.4 \mathrm{~g} \mathrm{SST/L}$ en la alimentación se llega a tener concentraciones de 6.5 a $32.8 \mathrm{~g} \mathrm{SST/L}$ en el reactor alcanzando TRS de 7 a 22.9 d. La mayor destrucción de sólidos se logró a TRS de 7.4 d con 66\% a una Bv de $3.5 \mathrm{kgSSV} / \mathrm{m}^{3}$ d y en un $55 \%$ a una Bv de $7.2 \mathrm{KgSSV} / \mathrm{m}^{3}$ d y TRS de $15.2 \mathrm{~d}$ con velocidades de $\mathrm{Q}_{\mathrm{CH} 4}$ de 0.005 y $0.09 \mathrm{~L}_{\mathrm{CH} 4} / \mathrm{L}_{\mathrm{R}} \cdot \mathrm{d}$. Se observa una correlación entre la $\mathrm{Bv}$, el TRH y el TRS en la destrucción de sólidos. Existe una dependencia en la eliminación de microorganismos patógenos y de parásitos con el TRH, el TRS y la T. Las velocidades de reacción en el rMT son más rápidas en relación al rAM debido a la temperatura de operación. Mientras que con el valor de $\mathrm{k}_{4}$ se confirma su lentitud en la conversión de AGV a $\mathrm{CH}_{4}$. 


\subsection{Comportamiento del reactor metanogénico termofílico}

\subsubsection{Reactor de lodos de flujo ascendente como sedimentador}

La siguiente figura muestra que hay una dependencia de la concentración de sólidos de la cama de lodo del reactor con base a la carga orgánica alimentada. Se observa que a mayor carga, mayor concentración de SST en el rMT. Con concentraciones de SST a la entrada de; $2.5,2.9,5.5,9.4,4.4,2.1$ y $1.8 \mathrm{~g} / \mathrm{L}$ respectivamente.

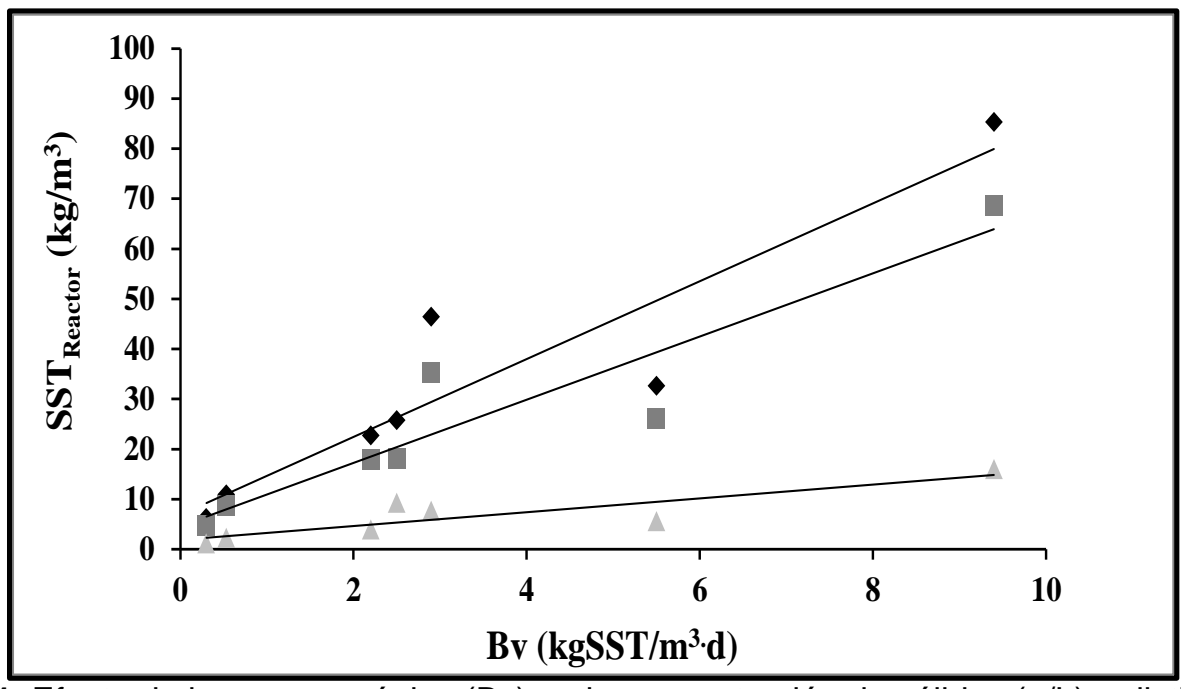

Figura 4.1. Efecto de la carga orgánica (Bv) en la concentración de sólidos ( $\mathrm{g} / \mathrm{L}$ ) a distinta altura;

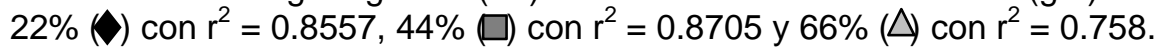

Las figura 4.1a muestra el promedio de la concentración de SST de la cama de lodo del rMT a distinta altura; $15 \mathrm{~cm}(32.78 \pm 26.73 \mathrm{~g} / \mathrm{L}), 30 \mathrm{~cm}(25.63 \pm 21.51)$ y $45 \mathrm{~cm}(6.46 \pm 5.06) \mathrm{con}$ base a la concentración de SST que entraba. Lo que confirma su comportamiento como sedimentador-reactor.

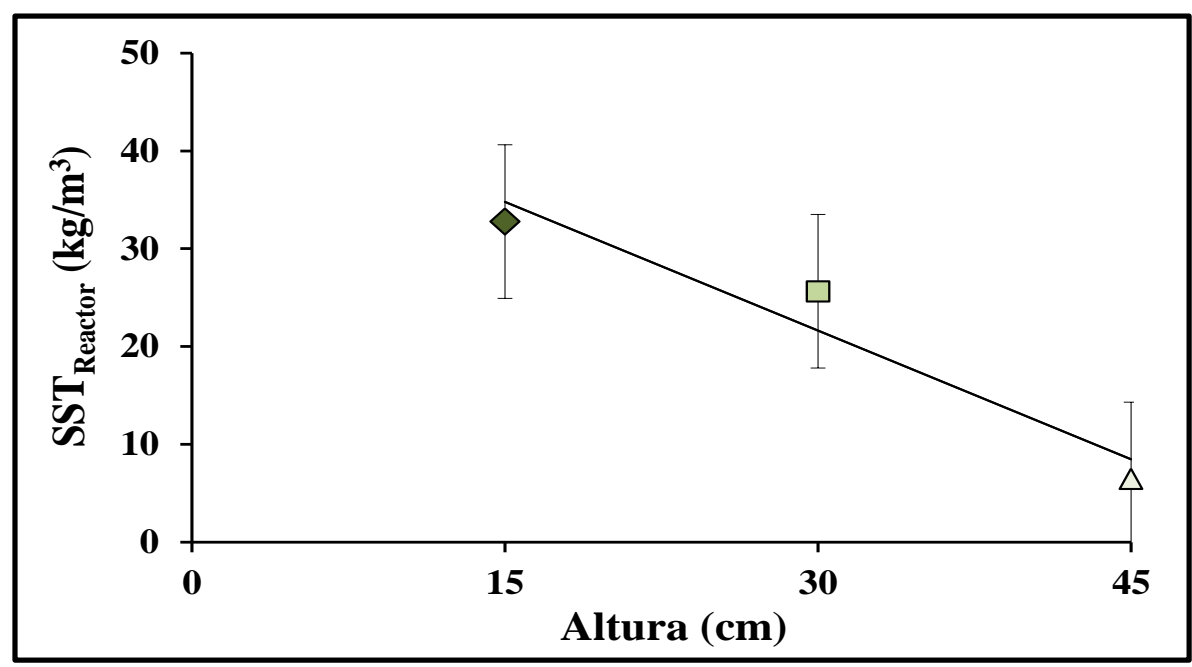

Figura 4.1a. Concentración de sólidos a distinta altura en la cama de lodo; $22 \%(\nabla), 44 \%(\square)$ y $66 \%(\triangle)$ con $r^{2}=0.935$. 
Y se observa que a medida que se varía el TRH (figura 4.1b) la concentración promedio de SST en la cama de lodo a distinta altura tiene una tendencia a la baja debido a los tiempos de exposición de las distintas cargas de sólidos con la biomasa activa de este reactor.

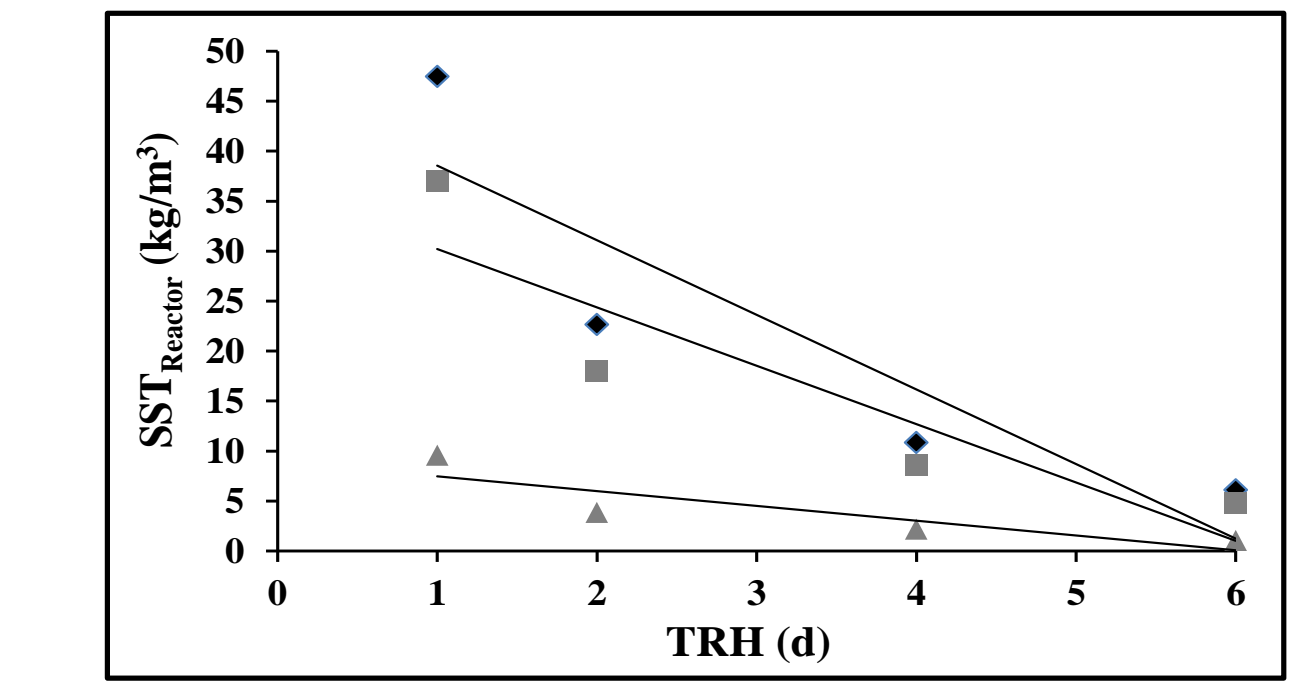

Figura 4.1b. Efecto del TRH en la concentración de sólidos a distinta altura de la cama de lodo; $22 \%(\checkmark)$ con $r^{2}=0.8022,44 \%(\square)$ con $r^{2}=0.8095$ y $66 \%(\triangle)$ con $r^{2}=0.751$.

\subsubsection{Destrucción de sólidos suspendidos volátiles (SSV) y formación de $\mathrm{DQO}_{\text {soluble }}$}

La figura 4.2 muestra la $\mathrm{DQO}_{\mathrm{s}}$ en el efluente del rMT a partir de la destrucción de los sólidos suspendidos volátiles (SSV); los rombos representan los SSV en el influente y los cuadros los SSV en el efluente. Los tríangulos representan la $\mathrm{DQO}_{S}$ en el influente y los círculos la $\mathrm{DQO}_{\mathrm{S}}$ en el efluente. Se observa que una vez que el reactor se aclimata al lodo predigerido por el primer reactor como sustrato, alcanza la máxima destrucción de SSV y conversión de la $\mathrm{DQO}_{\mathrm{s}}$ durante la corrida III (66 y 70\%) a una carga orgánica (CO) de 3.5 $\mathrm{kgSSV} / \mathrm{m}^{3} \cdot \mathrm{d}$ que disminuyen a consecuencia de la composición de la mezcla alimenta al primer reactor rAM durante la corrida IV en un 55 y $62 \%$ a una carga de $7.2 \mathrm{kgSSV} / \mathrm{m}^{3} \cdot \mathrm{d}$. A partir de la las tres subsiguientes (menor carga de sólidos) el TRH se ajusta a voluntad desechando parte del efluente del primer reactor. El criterio que guiaba para ajustar el TRH en las últimas corridas era buscar la máxima eliminación de patógenos y parásitos. Se observa que la mejor destrucción de SSV y conversión de $\mathrm{DQO}_{\mathrm{s}}$ se da a 2 días de TRH durante la corrida $\mathrm{V}\left(69\right.$ y $90 \%$ ) a menor $\mathrm{CO}=1.5 \mathrm{kgSSV} / \mathrm{m}^{3} \cdot \mathrm{d}$ en relación a las corridas VI y VII. Estas eficiencias son similares o mayores que las reportadas en la literatura. En sistemas termofílicos las eficiencias de remoción de sólidos volátiles son del 40 al 50\% (Roberts y col., 1999) pero puede llegar a ser hasta del 50 al 70\% (Arnaiz y -53- 
col., 2006). De la Rubia y col. (2002 y 2006) mostraron que no existe diferencia en la eficiencia de destrucción de SV entre un reactor mesofílico y un termofílico (53\% en ambos reactores). En sistemas de dos etapas termofílico-mesofílico la remocion de SV se da entre 38 y $45 \%$, para tiempos de retención menores a 15 días y de $58.8 \%$ para TRS mayores a 21 d. Rubio y col. (2010) en un sistema acidogénico-termofílico (AT) alimentado con mezcla de lodo primario-secundario en 56 y $44 \%$ en volumen y carga de sólidos de $10 \mathrm{kgSSV} / \mathrm{m}^{3} \cdot \mathrm{d}$ a 3 días de TRH y con el efluente de este reactor alimentaron en paralelo un reactor metanogénico mesofílico (MM) y un metanogénico termofílico (MT) a 13 días de TRH obtienen una reducción de SSV en el sistema AT-MM del 31\% y del $28 \%$ en el arreglo AT-MT y con 10 días de TRH, un $32 \%$ en ambos sistemas. En sistemas de dos etapas termofílico-mesofílico presentan remociones de SV entre 38 y $45 \%$, para tiempos de retención menores a 15 días y de $58.8 \%$ para TRS mayores a 21 d, durante la DA termofílica, con TRS cortos (entre 5 y 10 días) se logra un $32 \%$ más de destrucción de SV y un $37 \%$ más de producción de metano, con respecto a los sistemas de DA mesofílica convencional (De la Rubia y col., 2006).

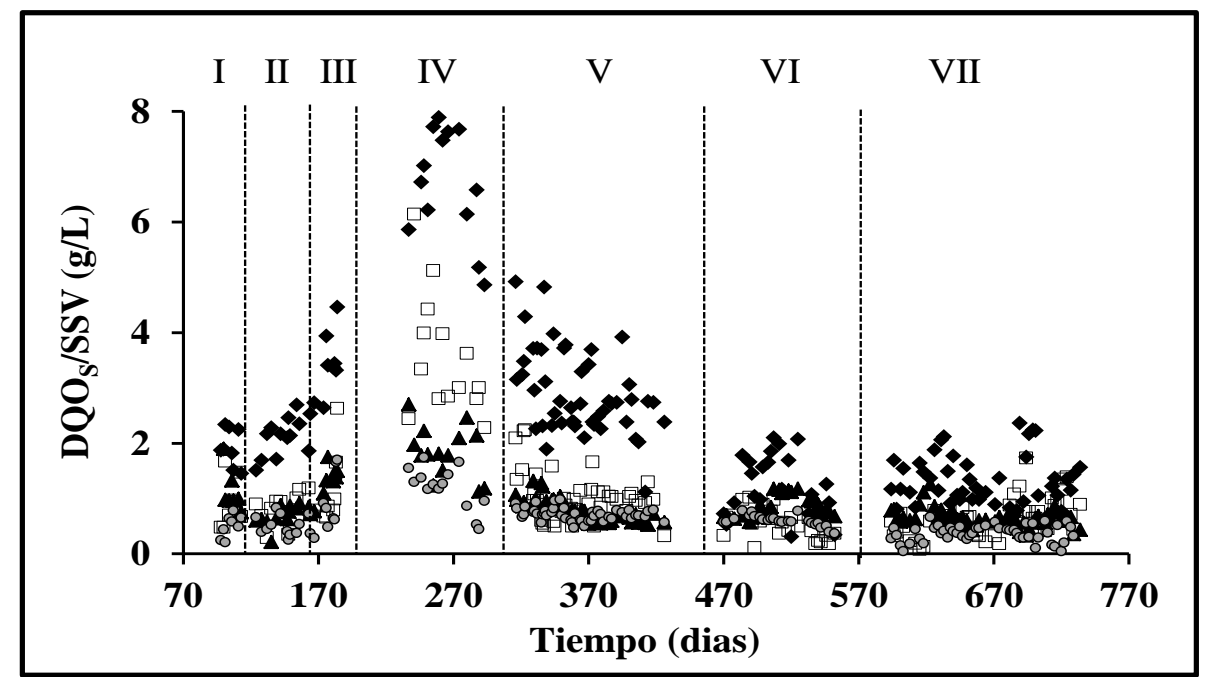

Figura 4.2. Concentración de SSV y $\mathrm{DQO}_{\mathrm{S}}$ en el efluente del reactor rMT.

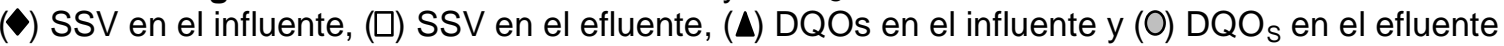

A partir de la figura 4.2 se construye la figura $4.2 a$ que muestra el efecto de la carga orgánica en la velocidad de destrucción de sólidos y se observa que a mayor concentración de sólidos en el efluente del rAM (lodo predigerido), mayor es la velocidad de destrucción de sólidos en el reactor MT. 


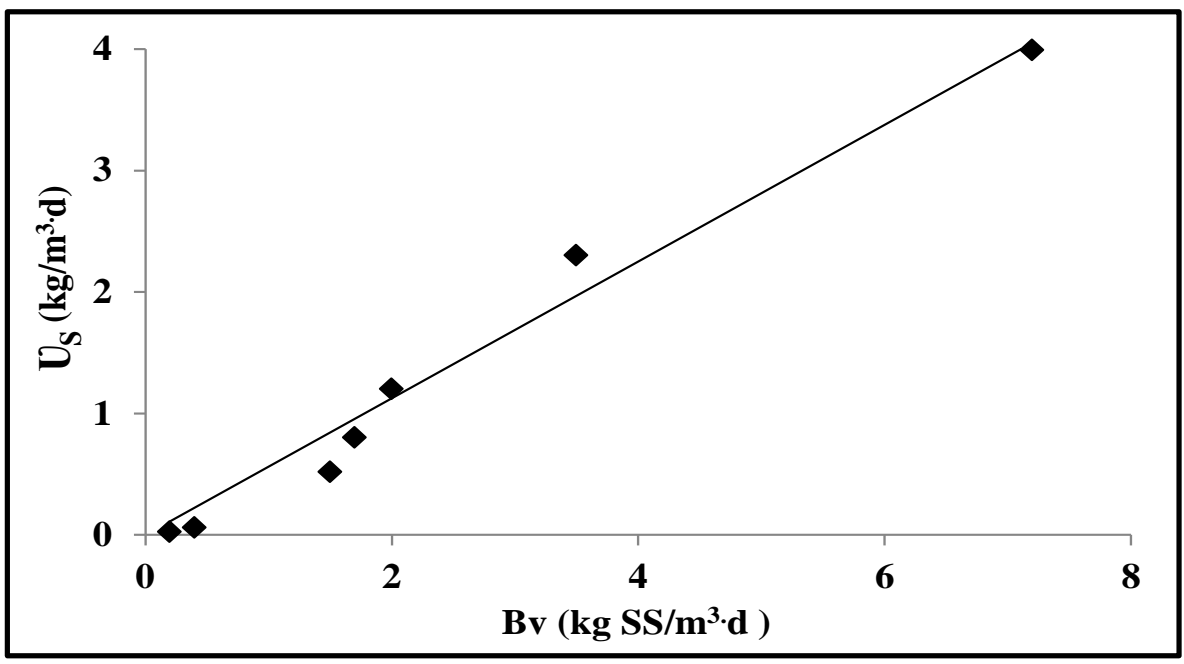

Figura 4.2a. Efecto de la carga orgánica (Bv) en la velocidad de destrucción de sólidos $\left(U_{s}\right)$ con una eficiencia $(\eta)$ del $56.3 \%$ y $r^{2}$ de 0.9767 .

\subsubsection{Eliminación de $\mathrm{DQO}_{\text {total }}$}

La figura 4.3 muestra el comportamiento del reactor rMT sobre la eliminación de la $\mathrm{DQO}_{\text {total }}$ remanente en los lodos predigeridos por el rAM. Se observa que la mayor eliminación de la DQO se da en la corrida IV (51\%) con una carga de $7.2 \mathrm{kgSSV} / \mathrm{m}^{3} \cdot \mathrm{d}$, un TRS de 15.9 días y 1 día de TRH. Este resultado puede compararse con el reportado por De la Rubia y col. (2002) quienes mencionan una eficiencia de remoción de $\mathrm{DQO}_{\text {total }}$ en el reactor termofílico del $35.3 \%$ en relación al valor alcanzado en el reactor mesofílico (52.8\%) en reactores RCTA con mezclas de LP:LS a 27 días de TRS y carga orgánica de $1.3 \mathrm{kgSSV} / \mathrm{m}^{3} \cdot \mathrm{d}$. Buffiere y col. (2006) en su estudio con LP reportaron una eliminación de $\mathrm{DQO}_{\text {total }}$ del $25 \%$ a $55^{\circ} \mathrm{C}$ a un TRH de 10 días.

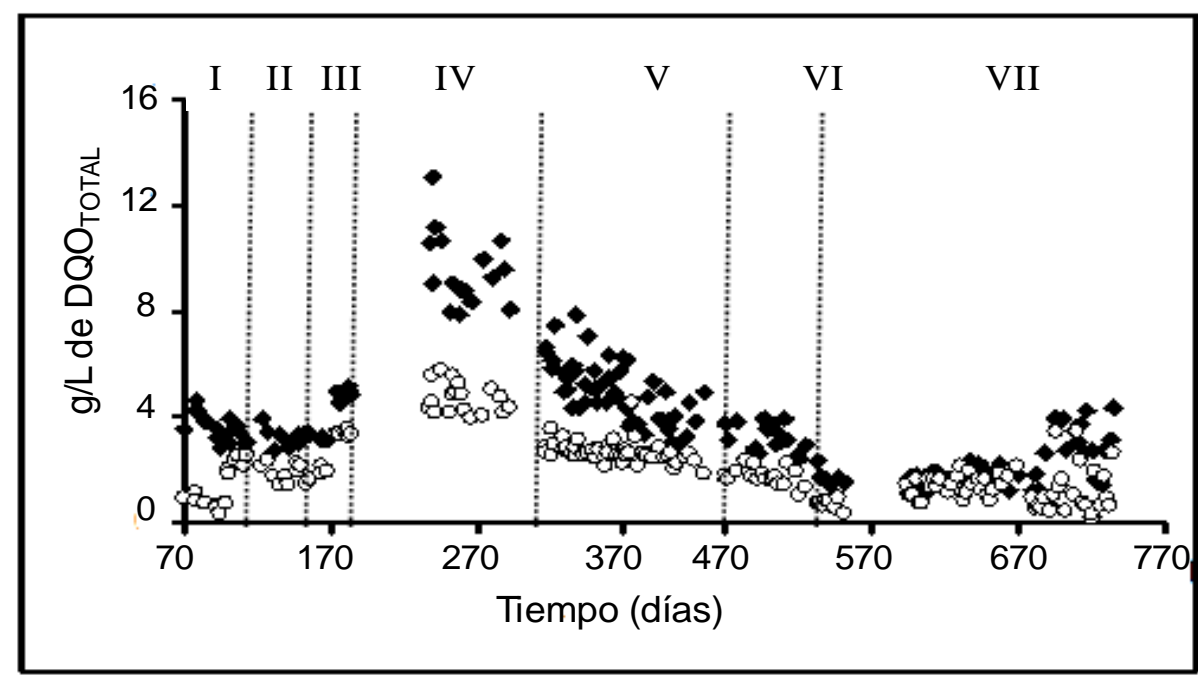

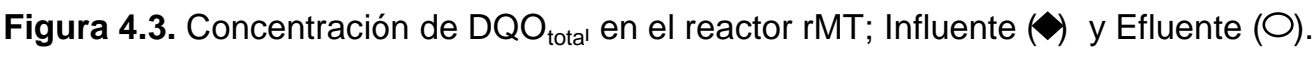


A partir de las figuras 4.2 y 4.3 se construye la figura $4.3 a$ que muestra una alta correlación entre la carga orgánica y la eliminación de la DQO que aporta los sólidos del lodo predigerido por el rAM. Se encuentra que a menor carga orgánica (< a $3 \mathrm{kgSSV} / \mathrm{m}^{3} \cdot \mathrm{d}$ ) a 2, 4 y 6 días de TRH, la destrucción de sólidos y eliminación de la DQO es tan solo del 19.7 y $12.3 \%$. Con cargas orgánicas entre 3 y $5 \mathrm{kgSSV} / \mathrm{m}^{3} \cdot \mathrm{d}$, los resultados mejoran en un 57.7 y $35 \%$, pero con cargas orgánicas mayores a $8 \mathrm{kgSS} / \mathrm{m}^{3} \cdot \mathrm{d}$ y $\mathrm{TRH}=1$ día, la destrucción de sólidos no mejora pero sí la eliminación de $\mathrm{DQO}_{\text {total }}(51 \%)$ a consecuencia de la concentración de sólidos que se alcanza en la cama de lodo del reactor a distinta altura con base a la carga orgánica alimentada y a la capacidad de la biomasa activa (hidrólisis) en su eliminación.

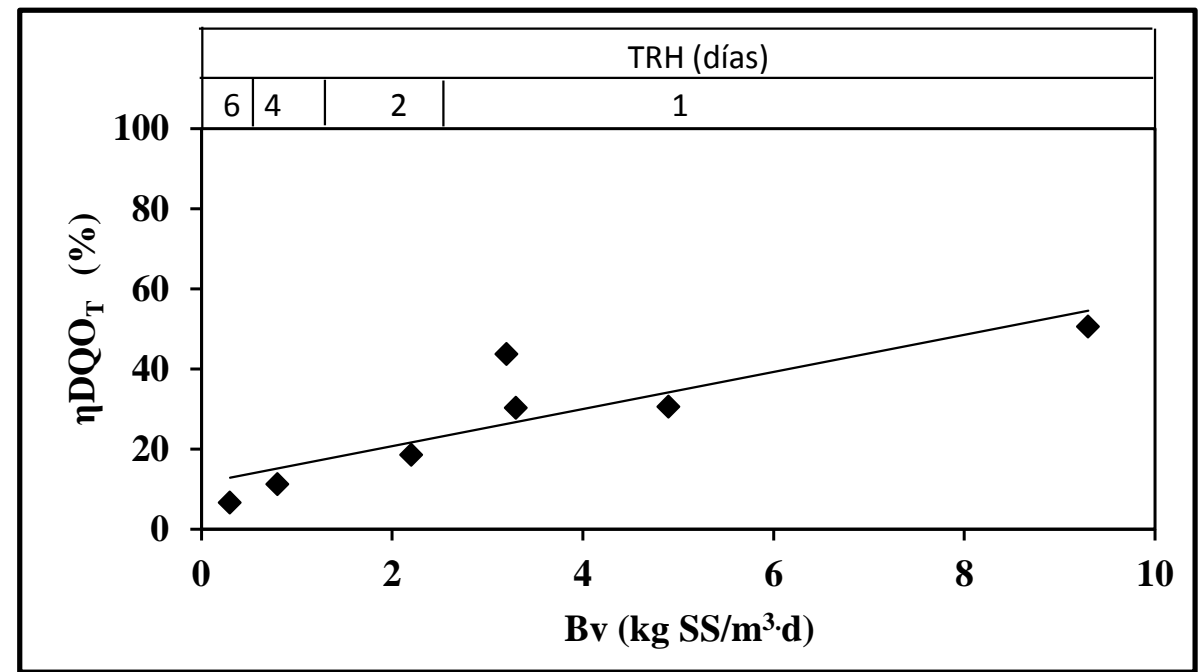

Figura 4.3a Efecto de la carga orgánica $(\mathrm{Bv})$ en la eliminación de la $\mathrm{DQO}_{\text {Total }}$ con $\eta=46.3 \%$ y $r^{2}$ de 0.743 .

\subsubsection{AGV no convertidos a metano $\left(\mathrm{CH}_{4}\right)$}

La figura 4.4 muestra los AGV remanentes en el efluente del rMT $(0.12,0.1,0.14,0.17,0.13$, 0.081 y $0.04 \mathrm{~g} / \mathrm{L}$ ) a partir de los que entran; $0.36,0.22,0.25,0.23,0.28,0.32$ y $0.2 \mathrm{~g} / \mathrm{L}$. Se observa durante todas las corridas concentraciones de AGV menores a $0.17 \mathrm{~g} / \mathrm{L}$ predominando el acetato y en menor concentración el resto de AGV, que da cuenta del comportamiento del reactor MT en su conversión a metano. Se aprecia que en la medida en que se cambia a voluntad el TRH (a 2, 4 y 6 días) los AGV se ven afectados pero también la producción de biogás. Yue (1995) reportaron en efluentes termofílicos de una fase, valores de AGV de 800 a 2,200 mg/L a 25 días de TRH, lo que resulta un $83 \%$ más con respecto al obtenido en sistemas mesofilicos a TRH de 10 a 40 días. Han \& Dague (1997) en un 
sistema termofilico-mesofílico lograron concentraciones entre 1,600 y 2,200 mg/L con TRH de 3.3 a 5 días y de 180 a 300 mg/L de AGV con TRH de 6.7 a 10 días. Cheunbarn y Pagilla (2000) en un estudio con reactores; termofílico-mesofílico reportaron concentraciones de AGV de $3500 \mathrm{mg} / \mathrm{L}$ con concentraciones de 260 a $450 \mathrm{mg} / \mathrm{L}$ de ácido acético en el efluente de reactor mesofílico en relación a la concentración de AGV en el influente ( $960 \mathrm{mg} / \mathrm{L}$ ). Tsakou y col., (2000), reportaron un 53.3\% de formación de AGV con un TRS de 10 días. Por su parte, Eckenfelder, Wesley (2000) reportaron que la concentración de AGV se mantiene entre 20 y $200 \mathrm{mg} / \mathrm{l}$ de acuerdo a la carga orgánica alimentada.

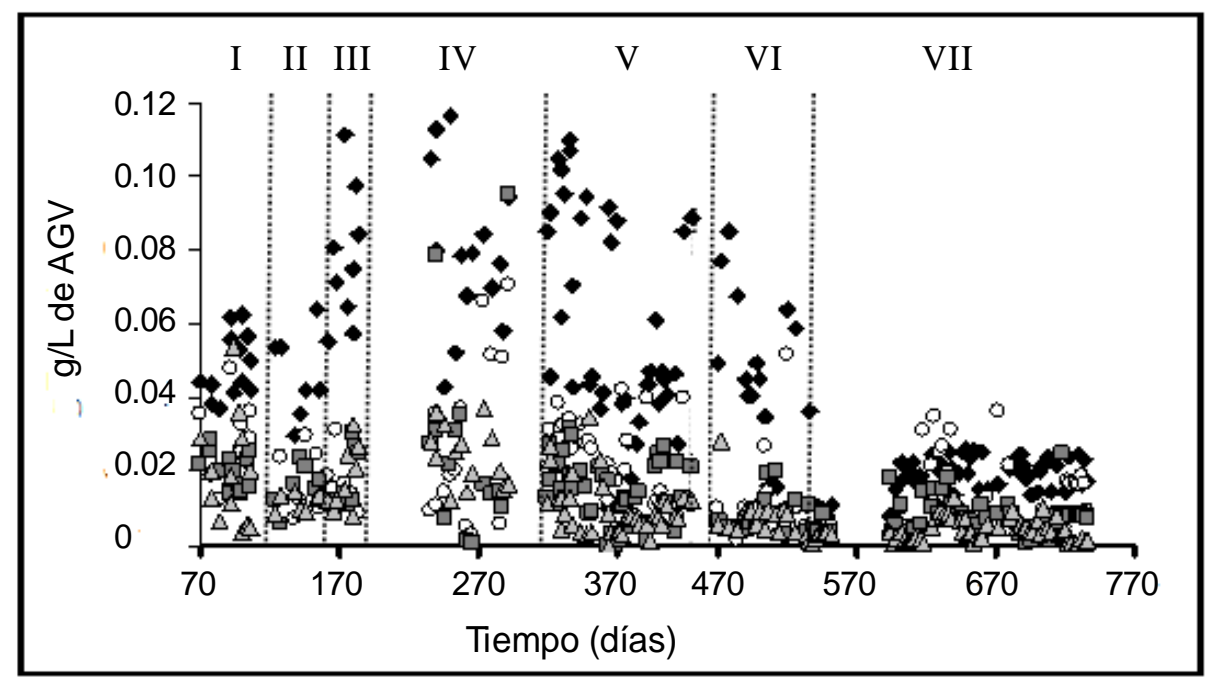

Figura 4.4. AGV remanentes en el lodo estabilizado por el reactor metanogénico. Acetato $(\checkmark)$, Propiónato $(\bigcirc)$, Isobutírato $(\square)$ y Butírato $(\triangle$

\subsubsection{Producción de biogás}

La figura 4.5 muestra baja producción de biogás (en promedio de $42.08 \mathrm{~mL} / \mathrm{L}_{R} \cdot \mathrm{d}$ ) durante las primeras cuatro corridas a un día de $\mathrm{TRH}$. Se observa que a medida que se incrementa el TRH a 2, 4 y 6 días mejora la producción de biogás en 64.8, 108.5 y 131.8 $\mathrm{mL} / \mathrm{L}_{\mathrm{R}} \cdot \mathrm{d}$ con un contenido promedio del $74 \%$ de metano con cargas orgánicas de 1.45 , 0.35 y $0.23 \mathrm{kgSSV} / \mathrm{m}^{3} \cdot \mathrm{d}$, velocidades de producción de 0.005 y $0.09 \mathrm{~m}^{3} \mathrm{CH}_{4} / \mathrm{m}^{3} \cdot \mathrm{d}$ y un rendimiento de $0.4 \mathrm{~m}^{3} \mathrm{CH}_{4} / \mathrm{kgSV}_{\text {rem. }}$. Este resultado obtenido fue similar al reportado por Rubio y col. (2010) en su estudio en un reactor MM pero menor al obtenido en el reactor MT y similar al reportado por Vigueras y col., (2011).

Yue y col. (1995) en reactores RCTA a 55 y $35^{\circ} \mathrm{C}$ con 4 y 10 días de TRS y carga orgánica de 2.1-2.3 $\mathrm{kgSSV} / \mathrm{m}^{3} \cdot \mathrm{d}$ reportaron una producción de $0.728 \mathrm{~kg} \mathrm{CH}_{4} / \mathrm{m}^{3} \cdot \mathrm{d}$. Por lo que en este tipo de sistemas la producción específica de metano es del orden de 0.39 
$\mathrm{m}^{3}{ }_{\mathrm{CH}} / \mathrm{kg} \mathrm{SV}$ eliminado (Roberts y col., 1999). García-Heras y col. (1999) y Song y col. (2004) reportan velocidades de producción de metano de entre $0.178-0.230 \mathrm{~kg}_{\mathrm{CH}_{4}} / \mathrm{m}^{3} \cdot \mathrm{d}$ para cargas orgánicas entre 1.21 y $1.44 \mathrm{~kg} \mathrm{SSV} / \mathrm{m}^{3} \cdot \mathrm{d}$.

Carrozzi y Steinle (1994) y Killilea y col. (2000) reportaron valores de producción de metano de entre 0.392 y $0.525 \mathrm{~kg}_{\mathrm{CH}_{4}} / \mathrm{m}^{3} \mathrm{~d}$ para cargas orgánicas entre 1.75 y $2 \mathrm{~kg}$ $\mathrm{SSV} / \mathrm{m}^{3} \cdot \mathrm{d}$. El rendimiento en la producción de metano disminuye bajo condiciones termofílicas en un $50 \%$ con respecto al producido bajo condiciones mesofílicas (De la Rubia y col., 2002). Pero en un estudio posterior De la Rubia y col. (2006) señalan que en condiciones termofílicas la eficiencia de remoción es independiente del TRS cuando éste es mayor de $15 \mathrm{~d}$. En ese mismo estudio se observa que al disminuir el TRS se genera un aumento en el rendimiento de metano.

Rubio y col. (2010) en su estudio a 13 días de TRH reportaron una producción de biogás de $1573 \mathrm{~mL} / \mathrm{d}$ en el reactor metanogénico mesofílico (MM) con rendimientos de 0.4 $\mathrm{m}^{3} \mathrm{CH}_{4} / \mathrm{kgSSV}_{\text {rem }}$ y en el digestor metanogénico termofílico (MT) una producción de 1,054

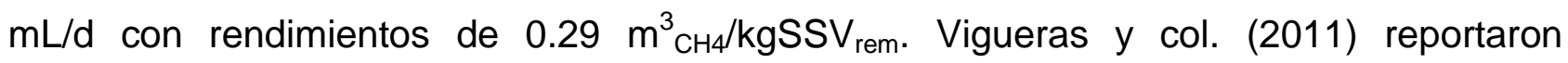
rendimientos de $0.4 \mathrm{~m}^{3} \mathrm{CH}_{4} / \mathrm{kgSSV}_{\text {rem }}\left(0.12 \mathrm{~kg}_{\mathrm{CH}} / \mathrm{m}^{3} \cdot \mathrm{d}\right)$ para el reactor termofílico.

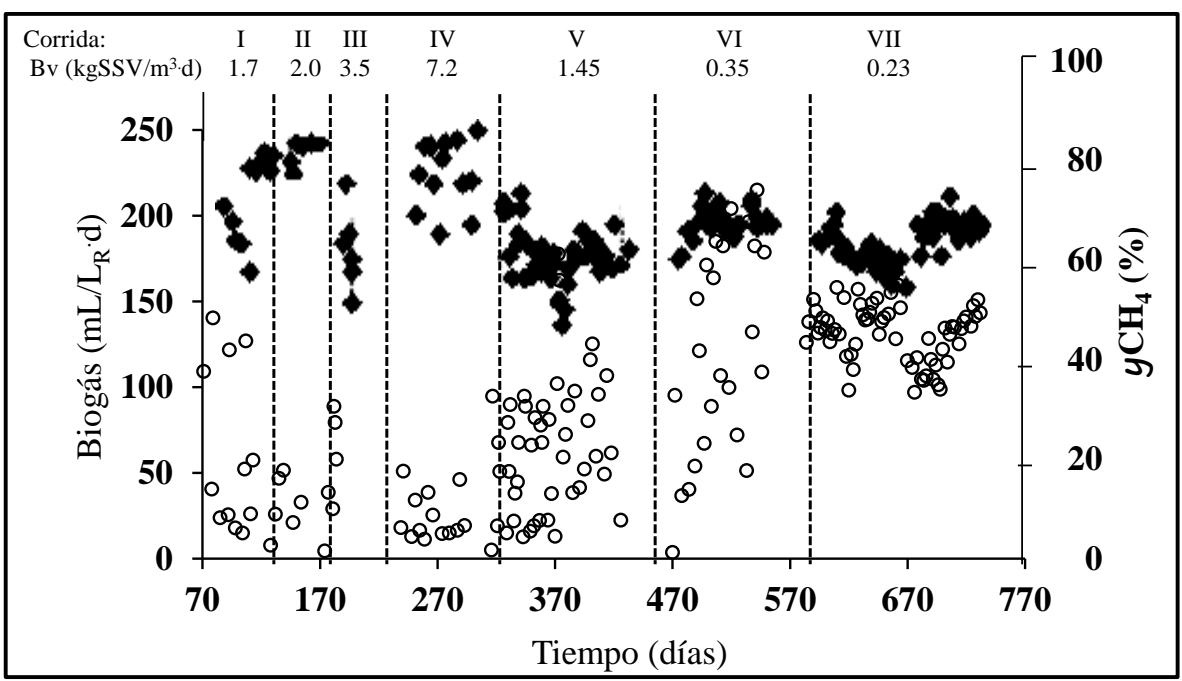

Figura 4.5. Producción $(0)$ y composición $(\$)$ de biogás en el reactor metanogénico.

A partir de las figuras 4.1 a la 4.4 , se contruye el cuadro 4.1 que muestra los resultados de los parámetros evaluados al lodo tratado por el rMT previamente predigerido por el rAM. 
Cuadro 4.1. Características del lodo y biogás a la salida del rMT.

\begin{tabular}{|c|c|c|c|c|c|c|c|}
\hline Corrida & 1 & II & III & IV & V & VI & VII \\
\hline $\mathrm{pH}$ & $7.5 \pm 0.3$ & $7.2 \pm 0.3$ & $6.9 \pm 0.4$ & $6.9 \pm 0.2$ & $7.0 \pm 0.3$ & $7.1 \pm 0.2$ & $7.2 \pm 0.3$ \\
\hline $\mathrm{ST}(\mathrm{g} / \mathrm{L})$ & $2.1 \pm 0.6$ & $1.9 \pm 0.7$ & $3.2 \pm 1.3$ & $7.85 \pm 1.7$ & $3.0 \pm 0.6$ & $2.7 \pm 1.1$ & $1.8 \pm 0.9$ \\
\hline $\operatorname{SST}(\mathrm{g} / \mathrm{L})$ & $1.6 \pm 0.4$ & $1.6 \pm 0.7$ & $2.6 \pm 0.7$ & $5.85 \pm 1.1$ & $1.4 \pm 0.8$ & $1.6 \pm 0.8$ & $0.6 \pm 0.2$ \\
\hline $\operatorname{SSV}(\mathrm{g} / \mathrm{L})$ & $0.9 \pm 0.4$ & $0.8 \pm 0.3$ & $1.2 \pm 0.7$ & $3.21 \pm 0.7$ & $0.9 \pm 0.3$ & $0.6 \pm 0.3$ & $0.5 \pm 0.2$ \\
\hline gSSV/gSST & 0.54 & 0.49 & 0.45 & & 0.61 & 0.38 & 0.73 \\
\hline $\mathrm{DQO}_{\text {total }}(\mathrm{g} / \mathrm{L})$ & $2.3 \pm 0.3$ & $1.8 \pm 0.3$ & $3.4 \pm 0.1$ & $4.6 \pm 0.5$ & $2.7 \pm 0.3$ & $1.7 \pm 0.3$ & $1.2 \pm 0.7$ \\
\hline $\mathrm{DQO}_{\text {soluble }}(\mathrm{g} / \mathrm{L})$ & $0.54 \pm 0.19$ & $0.49 \pm 0.18$ & $0.7 \pm 0.18$ & $1.36 \pm 0.18$ & $0.74 \pm 0.14$ & $0.59 \pm 0.02$ & $0.44 \pm 0.08$ \\
\hline $\operatorname{AGV}(g / L)$ & $0.12 \pm 0.02$ & $0.1 \pm 0.02$ & $0.14 \pm 0.02$ & $0.17 \pm 0.1$ & $0.13 \pm 0.05$ & $0.081 \pm 0.04$ & $0.04 \pm 0.01$ \\
\hline Acetato $(\mathrm{g} / \mathrm{L})$ & $0.05 \pm 0.01$ & $0.05 \pm 0.02$ & $0.09 \pm 0.02$ & $0.08 \pm 0.02$ & $0.07 \pm 0.03$ & $0.045 \pm 0.02$ & $0.02 \pm 0.01$ \\
\hline Propionato (g/L) & $0.03 \pm 0.01$ & $0.02 \pm 0.01$ & $0.01 \pm 0.003$ & $0.03 \pm 0.02$ & $0.03 \pm 0.007$ & $0.02 \pm 0.01$ & $0.01 \pm 0.009$ \\
\hline Isobutirato (g/L) & $0.02 \pm 0.005$ & $0.02 \pm 0.005$ & $0.02 \pm 0.01$ & $0.03 \pm 0.03$ & $0.02 \pm 0.01$ & $0.01 \pm 0.007$ & $0.007 \pm 0.005$ \\
\hline Butirato $\quad(\mathrm{g} / \mathrm{L})$ & $0.02 \pm 0.02$ & $0.01 \pm 0.002$ & $0.02 \pm 0.01$ & $0.03 \pm 0.03$ & $0.01 \pm 0.01$ & $0.006 \pm 0.005$ & $0.004 \pm 0.003$ \\
\hline Proteínas $_{\text {totales }}(\mathrm{g} / \mathrm{L})$ & $1.9 \pm 0.18$ & $1.5 \pm 0.19$ & $2.9 \pm 0.13$ & $4.03 \pm 0.76$ & $2.3 \pm 0.49$ & $1.65 \pm 0.8$ & $0.36 \pm 0.16$ \\
\hline Proteínas $_{\text {solubles }}(\mathrm{g} / \mathrm{L})$ & $0.23 \pm 0.1$ & $0.32 \pm 0.02$ & $0.59 \pm 0.03$ & $0.93 \pm 0.06$ & $0.53 \pm 0.15$ & $0.41 \pm 0.09$ & $0.41 \pm 0.07$ \\
\hline $\mathrm{Q}_{\text {BiogásTPS }}\left(\mathrm{mL} / \mathrm{L}_{\mathrm{R}} \cdot \mathrm{d}\right)$ & $63.1 \pm 47.7$ & $30.9 \pm 16.4$ & $49.8 \pm 31.9$ & $24.5 \pm 13.4$ & $64.8 \pm 38.6$ & $108.5 \pm 60.6$ & $131.8 \pm 36.0$ \\
\hline $\mathrm{CH}_{4}$ en el biogás (\%) & 82.3 & 90.3 & 71.8 & 85.7 & 71.0 & 77.2 & 74.4 \\
\hline $\mathrm{L} \mathrm{CH}_{4} / \mathrm{g} \mathrm{SSV}_{\text {removido }}$ & 64.9 & 23.3 & 15.2 & 5.3 & 22.9 & 104.6 & 108.9 \\
\hline
\end{tabular}

TPS: temperatura y presión estándar; DQO: demanda química de oxígeno; $\mathrm{CH}_{4}$ : metano; $\mathrm{CO}_{2}$ : dióxido de carbono. Resultados expresados como la media \pm desviación estándar.

\subsubsection{Análisis cinético del rMT}

Las figuras 4.6 y $4.6 a$ muestran las ecuaciones 1.6 y 1.7 para calcular las constantes de velocidad de destrucción de sólidos suspendidos $\left(k_{1}\right)$ y de acidogénesis $\left(k_{2}\right)$.

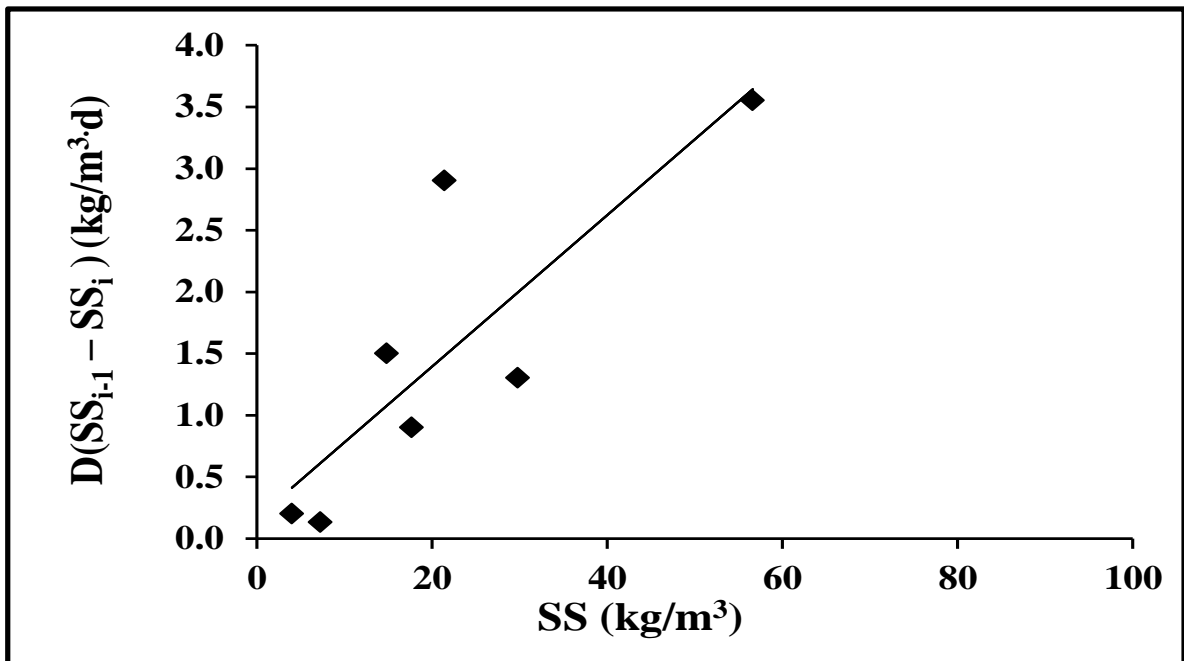

Figura 4.6. Estimación de $\mathrm{k}_{1}=0.0614 \mathrm{~d}^{-1} \operatorname{con} \mathrm{r}^{2}=0.6956$. 


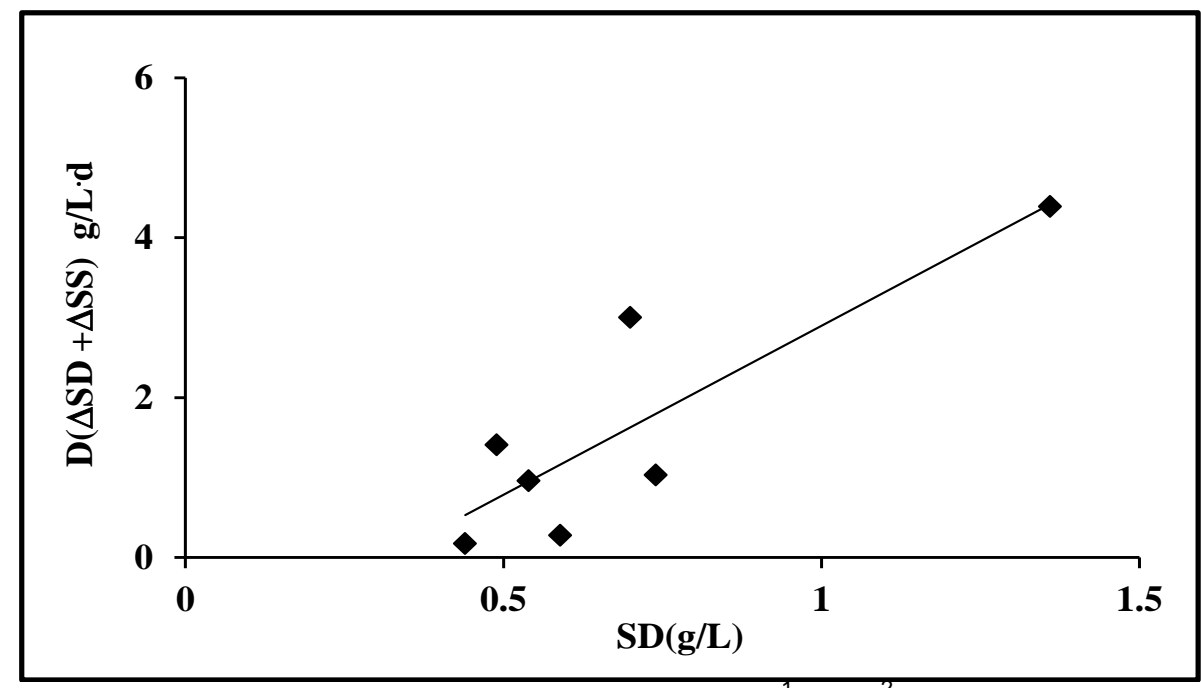

Figura 4.6a. Estimación de $\mathrm{k}_{2}=4.2 \mathrm{~d}^{-1} \operatorname{con} \mathrm{r}^{2}=0.7321$.

La figura 4.6b se construye a partir del total de AGV (ionizados y protonados), estimando a partir de los AGV ionizados la producción de metano, por lo que es necesario obtener $\mathrm{B}^{-}$ en función del pH de cada corrida utilizando las mismas ecuaciones que se emplearon en el análisis del rAM y que muestra la formación de AGV no ionizados a partir de la fermentación de la SD.

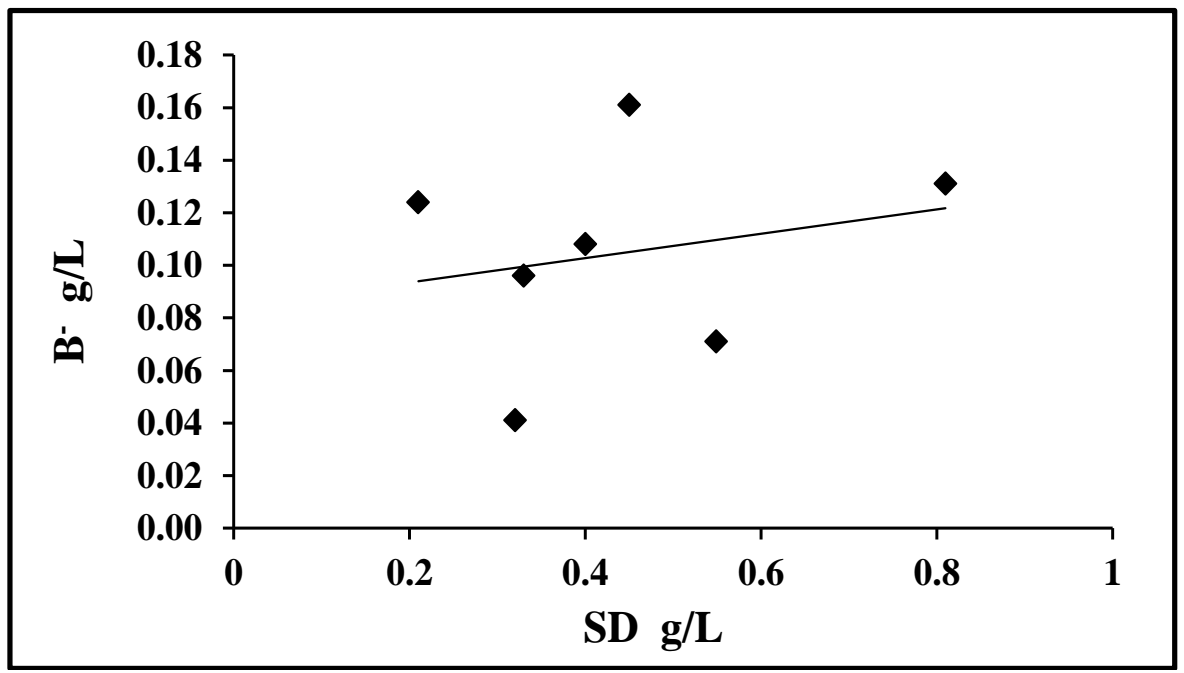

Figura 4.6b. Estimación de la tasa de formación de AGV no ionizados $\left(\mathrm{B}^{-}\right)$ a partir de la $\mathrm{DQO}_{\text {soluble }}(\mathrm{SD})$ con $\mathrm{k}_{\mathrm{AGV}}=0.0463 \mathrm{~d}^{-1}$.

La figura 4.6c muestra la ecuación 1.9 (capitulo 1) a partir de la cual se estima la $k_{3}$. 


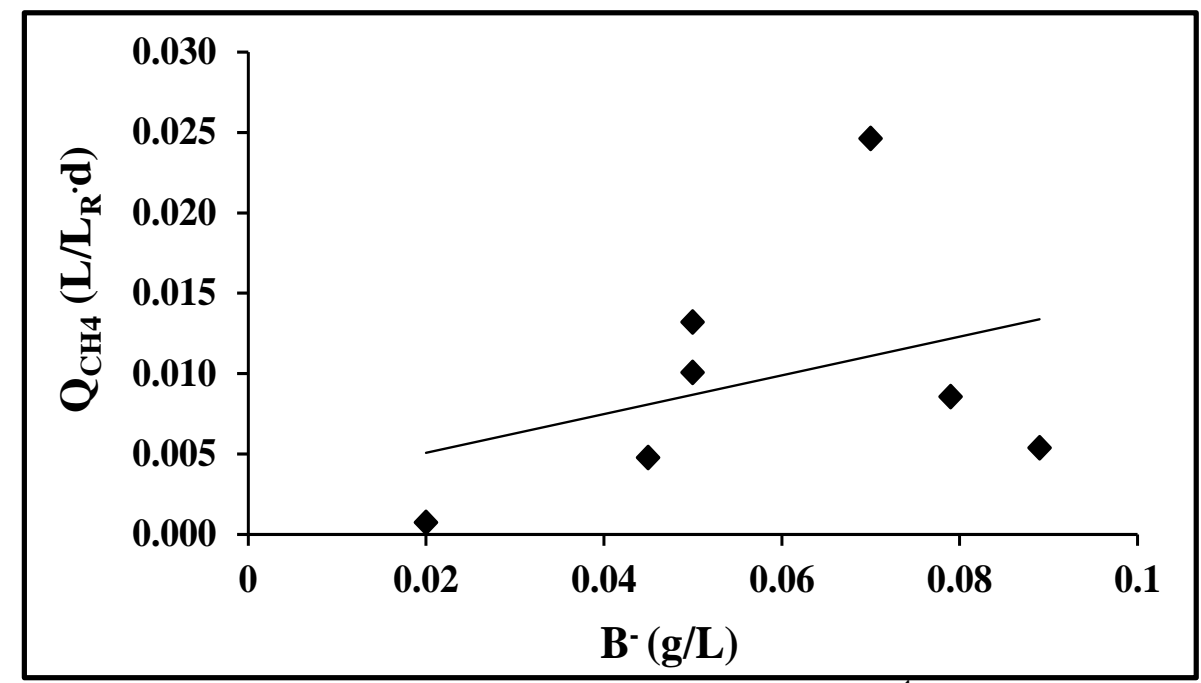

Figura 4.6c. Estimación de $\mathrm{k}_{3}=0.12 \mathrm{~d}^{-1}$.

A partir de las figuras $4.6,4.6 a, 4.6 b$ y $4.6 \mathrm{c}$ se concluye por los valores de $\mathrm{k}_{1}$ y $\mathrm{k}_{2}$ que las tasas de reacción en el rMT son más rápidas que en el reactor mesofílico, pero por el valor de $\mathrm{k}_{3}$ queda confirmada su lentitud en la conversión de $\mathrm{AGV}$ a $\mathrm{CH}_{4}$.

\subsubsection{Estimación de constantes de velocidad de reacción $(k)$}

El cuadro 4.2 resume el valor de las constantes cinéticas que se estimaron en el reactor rMT de acuerdo al modelo de la DA.

Cuadro 4.2. Constantes de velocidad de reacción (k) en el rMT.

\begin{tabular}{|c|c|c|}
\hline Reacción & Velocidad de reacción & $\mathbf{k}\left(\mathbf{d}^{-1}\right)$ \\
\hline \multirow{3}{*}{$\begin{array}{c}\mathrm{SS} \rightarrow \mathrm{SD} \rightarrow \mathrm{AGV} \rightarrow \\
\mathrm{CH}_{4}\end{array}$} & $\mathrm{r}_{\mathrm{SS}}=\mathrm{k}_{1} \mathrm{SS}$ & $\mathrm{k}_{1}=0.0614$ \\
\cline { 2 - 3 } & $\mathrm{r}_{\mathrm{SD}}=\mathrm{k}_{1} \mathrm{SS}-\mathrm{k}_{2} \mathrm{SD}$ & $\mathrm{k}_{2}=4.2$ \\
\cline { 2 - 3 } & $\mathrm{r}_{\mathrm{AGV}}=\mathrm{k}_{2} \mathrm{SD}-\mathrm{k}_{3} \mathrm{AGV}\left(\mathrm{B}^{-}\right)$ & $\mathrm{k}_{\mathrm{AGV}}=0.0463$ \\
\cline { 2 - 3 } & $\mathrm{r}_{\mathrm{CH} 4}=\mathrm{k}_{3} \mathrm{AGV}\left(\mathrm{B}^{-}\right)$ & $\mathrm{K}_{3}=0.12$ \\
\hline
\end{tabular}

Se observa un comportamiento de las contantes (k) en el siguiente orden $k_{2}>k_{3}>k_{1}$ lo que confirma a la hidrólisis como etapa limitante de la DA y la lentidud del rMT en la conversión de $\mathrm{AGV}$ a $\mathrm{CH}_{4}$. 


\subsubsection{Hidrólisis de proteínas}

La figura 4.7 muestra la eliminación de proteínas por el rMT. Durante las primeras corridas (I-III) con un TRH = 1 día, se aprecia una mínima hidrólisis debido a la composición de los SSV del LS (del 30 al 54\% son proteínas) (Bougrier y col., 2008). Se observa que la mayor hidrólisis (51\%) se da durante la corrida IV a un día de TRH y TRS de 16 días por el TRS y la temperatura de exposición en el reactor.

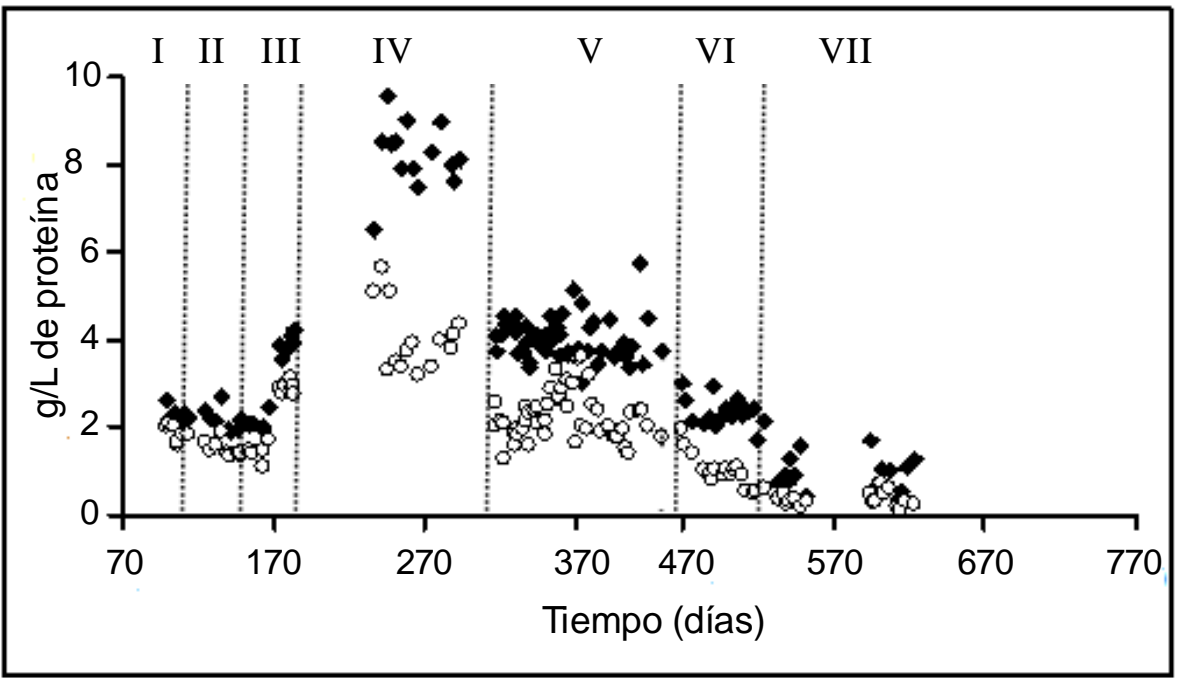

Figura 4.7. Concentración de proteína en el reactor rMT; influente $(\lambda$ y efluente $(0)$.

A partir de la figura 4.7, se construye la figura 4.7a que muestra una correlación entre la carga orgánica y la eficiencia de hidrólisis de las proteínas y se concluye que entre mayor es la carga orgánica, mayor es la capacidad de hidrólisis del rMT sobre estos polímeros.

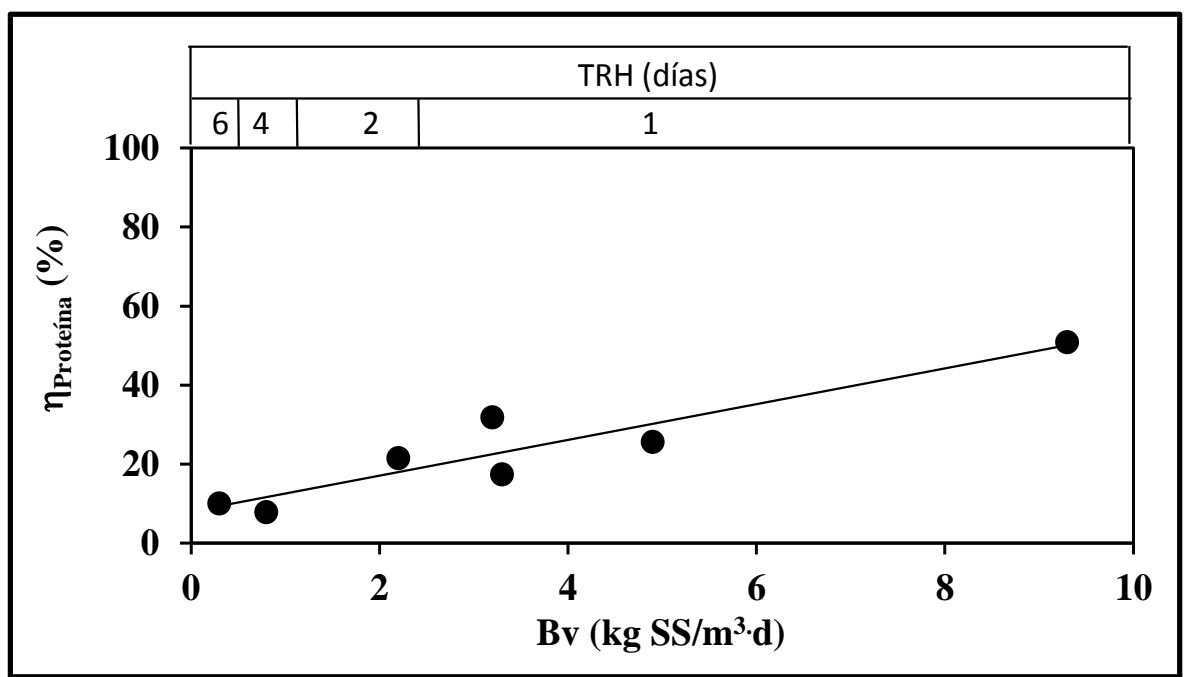

Figura 4.7a. Efecto de la carga orgánica (Bv) en la hidrólisis de proteína $(\eta=24 \%)$. 


\subsubsection{Eliminación de microorganismos patógenos y de parásitos}

En el cuadro 4.3 se resume los resultados obtenidos sobre la eliminación de coliformes fecales, Salmonella spp y de huevos de helminto. Se hace una comparación de su contenido en el lodo tratado por el rMT con respecto al lodo tratado por el rAM y se encuentra que con cargas orgánicas entre 3.5 y $7 \mathrm{kgSSV} / \mathrm{m}^{3} \cdot \mathrm{d}$, TRH $=1$ día y TRS entre 7 y 16 días, la eliminación de coliformes fecales y huevos de helminto no es significativa, pero sí la de Salmonella spp. Se observa que a cargas menores (entre 0.2 y 0.4 $\mathrm{kgSSV} / \mathrm{m}^{3} \mathrm{~d}$ ), TRH de 4 y 6 días y TRS entre 14 y 17 días mejora su eliminación. Sin embargo, los resultados obtenidos, no fueron satisfactorios comparados con los reportados en la literatura en reactores termofílicos-mesofílicos. Han y Dague (1997), utilizando un arreglo termofílico-mesofílico de dos fases alimentado con lodo primario y TRH global entre 10 y 15 días, lograron una eliminación de coliformes fecales de $3.1 \times 10^{2}$ NMP/gST. Huyard y col. (2000), con el mismo sistema; termofílico-mesofílico en mezclas de lodos residuales con proporción de LP:LS de 60:40, lograron una reducción de coliformes fecales y huevos de helminto en: $3.16 \times 10^{5} \mathrm{NMP} / \mathrm{gST}$ y $3.9 \times 10^{2} \mathrm{HH} / \mathrm{gST}$ respectivamente en el reactor termofílico a 2 días de TRH y mencionan que la destrucción de $\mathrm{HH}$ puede darse por inactivación o lisis del huevo de helminto. Cheunbarn \& Pagilla (2000), redujeron el número de coliformes fecales de $10^{8}$ a $10^{2} \mathrm{NMP} / \mathrm{gST}$. Rojas y col. (2001), en un sistema de dos fases; mesofílico-termofílico con un TRH de 15 y 20 días, utilizando lodo secundario a una concentración inicial de $1 \times 10^{5} \mathrm{NMP} / \mathrm{gST}$ de coliformes fecales, lograron una eliminación de $9.7 \times 10^{4} \mathrm{NMP} / \mathrm{gST}$ y de un $97 \%$ de huevos de helminto. Gantzer y col. (2001), reportaron una reducción de coliformes fecales de $2.3 \times 10^{1} \mathrm{NMP} / \mathrm{gST}$. Cabirol y col. (2002), en un sistema de dos fases; mesofílicotermofílico reportaron una reducción de $3.4 \times 10^{1} \mathrm{HH} / \mathrm{gST}$ en mesofília y de $6.9 \times 10^{1}$ $\mathrm{HH} / \mathrm{gST}$ en termofília. En otro estudio Hernández-Uresti y col. (2002) observaron una reducción en su viabilidad del $91-96 \%$ de Ascaris suum en presencia de altas concentraciones de AGV de $7600 \mathrm{~g} / \mathrm{L}$ a pH de 5.6 y $55^{\circ} \mathrm{C}$ a TRH de 3 días. Song y col. (2004) alcanzaron en termofília una reducción de $9.7 \times 10^{1} \mathrm{NMP} / \mathrm{gST}$ de coliformes fecales. Los resultados insatisfactorios de su eliminación con el sistema estudiado en esta tesis probablemente fue consecuencia del desarrollo de zonas donde no se alcanzó las condiciones de temperatura necesarias para su eliminación por declinación de la misma ocasionando un recrecimiento en el biosólido (Iranpour y Cox (2007). Cabirol y col. (2002) 
reportaron que un mezclado ineficiente reduce la eficiencia de remoción de patógenos y de parásitos a temperaturas termofílicas. El impacto de los ácidos orgánicos sobre los patógenos y parásitos tiene mayor efecto a temperaturas mesofílicas (21-35ํㅡ) (Fukushi y col., 2003; Puchajda y Oleszkiewicz, 2004). Salsali y col. (2004) obtienen reducciones de patógenos (Clostridium perfringens) a elevadas concentraciones de ácidos orgánicos (3000-6000 mg/L) a temperaturas de $49-55^{\circ} \mathrm{C}$. Se concluye que debido a; 1) la falta de mezclado y 2) a la concentración de AGV alcanzado en este reactor no fue posible cumplir con la calidad del biosólido esperada.

Cuadro 4.3. Eliminación de patógenos y de parásitos.

\begin{tabular}{|c|c|c|c|c|c|c|}
\hline Corrida & II & III & IV & V & VI & VII \\
\hline TRH (d) & 1 & 1 & 1 & 2 & 4 & 6 \\
\hline TRS (d) & 22.9 & 7.4 & 15.9 & 8.01 & 16.9 & 14.08 \\
\hline $\mathrm{Bv}\left(\mathrm{kg} \mathrm{SSV} / \mathrm{m}^{3} \cdot \mathrm{d}\right)$ & 2 & 3.5 & 7.2 & 1.5 & 0.4 & 0.2 \\
\hline $\mathrm{CF}_{0}(\mathrm{NMP} / \mathrm{gST})$ & $4.80 \mathrm{E}+08$ & $4.00 \mathrm{E}+08$ & $5.00 \mathrm{E}+08$ & $4.30 \mathrm{E}+08$ & $2.80 \mathrm{E}+08$ & $3.10 \mathrm{E}+08$ \\
\hline CF (NMP/gST) & $4.00 \mathrm{E}+08$ & $2.80 \mathrm{E}+08$ & $4.00 \mathrm{E}+08$ & $4.30 \mathrm{E}+07$ & $2.20 \mathrm{E}+07$ & $9.70 \mathrm{E}+06$ \\
\hline$\Delta \mathrm{CF}$ & $2.00 \mathrm{E}^{-0} 01$ & $4.29 \mathrm{E}^{-0} 01$ & $2.50 \mathrm{E}^{-0} 01$ & $9.00 \mathrm{E}+00$ & $1.17 \mathrm{E}+01$ & $3.10 \mathrm{E}+01$ \\
\hline ПCF (\%) & 17 & 30 & 20 & 90 & 92 & 99 \\
\hline Salmo $_{\mathrm{o}}$ (NMP/gST) & $4.30 \mathrm{E}+08$ & $4.60 \mathrm{E}+08$ & $5.50 \mathrm{E}+08$ & $4.00 \mathrm{E}+08$ & $3.80 \mathrm{E}+08$ & $3.70 \mathrm{E}+08$ \\
\hline Salm (NMP/gST) & $2.90 \mathrm{E}+08$ & $1.20 \mathrm{E}+08$ & $3.00 \mathrm{E}+07$ & $7.90 \mathrm{E}+07$ & $3.20 \mathrm{E}+07$ & $5.00 \mathrm{E}+06$ \\
\hline$\Delta$ Salm & $4.83 \mathrm{E}^{-} 01$ & $2.83 E+00$ & $1.73 \mathrm{E}+01$ & $4.06 \mathrm{E}+00$ & $1.09 \mathrm{E}+01$ & $7.30 \mathrm{E}+01$ \\
\hline$\eta$ Salm (\%) & 33 & 74 & 95 & 80 & 92 & 99 \\
\hline $\mathrm{HH}_{\mathrm{o}}(\mathrm{HH} / \mathrm{gST})$ & 30 & 19 & 21 & 19 & 20 & 20 \\
\hline $\mathrm{HH}(\mathrm{HH} / \mathrm{gST})$ & 22 & 13 & 13 & 12 & 7 & 3 \\
\hline$\Delta \mathrm{HH}$ & 8 & 6 & 8 & 7 & 13 & 17 \\
\hline$\eta \mathrm{HH}(\%)$ & 27 & 32 & 38 & 37 & 65 & 85 \\
\hline
\end{tabular}

La figura 4.8 y 4.8a muestra una correlación entre el TRH y la eliminación de coliformes fecales y de Salmonella spp. Se observa que su eliminación depende del $\mathrm{TRH}$, de la temperatura, de condiciones de ácidez (altas concentraciones de AGV) (Salsali y col., 2004) y de un mezclado eficiente (Cabirol y col., 2002).

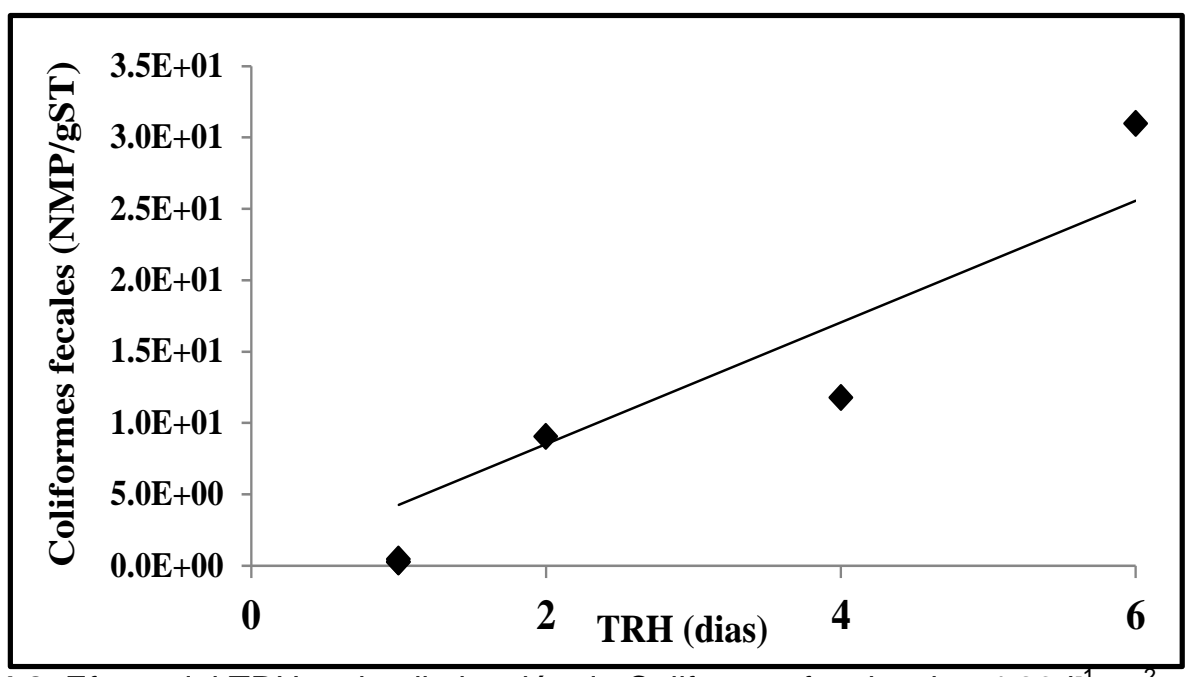

Figura 4.8. Efecto del TRH en la eliminación de Coliformes fecales. $\mathrm{k}=4.26 \mathrm{~d}^{-1} \mathrm{y}^{2}=0.8537$. 


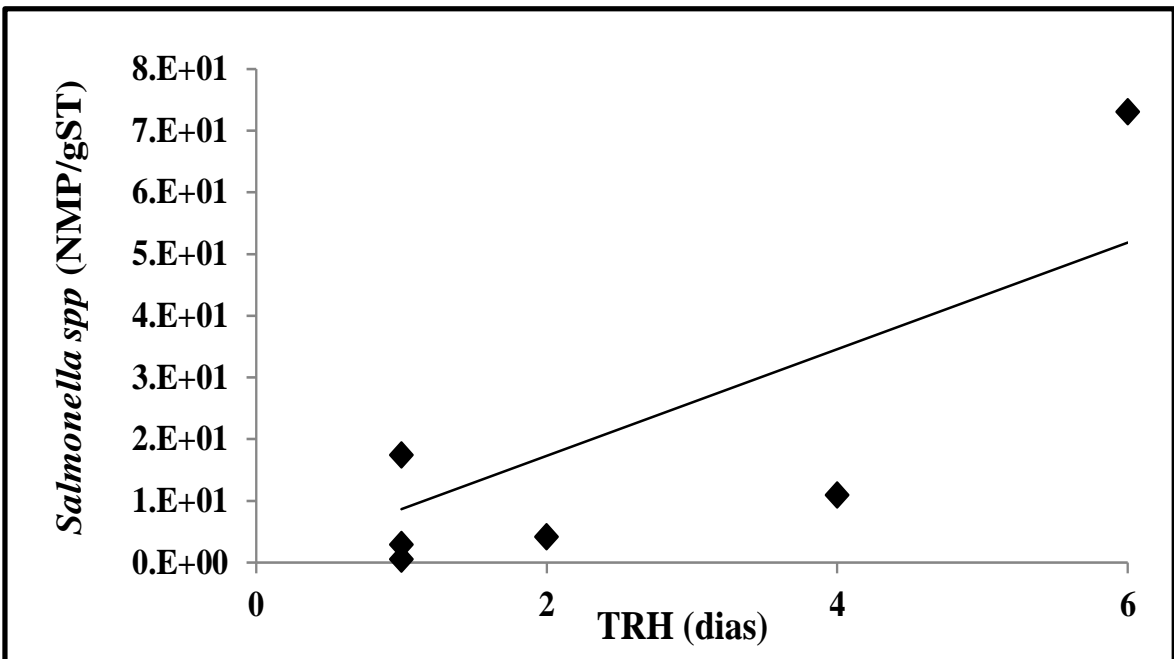

Figura 4.8a. Efecto del TRH en la eliminación de Salmonella spp. $\mathrm{k}=8.65 \mathrm{~d}^{-1} \mathrm{y} \mathrm{r}^{2}=0.643$.

\subsubsection{Conclusiones parciales}

> El reactor MT de flujo ascendente actuó como sedimentador-reactor dado a la concentración de SST que se observó en la cama de lodo a distinta altura. Con suspensiones de 1.8 a $9.4 \mathrm{~g} \mathrm{SST/L}$ se llega a tener concentraciones de 6.5 a 32.8 g SST/L en el reactor propiciando TRS de 7 a $22.9 \mathrm{~d}$.

> La mejor destrucción de sólidos se logró a TRS de 7.4 d con $66 \%$ de destrucción de sólidos ó $2.3 \mathrm{kgSSV} / \mathrm{m}^{3} \cdot \mathrm{d}$ con una $\mathrm{Bv}$ de $3.5 \mathrm{kgSSV} / \mathrm{m}^{3} \cdot \mathrm{d}$ y del $55 \%$ de destrucción de sólidos a una Bv de $7.2 \mathrm{KgSSV} / \mathrm{m}^{3} \cdot \mathrm{d}$ y TRS de 15.2 d.

> La tasa de reacción $\left(\mathrm{k}_{2}\right)$ en el rMT fue más rápida que en el reactor mesofílico, debido a la temperatura de operación, sin embargo por el valor de $\mathrm{k}_{3}$ queda confirmada su lentitud en la conversión de AGV a $\mathrm{CH}_{4}$.

> Hay una correlación entre la carga orgánica, el TRH y el TRS en la destrucción de sólidos y una correlación entre el TRH y la temperatura en la eliminación de microorganismos patógenos

> Bajo las condiciones probadas en este estudio la estabilización de la mezcla de lodo no cumplió con la NOM-004-SEMARNAT-2002 para su reuso. 


\section{CAPÍTULO 5}

\section{CONCLUSIONES GENERALES $Y$}

\section{RECOMENDACIONES}

Se presentan las conclusiones generales de este estudio y la recomendación que podrá servir como antecedente para futuras investigaciones. 


\subsection{Conclusiones generales}

> La digestión de sólidos requiere de un paso de concentración entre el 3 y el $6 \%$, que normalmente se hace por decantación, con centrifugas o tanques de consolidación, en este trabajo se logró compactar el lodo por decantación.

$>$ Con la separación de la DA en dos etapas fue posible controlar mejor el proceso, evitando sobrecargas en el sistema.

> La concentración de sólidos en la cama de lodo de ambos reactores a distinta altura confirma que los reactores actuaron como sedimentador-reactor.

> Con el flujo ascendente los sólidos suspendidos en la mezcla de lodos residuales fueron compactados, hidrolizados, fermentados en AGV y metanizados.

> Los resultados muestran que no hay influencia de la mezcla de lodo (LP:LS) en la destrucción de los sólidos, pero sí de la carga orgánica y del TRS. Y se encuentra que a mayor concentración de sólidos, mayor es la velocidad de reacción $\left(U_{S}\right)$.

$>$ Se concluye que la $K_{1}$ del reactor acidogénico mesofílico ( $\mathrm{rAM}$ ) es ligeramente mayor a la del reactor metanogénico termofílico ( $\mathrm{rMT}$ ) y $\mathrm{k}_{2}$ para ambos reactores es mucho mayor al valor de su $\mathrm{K}_{1}$ lo que confirma a la hidrólisis como etapa limitante de la DA.

$>$ Con el valor de $\mathrm{k}_{3}$ (mucho menor a $\mathrm{k}_{2}$ ) en los dos reactores, se confirma la lentitud de la digestión anaerobia de lodos residuales debido al poco material soluble fermentable en AGV en el rAM y la lentidud en la conversión de AGV a $\mathrm{CH}_{4}$ en el rMT.

> Hay una correlación entre la carga orgánica, el TRH y el TRS en la destrucción de sólidos y una correlación entre el TRH y la temperatura en la eliminación de microorganismos patógenos en el rMT.

> Bajo las condiciones probadas en este estudio la estabilización de la mezcla de lodo no cumplió con la NOM-004-SEMARNAT-2002 para su reuso.

\subsection{Recomendación}

> Para futuras investigaciones sobre estabilización de mezcla de lodos residuales (primarios-secundarios) con este tipo de configuración (rAM-rMT), se recomienda agitar la mezcla de lodo para lograr mayores eficiencias en la destrucción de SSV y 
homogeneizar la temperatura para lograr una mayor destrucción de microorganismos patógenos y parásitos. 


\section{Referencias}

Aguilar, F. y Llaguno, V. (2003). Manual de prácticas del curso y temario teórico por objetivos. Protozoología Médica Veterinaria; Departamento de Parasitología Instituto Politécnico Nacional, México DF.

Aguilar, R. y Álvarez, M. (2007). Síntesis evolutiva del proceso para la licuefacción de metano. Revista Mexicana de Ingeniería Química 6(1), 81-88.

Ahn, Y. y Speece, R. (2006). "Elutriated acid fermentation of municipal primary sludge,"Water Research, vol. 40, no. 11, pp. 2210-2220.

Ahumada, I., Escudero, P., Carrasco, A., Castillo, G., Ascar, L. y Fuentes, E. (2004). Use of sequential extraction to assess the influence of sewage sludge amendment on metal mobility in chilean soil. Journal of Environmental Monitoring 6, 327-334.

Andreoli, C. V.; Ferreira, A. C.; Cherubini, C.; Rodrigues, C.; Carneiro, C. y Fernandes F. (2001). Capítulo 4: Higienização do lodo de esgoto. En: Resíduos sólidos do saneamento; processamento, reciclagem e disposição final. ABES y PROSAB. Brasil. 282 p. ISBN 8586552-19-4.

Angelidaki, I. y Ahring, B.K. (1997). Thermophilic anaerobic digestion of livestock waste: the effect of ammonia. Applied Microbiology and Biotechnology. (38), 560-564.

Anise, U.A. y Darwin, L.S. (1995). Kinetics of pathogen on destruction during storage of dewatered biosolids. Water Environmental Research 67, 143-149.

APHA, AWWA, WPFC. (2005). Standard methods for the examination of water and wastewater. 19th ed. American Public health Association, Washington, D.C., U.S.A.

Appels L., Baeyens J., Degréve J., Dewil R (2008). Principles and potential of the anaerobic digestion of waste-activated sludge. Progress in Energy \& Combustion Sc 34, 755-781.

Arnaiz, Z.C., Gutierrez, J.C. y Lebrato, J. (2006). Biomass stabilization in the anaerobic digestion of wastewater sludges, Bioresour. Technol. (97), 1179-1184.

Balagurusamy, N. (2005). Anaerobic Bioremediation an untapped potential. Revista Mexicana de Ingeniería Química 4(3), 273-287.

Barrios. J. A., Rodríguez. A., González. A., Jiménez. B. y Maya C. (2000). Destrucción de coliformes fecales y huevos de helmintos en lodos fisicoquímicos por vía ácida. Memorias XII Congreso Nacional 2000. FEMISCA. AIDIS. Morelia, Mich. México. Año 1. No. 1. Tomo 1. $\mathrm{pp} 913$.

Barrios A., Briones R. y Noyola A. (2005). Digestión anaerobia de lodos de desecho de planta de tratamiento mediante un reactor tipo lecho de lodos (UASB). 
Bastian R. K. (1997). Biosolids management in the United Status. A state-of-the- nation overview. Water Environment Technology. Mayo, 45-50.

Bhattacharya, S. K., Madura R. L., Walling D. A., and Farrell, J. B., Volatile solids reduction in two-phase and conventional anaerobic sludge digestion. Water Res., 30, 1041-1048 (1996).

Bitton, G. (1999). Wastewater microbiology. Second edition. Wiley series in Ecological and Applied Microbiology. Ralph Mitchell, series editor. New York, USA.

Boehler, M. y Siegrist, H. (2006). Potential of activated sludge disintegration. Water Sci. Technol., 53 (12), 207.

Bolzonella, D., Pavan, P., Zanette, M y Cecchi, F. (2007). Two-Phase Anaerobic Digestion of Waste Activated Sludge: Effect of an Extreme Thermophilic Prefermentation. Ind. Eng. Chem. Res., Vol. 46, №. 21 p. 6650-6655.

Bouallagui, H., Touhami, Y., Cheikh, R. B. y Hamdi, M. (2005). Bioreactor performance in anaerobic digestion of fruit and vegetable wastes. Process Biochemistry. 40: 989-995.

Buffiere, P., Loisel, D., Bernet, N., Delgenes, J.P. (2006). Towards new indicators for the prediction of solid waste anaerobic digestion properties. Water Science Technology 53, 233-241.

Bougrier, C., Delgenès J. P., Carrère, H. (2008). Effects of thermal treatments on five different waste activated sludge samples solubilisation, physical properties and anaerobic digestion. Chemical Engineering Journal 139, 236-244.

Bouzas, A., Ribes, J., Ferrer, J. y Seco, A. (2007). "Fermentation and elutriation of primary sludge: Effect of SRT on process performance". Water Research, col. 41, issue 4, February 2007, pp 747-756. http://dx.doi.org/10.1016/j.watres.2006.11.034

Cabirol, N., Rojas Oropeza M. y Noyola A. (2002). Removal of helminthes eggs by anaerobic thermophilic sludge digestion. Water Science and Technology 45 (10), 269-274.

Carrozzi, A. y Steinle, E. (1994). Tratamiento anaerobio de plantas municipales. III Taller y Seminario Latinoamericano. "Tratamiento de Aguas Residuales". Universidad de la Republica, Montevideo Uruguay. Pp. 200-205.

Cheunbarn, T. y Pagilla, K. (2000). Anaerobic thermophilic/mesophilic dual-stage sludge treatment. Journal of Environmental Engineering 126 (9), 796-801.

Clark, R.H. y Speece, R.E. (1989). The pH tolerance of anaerobic digestion. Advanced wáter pollution research. Int. Conf. 5th, 27/1-27/14. 
Cokgor, E.U., Oktay, S., Tas, D.O., Zengin, G.E y Orhon, D. (2009). Influence of pH and temperature on soluble substrate generation with primary sludge fermentation. Bioresource Technology, vol. 100, no. 1, pp. 380-386.

Comisión Nacional del Agua (2010). Inventario de plantas de tratamiento de aguas residuales municipales 2005. Subdirección General Técnica, Gerencia de Saneamiento y Calidad del Agua, México.

Couturier, C. y Galtier, L. (2000). Etat desconnaissances sur le devenir des germes pathogens et des micropolluants au cours de la methanisation des dechets et sousproduits organiques (Programme ADEME, $\mathrm{N}^{\circ}$ contrat: 9893024).

Report:http://www.solagro.org/site/im_user/034 impacts.pdf.

Annex:http://www.solagro.org/site/im user/034annexes sanitaire.

De la Rubia M. A., Perez M, Romero L. I., Sales D. (2002). Anaerobic Mesophilic and Thermophilic Municipal Sludge Digestion. Chemical Biochemical Engineering Quarterly 16, (3), 119-124.

De la Rubia M. A., M. Romero, L.I. Perez, D. Sales (2006). Effect of solids retention time (SRT) on pilot scale anaerobic thermophilic sludge digestion. Process Biochemistry 41, 79-86.

Deublein D., Steinhauser A. 2008. Biogas from waste and renewable resources: An Introduction. Wiley-VCH Verlag GmbH \& Co KGaA, Weinheim. 443 p.

Diaz, M., Espitia, V. y Molina, P. (2002). Digestión Anaerobia. Una aproximación a la Tecnología. Universidad Nacional de Colombia. Instituto de Biotecnología. Primera edición.

Dichtl, N. (1997). Thermophilic and mesophilic (two-stage) anaerobic digestion. Water and Env. Mgmt: Journal of CIWEM. 11, 2, 98-104.

Dimock, R. y Morgenroth, E. (2006). The influence of particle size on microbial hydrolysis of protein particles in activated sludge. Water Research 40, 2064-2074.

Donoso-Bravo, A., Retamal, C., Carballa, M., Ruiz-Filippi, G. and Chamy, R. (2009). Influence of temperature on the hydrolysis, acidogenesis, and methanogenesis in mesophilic anaerobic digestion: parameter identification and modeling application. Water Science and Technology 60(1), 9-17.

Dubois, M., Gilles, K.A., Hamilton, J.K., Roberts, P.A. y Smith, F. (1956). Colorimetric method for determination of sugars and related substances. Analytical Chemistry 28, 350356.

Dumontet, S., Scopa, A., Kerje, S. y Krovacek, K. (2001). The importance of pathogenic organisms in sewage and sewage sludge. Journal of the Air and Waste Management Association 51(6), 848-860. 
Eastman, J.A., Ferguson, J.F., 1981. Solubilization of particulate organic carbon during the acid phase of anaerobic digestion. J. Water Pollut. Control Fed. 53 (3), 266-352.

Eckenfelder, Wesley. (2000). Industrial water pollution control. USA. Mc Graw Hill.

Elefsiniotis P., Oldham A. K. (1994) Substrate degradation patterns in acid-phase anaerobic-digestion of municipal primary sludge. Environmental Technology 15, 741-751.

Environmental Protection Agency (EPA) (2003). A Plain English Guide to the EPA, Part 503 Biosolids Rule. U.S. EPA/832/R-93-003.

Ferreiro, N. y Soto, M. (2003). Anaerobic hydrolysis of primary sludge: influence of sludge concentration and temperature. Water Science and Technology, vol. 47, no. 12, pp. 239246.

Flotats, X., Bonmatí, A., Campos, E. y Teira, R. (2005). El proceso de secado de purines en el marco de gestión integral de residuos ganaderos. Residuos, 53, 40-46.

Forbes BA, Sahm DF, Weissfeld AS Ed. Bailey y Scott's Diagnostic Microbiology. Sección 12. Anaerobic Bacteriology. Pp 511-537. Mosby, 11 a . ed. 2002.

Frohlund B., Palmgren R., Keiding K., Nielsen P.H. (1996) Extraction of extracellular polymers from activated sludge using a cation exchange resin. Water Research 30, (8), 1749-1758.

Fukushi, K., Babel, S., Burakrai, S., 2003. Survival of Salmonella spp. in a simulated acidphase anaerobic digester treating sewage sludge. Bioresource Technology 86, 53-57.

Gale, P. (2002). Risk assessment: use of composting and biogas treatment to dispose of catering waste containing meat (Final Report to the Department for Environment, Food and Rural Affairs).

http://www.defra.gov.uk/animalh/byprods/publicat/report5.pdf

Gantzer, C., Gaspard, P., Galvez, L., Huyard, A., Dumouthier, N. y Schwartzbrod, J. (2001). Monitoring of bacterial and parasitological contamination during various treatment of sludge. Water Research 35 (16), 3763-3770.

García-Heras J. L., Salaberría A., Prevot C., Sancho L. (1999). Increase of organic loading rate and specific methane production by splitting phases in anaerobic digestion of sewage sludge. II International symposium on anaerobic digestion of solid waste. Barcelona España

Gavala, H.N., Yenal, U., Skiadas, I.V., Westermann, P. y Ahring, B.K. (2003). Mesophilic and thermophilic anaerobic digestion of primary and secondary sludge. Effect of pretreatment at elevated temperature. Water Research, 37 (19): 4561-4572. 
Griffin, M. E., McMahon, K. D., Mackie, R. I. y Raskin, L. (1998). Methanogenic population dynamics during start-up anaerobic digesters treating municipal solid waste and biosolids. Biotechnology and Bioengineering. 57(3): 342-355.

Goméz, E., Martin, J. y Michel, F. (2011). Effects of organic loading rate on reactor performance and archaeal community structure in mesophilic anaerobic digesters treating municipal sewage sludge. Waste Manag Res 2011 29: 1117.

Ghosh, S. (1991) Improved sludge gasification by two-phase anaerobic digestion. ASCE J. Environ. Eng., 113, 6, 1265-1284.

Han, Y. y Dague, R. (1997). Laboratory studies on temperature-phased anaerobic digestion of domestic primary sludge. Water Environmental Research 69(6), 1139-1143.

Hayes, T.D., Theis, T.L. (1982). The distribution of heavy metals in anaerobic digestion. Journal water pollution control federation. 50 (1), 31-72.

Hernández-Uresti, A., Rojas, M., Durán, A., Cabirol, N., 2002. Evaluation of temperature effect and volatile fatty acids (VFA) on helminth eggs (Ascaris suum) under anaerobic conditions. In: Proceedings of VII Latin American Workshop and Symposium on Anaerobic Digestion (in Spanish), Mérida, Yucatán, México, pp. 279-281.

Hickey, R. F. y Switzenbaum, M. S. (1991). Thermodynamics of volatile fatty acid accumulation in anaerobic digesters subject to increases in hydraulic and organic loading. Journal Water Pollution Control Federation, 141-144.

Hulshoff Pol, L., Lens, P., Stams, A. y Lettinga, G. (1998). Anaerobic treatment of sulphate-rich wastewaters. Biodegradation. (9), 213-224.

Huyard, A., Ferran, B. y Audie, J.M. (2000). Two phase anaerobic digestion process: sludge stabilization and pathogens reduction. Water Science and Technology 42 (9), 4147.

Hwu, C.-S., Donlon, B. y Lettinga, G. (1997). Acute toxicity of oleate to acetate-utilizing methanogens in mesophilic and thermophilic anaerobic sludges. Enzyme and Microbial Technology. 21, pag. 297-301.

Ingallinella, A., Sanguinetti, G., Koottatep, T., Montangero, A. y Strauss, M. The challenge of faecal sludge managementin urban areas-estrategies, regulations and treatment options. Sludge Management: regulation, treatment, utilisation and disposal. Acapulco, 2527 October 2001.

Inman, D.C. (2004) Manuscript 1: Comparing acid/gas-phased to temperature-phased and conventional mesophilic digestion. M.S. Thesis, Virginia Polytechnic Institute and State University, Blacksburg. 
Iranpour, R., Cox, H.H.J., 2007. Evaluation of thermophilic anaerobic digestion processes for full-scale Class A biosolids disinfection at hyperion treatment plant. Biotechnology \& Bioengineering 97, 19-39.

Iza, J. (1995). Control del proceso anaerobio. Aplicación en el aprovechamiento energético deresiduos ganaderos. $3 r$ curs d'enginyeria ambiental. Aprovechamiento energético de residuos orgánicos. X.Flotats (ed.). Paperkite edn., Lleida. 175-201.

Jimenez, B., Maya, C., Sanchez, E., Romero, A. y Lira, L. (2001). Comparison of the quantity and quality of the microbiological content of sludge in countries with low and high contentof pathogens. Sludge Management: regulation, treatment,utilisation and disposal. Acapulco, 25-27 October 2001.

Keller, R., Passamani-Franca, R.F., Cassini, S.T. y Goncalves, F.R. (2004). Disinfection of sludge using lime stabilisation and pasteurisation in a small wastewater treatment plant. Water Science and Technology 50: 13-17.

Killilea J. E., Colleran E., Scahill C. (2000). Establishing procedures for design, operation and maintenance of sewage sludge anaerobic treatment plants. Water Science \& Technology 41, (3), 305-312.

Kim, M., Speece, R.E. (2002). Aerobic waste activated sludge (WAS) for start-up seed of mesophilic and thermophilic anaerobic digestion. Water Res. 36, 3860-3866.

Koster, I.W. (1989). Toxicity in anaerobic digestion, with emphasis on the effect of ammonia, sulfide and long-chain fatty acids on methanogenesis. Doctoral dissertation, Wageningen Agricultural University, Wageningen, The Netherlands.

Kyung-Yub, H., Shin E-B. y Choi H-B (1997). A mechanical pretreatment of waste activated sludge for improvement of anaerobic digestion system. Water Science and Technology. 36, 12: 111-116.

Lay, J.-J., Li, Y.-Y., Noike, T., 1997. Influences of pH and moisture content on the methane production in high-solids sludge digestion. Water Res. 31 (6), 1518-1524.

Lettinga, G., Van Vesel, A., Hobma de Zeeuv, S.W. y Klapwijk, A. (1980). Use of the up flow sludge blanket (USB) reactor concept for biological wastewater treatment. Biotechnology and Bioengineering 12, 699-734.

Liu, H., y Fang, H.H.P. (2002). Extraction of extracellular polymeric substances (EPS) of sludges. J. Biotechnol. 95 (3), 249-256.

Lowry, O.H., Rosen Brough, N.J., Farr, A.L. y Randall, R.J. (1951). Protein measurement with the fooling phenol reagent. Journal of Biology and Chemistry, 265-275. 
Lue-Hing, C., Matthew, P., Namer, J., Okuno, N. y Spinosa, L. (1996). Sludge management in highly urbanized areas. En: A global atlas of wastewater sludge and biosolids: use and disposal Matthew P. (ed) Reporte cientifico y tecnico N 40 IAWQ. Gran Bretaña.

Maharaj, I. y Elefsiniotis, P. (2001). The role of HRT and low temperature on the acidphase anaerobic digestion of municipal and industrial wastewaters. Bioresource Technology, 76 (3): 191-197.

Mahmoud, N., Zeeman, G., Gijzen, H. y Lettinga, G. (2004). Anaerobic stabilization and conversion of biopolymers in primary sludge--effect of temperature and sludge retention time. Water Research 38(4), 983-991.

Mancebo del Castillo U. (2001). Digestión anaerobia de lodos combinados utilizando un reactor UASB. Tesis de maestría, División de Estudios de Posgrado Facultad de Ingeniería, UNAM, México. Pp 108.

Madigan, M.T., Mortinko, J. y Parker, J. (2000). Brock Biology of Microorganisms. Paperback, 1152 pages, Global ed of $13^{\text {th }}$ re Edition, Published In: United States, 09 April 2011.

Malina, J. F. y Pohland, F. G. (1992). Design of anaerobic processes for the treatment of industrial and municipal wastes. Technomic Publishing Co. USA., 167-207.

Méndez, J. M.; Jiménez, B. E. y Salgado, G. V. (2002). Efecto del amoniaco en la estabilización alcalina de lodos residuales. XXVIII Congreso Interamericano de Ingeniería Sanitaria y Ambiental. Cancún, México.

Metcalf y Eddy. (2004). Ingeniería de aguas residuales: Tratamiento, Vertido y Utilización. México. Editorial Mc-Graw-Hill, México.

Metzner G. y Lemmer H. (1997). Semi-continuous tests for simulation of municipal sludge digestion to evaluate anaerobic processes. International symposium environmental biotechnology part II, Ostende, Belgium.

Miron Y., Zeeman G.,van Lier J. y Lettinga G. (2000). The role of sludge retention time in the hydrolysis and acidification of lipids, carbohydrates and proteins during digestion of primary sludge in CSTR systems. Water Research 34, 1705-1713.

Moeller, G. y Ferat, C. (2000). Reducción de patógenos en lodos primarios digeridos anaeróbicamente Congreso Nacional de Ingeniería Sanitaria y Ciencias Ambientales, págs. 1-10. Morelia. México. http://www.cepis.opsoms. org

Monpoeho, S., Maul, A; Bonnin, C., Patria, I., Ranarijaona, S., Billaudel, S. y Ferre, V. (2004). Clearance of human-pathogenic virases from sludge: study of tour stabilization processes by real-time reverse transcription-PCR and cell cultura. Source Applied and Environmental Microbiology, 70 (9): 5434-5440. 
Montalvo, S. y Guerrero, L. (2003). Tratamiento anaerobio de residuos. Producción de biogás. Universidad Técnica Federico Santa Maria, Valparaiso Chile pp. 413.

Murto, M., BjÖrnsson, L. y Mattiasson, B. (2004). Impact of food industrial waste on anaerobic co-digestion of sewage sludge and pig manure. Journal of Environmental Manage.,70,101-107.

Nidal, M., Grietje, Z., Huub, G y Gatze, L. (2004). Anaerobic stabilisation and conversion of biopolymers in primary sludge effect of temperature and sludge retention time. Water Research. 38, 983-991.

Norma Oficial Mexicana NOM-004-SEMARNAT-2002. Protección ambiental. Lodos, biosólidos, especificaciones y límites máximos permisibles de contaminantes para su aprovechamiento y disposición final. Diario Oficial. México. 15 de agosto de 2003.

NORMA Oficial Mexicana NOM-052-ECOL-1993, que establece las características de los residuos peligrosos, el listado de los mismos y los límites que hacen a un residuo peligroso por su toxicidad al ambiente. 22-10-93

Noyola, A. (1998). Digestión anaerobia de lodos. Memorias del curso "Digestión anaerobia de lodos y aguas residuales". Federación Mexicana de Ingeniería Sanitaria y Ciencias Ambientales, A.C. México.

Parkin, G. F., Owen, W. F. (1986). Fundamentals of anaerobic digestion of wastewater sludges. J. Environ. Eng., 112, 867-920.

Pelczar, Michael (2006). Microbiología, 2da edición, México, D. F., México, Editorial McGraw Hill Book, 662 págs.

Pérez A. (2004). Escalamiento de un digestor no convencional para lodos biológicos de purga, caso de estudio: planta de tratamiento de aguas residuales Cerro de la Estrella. Tesis de licenciatura, Facultad de Química, UNAM, México. Pp. 115.

Peterson, M.E., Daniel, R.M., Danson, M.J. y Eisenthal, R. (2006). The dependence of enzyme activity on temperature; Determination and validation of parameters. Bioch. J., Vol U pp 1-26.

Pohland, F.G., Ghosh, S. (1971) Developments in anaerobic stabilization of organic wastes-the two-phase concept. Env. Letters, 1, 4, 255-266.

Puchajda, B., Oleszkiewicz, J., 2004. Pathogen inactivation by organic acids in sludge digestion. In: Proceedings of 10th World Congress of Anaerobic Digestionanaerobic bioconversion: answer for sustainability, Montréal, Canada, pp. 479 - 485.

Qin Yu, H y Herbert HPF. (2003). Acidogenesis of gelatin-rich wastewater in an upflow anaerobic reactor: influence of $\mathrm{pH}$ and temperature. Water Res. 37:56-66. 
Raszka, A., Chorvatova, M. y Wanner, J. (2006). The role and significance of extracellular polymers in activated sludge. Part I: literature review. Acta Hydrochimica Hydrobiologic 34, 411-424.

Rincón, M., Rincón, N., Araujo, I., Díaz, A. y Mata, J. (2010). Mesophilic and termophilic anaerobic sta bilization of activated Sludges from brewing industry Ciencia e Ingeniería Neogranadina, Vol. 20-1, pp. 5-21. Bogotá.

Roberts, R., Son, Le. y Forster, C. (1999). A thermophilic-mesophilic dual digestion system for treating waste activated sludge. Journal of chemical technology and Biotechnology 74, 445-450.

Rojas, M., Cabirol, N., Castro, L. y Noyola, A. (2001). Removal of fecal indicator organisms and parasites (Fecal coliforms and helminth eggs) from municipal biologic sludge by anaerobic mesophilic and thermophilic digestion. Wat. Sci. Tech., 38 (8-9), 409-416.

Ros, M., Pascual, J., Garcia, C., Hernández, M. e Insam, H. (2006). Hydrolyses activities, microbial biomass and bacterial community in a soil after long-term amendment with different compost. Soil Biology and Biochemistry 38, 3443-3452.

Rubio, L.A. y Noyola, A. (2010). Two-phase (acidogenic-methanogenic) anaerobic thermophilic/mesophilic digestion system for producing Class A biosolids from municipal sludge. Bioresource Technology 101 (2010) 576-585.

Salhi M. (2003) Sludge reduction in a wastewater treatment process combining activated sludge and ozonation (Procédés couplés boues activées-ozonation pour la réduction de la production de boues : étude, modélisation et intégration dans la filière de traitement de I.eau). Ph.D. thesis, Institut National des Sciences Appliquées, Toulouse, France.

Salsali, H.R., Parker, W.J., Saltar, S.A., 2004. The effect of volatile fatty acids on the activation of Clostridium perfringens in advanced anaerobic digestion. In: Proceedings of 10th World Congress of Anaerobic Digestion-Anaerobic Bioconversion: Answer for Sustainability, Montréal, Canada, pp. 486-490.

Sanchez, J., Cortacans, J. y del Castillo, I. (2012). Influence of Temperature, Agitation, Sludge Concentration and Solids Retention Time on Primary Sludge Fermentation. International Journal of Chemical Engineering Volume 2012. Article ID 861467, 8 pages

Sanders, W.T. M. (2001). Anaerobic Hydrolysis During Digestion of Complex Substrates, Ph. D. Thesis WageningenUniversity, The Netherlands.

Shana, A., Asaadi, M., Morchoisne, T. y Marsh, P. (2003). Acid phase digestion pretreatment and its impact on conventional mesophilic anaerobic digestion. Innovation $y$ Development, Thames Water, Spencer House, Reading RG2 0JN. 
Shelton D. R. y Tiedje J. M. (1984). General Method for determination Anaerobic Biodegradation Potencial. Application Environmental Microbiology 47, (4), 850-857.

Siegrist, H., Renggli, D. \& Gujer, W. (1992). Mathematical modeling of anaerobic mesophilic sewage sludge treatment. In Proc. Int. Symp. on Anaerobic Digestion of Solid Waste, Venice, 14-17 April 1992, pp. 51-64. Stamperia di Venezia.

Song Y. C, Kwon S-J. y Woo J-H. (2004). Mesophilic and thermophilic temperature cophase anaerobic digestion compared with single-stage mesophilic and thermophilic digestion of sewage sludge. Water Research 38, 1653-1662.

Souza, C.L., Aquino, S.F., Teixeira, A. R. y Chernicharo, C.A. (2006). Production and characterization of scum from UASB reactors treating typically domestic sewage.

Speece, R. E. (1987). Nutrient Requeriments. En: Anaerobic digestion of biomass, ed.Chynoweth y Isaacson. Elsevier applied science.

Tanaka S., Kobayashi T., Kamiyama K. y Signey B. (1997). Effects of thermochemical Pretreatment on the anaerobic digestion of Waste Activated Sludge. Water Science and Technology 35, (8), 209-215.

Thomas, M., Wright, P., Blackall, L., Urbain, V., Keller, J., 2003. Optimisation of Noosa BNR plant to improve performance and reduce operating costs. Water Sci. Technol. 47 (12), 141-148.

Thomas, M.T y Scopes, R.K. (1998). The effects of temperature on the kinetics and stability of mesophilic and thermophilic 3-phosphoglycerate kinases. Bioch. J. (33): 10871095.

Tsakou, A., Roulia, M. y Christodoulakis, N. (2000). Growth of cotton plants (Gossypium hirsutum) as affected by water and sludge from a sewage treatment Psant: I. Plant phenology and development. Bulletin of Environmental Contamination and Toxicology, 66 (6): 735-742.

Turovskiy Izrail S. y Mathai P. K. (2006). Wastewater Sludge Processing, Wiley Interscience.

USEPA, (2000). Environmental regulations and technology:control of pathogens and vector attraction in sewage sludgeunder 40 CFR part 503. EPA/625/R-92/013, Washington, DC.

Vandenburgh, S.R. y Ellis, T.G. (2002). Effect of varying solids concentration and organic loading on the performance of temperature phased anaerobic digestion process. Water Environmental Research 74 (2), 142-148.

Veeken, A. y Hemelers, B. (1999). Effect of temperature on the hydrolysis rate of selected biowaste components. Bioresource Technology 69 (3), 249-255. 
Vigueras, S., Ramírez, F., Noyola, A. y Monroy, O. (2011). Effect of the thermal alkaline pretreatment on the mesophilic and thermophilic anaerobic digestion ofwaste activated sludge. Revista Mexicana de Ingeniería Química. Vol. 10, No. 2 (2011) 247-255.

Water Pollution Control Federation. Sludge Stabilization. Manual of Practice FD-9. 1995.

Watts, S.; Hamilton, G. y Keller, J. (2005). Two-stage thermophilic-mesophilicanaerobic digestion of waste activated sludge from a biological nutrient removal plant. Water Sci. Technol.53 (8), 149.

WEF (1996). Operation of Wastewater Treatment Plants, $5^{\text {th }}$ ed, Manual of Practice No 11, vol. 3, Capítulos 27-33, Water Environment Federation, Alexandria, VA.

Wingender, J., Neu, T.R., Flemming, H.C. (1999). Microbial Extracellular Polymeric Substances: Characterisation, Structure and Function. Springer, Berlin, p. 123.

Wilén, B. M., Jin, B. y Lant, P. (2003). The influence of key chemical constituents in activated sludge on surface and floculating properties. Water Research 37, (9), 21272139.

Williford, C.; Chen, W. and Shammas, N. K. y Wang, L. K. (2007). Lime stabilization. Biosolids treatment processes. Handbook of Environmental Engineering. Springer, vol. 6, ISBN 978-1 58829-396-1, pp. 207-241.

Winkler M. (1994). Tratamiento biológico de lodos de desecho. Editorial Limusa. México.

Yinguang, C., Su, J., Hongying, Y., Qi, Z y Guowei, G. (2007). Hydrolysis and acidification of waste activated sludge at different pHs. Water Research. 41, 683-689.

Young Ho, A. y Richard, E.S. (2006). Elutriated acid fermentation of municipal primary sludge Water Research. 40, 2210-2220.

Yu, H.Q., Zheng, X.J., Hu, Z.H. y Gu, G.W. (2003). High-rate anaerobic hydrolysis and acidogenesisof sewage sludge in a modi.ed up.ow reactor, Water Sci. Technol. 48, 69-75.

Yuan, Q., Sparling, R. y Oleszkiewicz, J. A. (2009). "Waste activated sludge fermentation: effect of solids retention time and biomass concentration," Water Research, 43 (20), pp. $5180-5186$.

Yue, H., Sung, S. y Dague. (1995). Temperature-phased anaerobic digestion of wastewater sludge. Proc. $8^{\text {th }}$ International Conf. on Anaerobic Digestion, 1: 340-347.

Zhang, P., Chen, Y., Huang, T. y Zhou, Q. (2009). Waste activated sludge hydrolysis and short-chain fatty acids accumulation in the presence of sdbs in semi-continuous flow reactors: effect of solids retention time and temperature," Chemical Engineering Journal, vol. 148 , no. 2-3, pp. 348-353. 
Zeeman, G. y Sanders, W. T. M. (2001). Potential of Anaerobic Digestion of Complex Waste(water), Wat. Sci. and Tech. 44 (8) pp. 115-122, IWA Publishing.

Zitomer, D.H., Lynch, D.L., Kemp, J.S., y Kade, F. (2005). "Occurrence and prevention of high VFA in temperature phased digestion". Proceedings of the 10th World Congress Anaerobic Digestion. Montreal, Canada.

Zoetemeyer, R.J., van den Heuvel, J.C., Cohen, A., 1982. pH influence on acidogenic dissimilation of glucose in an anaerobic digester. Water Res. 16, 303-311. 


\title{
Revista Mexicana de Ingeniería Química
}

Vol. 8, No. 2 (2009) 153-161

\section{DIGESTIÓN ANAEROBIA DE LODO PRIMARIO Y SECUNDARIO EN DOS REACTORES UASB EN SERIE}

\section{ANAEROBIC DIGESTION OF PRIMARY AND SECONDARY SLUDGE IN TWO SERIAL UASB REACTORS}

\author{
J. Terreros-Mecalco ${ }^{1 *}$, A. Olmos-Dichara ${ }^{3}$, A. Noyola-Robles ${ }^{2}$, \\ F. Ramírez-Vives ${ }^{1}$ y O. Monroy-Hermosillo ${ }^{1}$ \\ ${ }^{1}$ Departamento de Biotecnología, Universidad Autónoma Metropolitana. \\ P.A. 55-535, 09340 Iztapalapa, México D.F., México \\ ${ }^{2}$ Instituto de Ingeniería, Coordinación de Procesos Ambientales. Universidad Nacional Autónoma de México, \\ Cd. de México, 04510 México. \\ ${ }^{3}$ Departamento de Bioprocesos. Instituto Politécnico Nacional, Cd. de México, 07340 México.
}

Recibido 23 de Enero 2009; Aceptado 03 de Julio 2009

\begin{abstract}
Resumen
En este trabajo, se estudió la hidrólisis en mesofilia (AM) y la estabilización bajo condiciones metanogénicas en termofília (MT), de una mezcla de lodo primario (LP) y lodo secundario (LS) en dos reactores de lecho de lodos de flujo ascendente (UASB) operados en serie. Los reactores AM y MT operaron a $32 \pm 2{ }^{\circ} \mathrm{C}$ y $56 \pm 1{ }^{\circ} \mathrm{C}$, respectivamente, con diferentes proporciones de LP:LS en la alimentación, sin agitación ni recirculación y a diferentes tiempos de retención hidráulica (TRH). En el reactor AM los mejores resultados fueron en la etapa V, con 2 días de TRH, 18 días de retención de sólidos (TRS), con una proporción LP:LS (50:50), una carga orgánica volumétrica $(\mathrm{Bv})$ de $3.6 \mathrm{~kg} \mathrm{DQO} / \mathrm{m}^{3} \cdot \mathrm{d}$., en donde se obtuvo una eficiencia de remoción de la materia orgánica (DQO) del 56.8\%, una formación de DQO soluble del $48.3 \%$, destrucción de sólidos suspendidos volátiles (SSV) de $68.6 \%$ con una velocidad de hidrólisis de $0.16 \mathrm{~kg} / \mathrm{m}^{3} \cdot \mathrm{d}$. El reactor MT, presentó la mejor estabilización a 6 días de TRH, con una producción de $107.7 \mathrm{~mL}_{\mathrm{CH} 4} / \mathrm{Kg}_{\mathrm{SSV} \text { rem }}$, un 66\% en la destrucción de SSV, una eliminación de coliformes fecales de $8.5 \log _{10}$ y una reducción de huevos de helminto del 85 \%. La separación en dos fases del tratamiento anaerobio de lodos, permitió obtener una mayor hidrólisis de la materia orgánica a TRS menores a los reportados en reactores completamente agitados y una reducción en los huevos de helminto similares a los reportados en la literatura.
\end{abstract}

Palabras clave: UASB, lodo, hidrólisis, patógenos, estabilización.

\begin{abstract}
The present research studies of mesophilic hydrolysis (AM) and stabilization under thermophilic methanogenic conditions (MT) for a mixture of primary sludge (PS) and secondary sludge (SS) using two serial Upflow Anaerobic Sludge Blanket reactors (UASB). The AM and MT reactors were operated at $32 \pm 2{ }^{\circ} \mathrm{C}$ and $56 \pm 1{ }^{\circ} \mathrm{C}$, respectively with different rates of PS:SS in the supply, without stir or recirculation at different hydraulic retention times (HRT). The AM reactor showed the optimal results in the stage V, HRT of 2 days, solid retention times (SRT) of 18.1 for a PS:SS rate of 50:50, and volumetric loading (Bv) of $3.6 \mathrm{~kg} \mathrm{DQO} / \mathrm{m} 3 . \mathrm{d}$., and it was observed a COD removal efficiency of $56.8 \%$, soluble COD production of $48.3 \%$, volatile suspended solids (VSS) removal of $68.6 \%$ using a hydrolysis rate of $0.16 \mathrm{~kg} / \mathrm{m} 3 . \mathrm{d}$. The MT reactor showed the optimal stabilization for HRT on the $6^{\text {th }}$ day of operation, methane $\left(\mathrm{CH}_{4}\right)$ production of $107.7 \mathrm{~mL} \mathrm{CH}_{4} / \mathrm{Kg} \mathrm{VSS}$ removed, VSS removal of 66\%, faecal coliform elimination of $8.5 \log _{10}$ and reduction for helminth eggs of $85 \%$. Partition in two stages of the sludge anaerobic treatment allowed us to achieve higher hydrolysis of the organic matter with lower SRT than those reported for completely stirred reactors; furthermore reduction of helminth eggs was similar to other previous reports.
\end{abstract}

Keywords: UASB, sludge, hydrolysis, pathogens, stabilization.

* Autor para la correspondencia.E-mail: jesusterr@yahoo.com.mx 


\section{Introducción}

Durante la depuración de aguas residuales municipales se produce lodo de desecho en aproximadamente 0.5 a $1.2 \mathrm{~kg} \quad \mathrm{SSV} / \mathrm{kg} \quad \mathrm{DBO}$ removida, cuya composición y producción depende del grado de tratamiento (primario, secundario o terciario); composición de la carga orgánica,

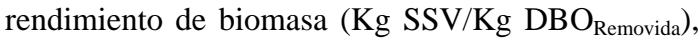
tiempo de residencia de sólidos, la temperatura y la naturaleza de las descargas industriales (Foundation for Water Research, 1999); así como de la concentración de agentes contaminantes orgánicos e inorgánicos; y de la presencia de microorganismos patógenos (Cabirol y col., 2002).

En México, en la mayoría de los casos, los lodos de desecho producidos en plantas de tratamiento de aguas residuales, son dispuestos sin tratamiento previo en tiraderos a cielo abierto, rellenos sanitarios y sistemas de alcantarillado, lo que provoca un impacto ambiental adverso y su aplicación directa a campos agrícolas, representa un riesgo potencial para la salud (Anise y Darwin, 1995), por la presencia de metales pesados (As, Cd, $\mathrm{Hg}, \mathrm{Pb}$, Se y Zn), a los cultivos (Cu, Ni y Zn) y ecosistemas del suelo y agua (N, P) (Ros y col., 2006). Por otro lado, la materia orgánica y otros compuestos aportados al suelo por los lodos, pueden modificar la distribución y movilidad de metales pesados, lo que podría afectar principalmente la asimilabilidad de $\mathrm{Cu}$ y Zn (Ahumada y col., 2004), además de un incremento en la biomasa microbiana del suelo, al incorporar una nueva carga microbiana al sistema o al estimular el crecimiento de la microbiota autóctona por la incorporación de nuevas fuentes de carbono (Ros y col., 2006). Sin embargo, al estabilizarlo y reducir significativamente el contenido de microorganismos patógenos, puede utilizarse como fertilizante (Dumontet y col., 2001). O bien, para la regeneración de suelos contaminados, ya que bacterias anaerobias juegan un papel importante en el ciclo del carbono, el nitrógeno y el azufre; además, sus diversos grupos poseen la habilidad de usar tipos diferentes de aceptores de electrones como el nitrato, el sulfato y carbonato durante la degradación de contaminantes orgánicos presentes en ecosistemas contaminados con hidrocarburos y en la biotransformación de metales pesados (Balagurusamy, 2005).

Los métodos comúnmente empleados para su estabilización, contempla a los procesos físicos (incineración), químicos (adición de cal), térmicos (calor) y biológicos (aerobio o anaerobio) (Metcalf y Eddy, 2003). La oxidación aerobia, además de requerir de un elevado consumo energético (500 a 2000 kW-hr/1000 kg de DBO $_{\text {removida); de TRH }}$ mayores a 30 días; soporta bajas cargas orgánicas de SSV, (Wilkie, 2005). En tanto que, la digestión anaerobia, a pesar de requerir de una elevada inversión inicial, comparable a la de la propia planta de tratamiento de aguas residuales, es una buena opción, ya que además de permitir la recuperación de energía en forma de metano $\left(\mathrm{CH}_{4}\right)$ con un rendimiento de $0.35 \mathrm{~m}^{3}$ de $\mathrm{CH}_{4} / \mathrm{kg}$ de DQO metabolizada, que equivale a la generación de 3517

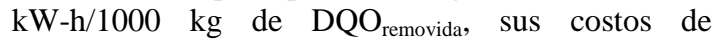
operación y mantenimiento, son relativamente bajos (Noyola, 1998). Y si se somete a un proceso de licuefacción, puede ser comercializado (Aguilar y Álvarez, 2007).

En México, los pocos digestores anaerobios de lodos construidos operan a temperaturas mesofílicas $\left(35^{\circ} \mathrm{C}\right)$, con el empleo de una variante termofílica a $55^{\circ} \mathrm{C}$, se ofrecen ciertas ventajas como son: la separación de la fase sólida de la líquida, incremento en el grado de destrucción de sólidos orgánicos (Zitomer y col., 2005), eliminación de microorganismos patógenos (Pike y col., 1989) y reducción de hasta un $56 \%$ en los SSV (Roberts $y$ col., 1999), lo que permite obtener un biosólido clase A de acuerdo a la clasificación de la USEPA (1996). Sin embargo, se ha observado que la limitada tasa de hidrólisis de la materia orgánica y mínima biodisponibilidad de materiales orgánicos solubles, durante su estabilización vía anaerobia, en digestores mesofílicos o termofílicos requiere de tiempos de retención de sólidos mayores a 20 días. Para favorecerla, se han empleado métodos físicos (térmico, mecánico, ultrasonido, hidrotérmico), químicos como ácidos minerales fuertes o álcalis, óxido de calcio (CaO), hidróxido de calcio $\left(\mathrm{Ca}(\mathrm{OH})_{2}\right)$, pre-tratamientos termo-alcalinos y oxidativos con ozono que además de ser costosos, no logran una solubilización mayor al 50\% (Tiehm y col., 2001).

En los reactores anaerobios de una sola fase todas las etapas de la digestión anaerobia (hidrólisis, acidogénesis, acetogénesis y metanogénesis) se llevan a cabo en un mismo ambiente, lo cual no es lo más apropiado para todos los miembros del consorcio, debido a que las actividades metabólicas de las bacterias acidogénicas (tasa de crecimiento mayor) y de las metanogénicas (crecimiento lento y requerimiento estricto de $\mathrm{pH}$ ) a largos $\mathrm{TRH}$, bajo condiciones ambientales que favorecen principalmente a las bacterias productoras de metano, suelen retardar el metabolismo de las poblaciones acidogénicas (Ghosh y col., 1995).

En el presente trabajo, se estudia el comportamiento de un sistema de digestión anaerobia en dos fases; hidrólisis en un reactor mesofílico y metanogénesis en un reactor termofílico, para una mezcla de dos clases de lodo: lodo del tratamiento primario (LP) y lodo secundario (LS) como una opción para la estabilización de la materia orgánica y reducción de microorganismos patógenos en reactores alimentados con flujo ascendente y separando las fases gas-líquido-sólido mediante un sistema colocado en la parte superior permitiendo la salida del biogás, pero limitando la salida del material en suspensión (Lettinga y col., 1980). Aprovechando las ventajas del AM (baja 
producción de AGV y generación de pocos olores, pero mayor solubilidad de biopolímeros) con las ventajas del MT (alta velocidad de destrucción de SSV y mayor destrucción de microorganismos patógenos) (Cheunbarn y Pagilla, 2000).

El objetivo de este trabajo, fue hidrolizar y estabilizar la materia orgánica contenida en una mezcla de lodo residual, a fin de establecer las mejores condiciones de operación del sistema propuesto, que permitan obtener un biosólido de buena calidad para su reuso, de acuerdo a los parámetros establecidos en la Norma Oficial Mexicana (NOM-004-ECOL-SEMARNAT-2002) y la Agencia de Protección Ambiental en los Estados Unidos (USEPA, 1996).

\section{Metodología}

Para el presente estudio, se empleó un arreglo de reactores UASB por sus siglas en ingles (Upflow Anaerobic Sludge Blanket) sin agitación en dos etapas (denominado sistema ADEMT). Un primer reactor acidogénico en mesofília (AM) a $32 \pm 2{ }^{\circ} \mathrm{C}$ y fue alimentado con una mezcla homogénea de lodo residual. Un segundo reactor metanogénico en termofília (MT) a $56 \pm 1{ }^{\circ} \mathrm{C}$ y fue alimentado con el efluente del reactor AM. Ambos reactores contaban con un volumen de diseño de $10 \mathrm{~L}$, volumen útil de 8.6 L, diámetro interno de $15 \mathrm{~cm}$ y altura de $53 \mathrm{~cm}$.

La biomasa empleada como inóculo, se colectó de un reactor UASB que trata aguas domésticas con una concentración de 27 g/L de SSV. Durante el periodo de arranque y estabilización, se empleó el medio mineral RAMM (Shelton y Tiedje, 1984), con glucosa como fuente de carbono para el reactor AM y acetato de sodio para el reactor MT.

Una vez que las poblaciones en los dos reactores se adaptaron a las condiciones establecidas (acidogénesis y metanogénesis, respectivamente), se inició con la alimentación del reactor acidogénico en continuo; sin control de $\mathrm{pH}$ y variando el $\mathrm{TRH}$, las concentraciones de sólidos totales (ST) y las proporciones de LP:LS con diferentes proporciones (30:70 y 50:50) en la mezcla alimentada. Para el experimento, el lodo primario se colectó de la línea de purga del sedimentador primario y el lodo secundario de la línea de recirculación de lodos activados de la planta de tratamiento de aguas residuales municipales Cerro de la Estrella, en la Ciudad de México. Una vez tomada la muestra de lodo, se realizó un tamizado, empleando una malla de $0.225 \mathrm{~mm}$, a fin de retirar los sólidos gruesos que pudieran interferir en la operación del sistema experimental. Mostrando en la tabla 1, los promedios de los principales parámetros evaluados a 14 lotes de ambos tipos de lodo colectados a lo largo del experimento, observándose una dispersión significativa en los datos, debido a la gran variabilidad que presentan los lodos en las diferentes épocas del año.
La evaluación de los principales parámetros de ambos tipos de lodo y el control del proceso (análisis de la diferencia de parámetros) entre la mezcla de lodo tratado y la mezcla de lodo crudo sin tratamiento se realizó de la siguiente manera: para el análisis de la fracción soluble, las muestras se centrifugaron a $5000 \mathrm{rpm}$ durante 10 minutos y se filtraron por medio de filtros de fibra de vidrio de 45 $\mu \mathrm{m}$. El análisis de ácidos grasos volátiles (AGV), se realizó por cromatografía de gases, mediante un cromatógrafo de gases (Hewlett Packard series II modelo 5890), equipado con detector FID y columna capilar Superox FA, AT 1000, utilizando un volumen de inyección de $0.2 \mu L$, a partir de una muestra preparada (volumen del filtrado: $950 \mu L$ y $50 \mu L$ de $\mathrm{HCl}$ al 50\%), bajo las siguientes condiciones de operación; temperatura de columna $120^{\circ} \mathrm{C}$ a $140^{\circ} \mathrm{C}$, incremento de $10^{\circ} \mathrm{C} /$ minuto, temperatura del inyector $130^{\circ} \mathrm{C}$, temperatura del detector $150^{\circ} \mathrm{C}, \mathrm{N}_{2}$ como gas acarreador a $3 \mathrm{~mL} / \mathrm{min}$.

El pH se evaluó mediante un potenciómetro (Corning pH/ion Analyzer 455). La DQO, los sólidos suspendidos totales (ST) y los SSV se determinaron de acuerdo al método estándar (APHA, AWWA, WPFC, 1995). El análisis de azúcares se realizó por la técnica del fenol sulfúrico (Dubois y col., 1956). El análisis de proteína, se realizó por la técnica de Lowry y col. (1951). La medición de biogás, se efectuó por medio de una columna invertida en un recipiente con solución salina $(\mathrm{pH}=2)$, donde el volumen de la solución desplazada, correspondía al volumen de biogás producido y su composición, se determinó por cromatografía de gases empleando un cromatógrafo Gow-Mac serie 550 con detector de conductividad térmica equipado con una columna de Carbosphere 80/100. El análisis microbiológico (coliformes fecales y Salmonella spp), se realizó de acuerdo a la NOM-004-SEMARNAT-2002 y el análisis de huevos de helminto, por la técnica de Ritchie modificada (Aguilar y Llaguno, 2003). En el reactor acidogénico, se evaluó el efecto de dos proporciones distintas de LP:LS en la mezcla alimentada sobre la formación de productos de hidrólisis; 30:70 con una $\mathrm{Bv}$ de 5.5, 3.9 y $7.5 \mathrm{~kg}$ $\mathrm{DQO} / \mathrm{m}^{3}$ d respectivamente, a 1 día de TRH (etapas I, II y III) y 50:50 a cargas orgánicas menores (7.3, 3.6 y $2.4 \mathrm{Kg} \mathrm{DQO} / \mathrm{m}^{3} \mathrm{~d}$ ), a 1,2 y 3 días de TRH respectivamente (etapas $\mathrm{IV}, \mathrm{V}$ y VI) a $32 \pm 2^{\circ} \mathrm{C}$, y se observó el efecto del TRH en el reactor metanogénico termofílico sobre la eliminación de microorganismos patógenos; a un día de TRH (etapas I, II y III), a un TRH de 2 días (etapa IV), a un TRH de 4 días (etapa V) y finalmente a un TRH de 6 días (etapa VI), a $56 \pm 1^{\circ} \mathrm{C}$. Las características de la mezcla del lodo primario y secundario alimentada al sistema experimental, en función de las etapas indicadas, se muestran en la Tabla 2. 
Tabla 1. Características generales de los lodos primario y secundario.

\begin{tabular}{lccc}
\hline \multicolumn{1}{c}{ Parámetro } & Unidades & Lodo primario & Lodo secundario \\
\hline pH & & $6.2 \pm 0.7$ & $6.9 \pm 0.4$ \\
Sólidos totales (ST) & $(\mathrm{g} / \mathrm{L})$ & $20.4 \pm 10.3$ & $9.6 \pm 5.3$ \\
Sólidos volátiles (SV) & $(\mathrm{g} / \mathrm{L})$ & $12.2 \pm 6.0$ & $7.4 \pm 4.2$ \\
Sólidos suspendidos totales (SST) & $(\mathrm{g} / \mathrm{L})$ & $19.4 \pm 9.8$ & $8.7 \pm 4.9$ \\
Sólidos suspendidos volátiles (SSV) & $(\mathrm{g} / \mathrm{L})$ & $11.6 \pm 5.4$ & $6.9 \pm 3.9$ \\
DQO $_{\text {total }}$ & $(\mathrm{g} / \mathrm{L})$ & $19.8 \pm 9.9$ & $8.6 \pm 4.8$ \\
DQO $_{\text {soluble }}$ & $(\mathrm{g} / \mathrm{L})$ & $1.1 \pm 0.6$ & $0.3 \pm 0.2$ \\
Azúcares totales & $(\mathrm{mg} / \mathrm{L})$ & $300 \pm 20$ & $50 \pm 30$ \\
Azúcares solubles & $(\mathrm{mg} / \mathrm{L})$ & $20 \pm 10$ & $2 \pm 1$ \\
Proteína total & $(\mathrm{g} / \mathrm{L})$ & $13.9 \pm 7.1$ & $8.5 \pm 4.6$ \\
Proteína soluble & $(\mathrm{g} / \mathrm{L})$ & $1.9 \pm 1.0$ & $0.02 \pm 0.01$ \\
\hline
\end{tabular}

Tabla 2. Características generales de la mezcla de lodo alimentado al reactor acidogénico.

\begin{tabular}{|c|c|c|c|c|c|c|}
\hline \multirow{2}{*}{ Parámetro } & \multicolumn{6}{|c|}{ Etapa } \\
\hline & I & II & III & IV & $\mathbf{V}$ & VI \\
\hline Proporción (LP:LS) & $30: 70$ & $30: 70$ & $30: 70$ & $50: 50$ & $50: 50$ & $50: 50$ \\
\hline $\mathrm{Bv}\left(\mathrm{kg} \mathrm{DQO} / \mathrm{m}^{3} \mathrm{~d}\right)$ & 5.5 & 3.9 & 7.5 & 7.3 & 3.6 & 2.4 \\
\hline TRH (d) & 1.0 & 1.0 & 1.0 & 1.0 & 2.0 & 3.0 \\
\hline TRS (d) & 34.7 & 34.3 & 14.8 & 18.7 & 18.0 & 33.2 \\
\hline $\mathrm{pH}$ & $6.5 \pm 0.2$ & $6.5 \pm 0.5$ & $6.7 \pm 0.6$ & $6.5 \pm 0.2$ & $6.5 \pm 0.2$ & $6.5 \pm 0.3$ \\
\hline $\mathrm{ST}(\mathrm{g} / \mathrm{L})$ & $4.5 \pm 0.7$ & $4.6 \pm 0.3$ & $8.7 \pm 0.3$ & $8.5 \pm 0.8$ & $8.8 \pm 0.8$ & $8.4 \pm 0.4$ \\
\hline SST (g/L) & $3.7 \pm 0.6$ & $4.0 \pm 0.5$ & $8.3 \pm 1.0$ & $7.5 \pm 0.9$ & $7.4 \pm 0.7$ & $7.6 \pm 0.5$ \\
\hline $\mathrm{SSV}(\mathrm{g} / \mathrm{L})$ & $2.4 \pm 0.5$ & $2.8 \pm 0.6$ & $5.3 \pm 1.2$ & $4.3 \pm 0.7$ & $4.3 \pm 0.8$ & $3.7 \pm 0.3$ \\
\hline $\mathrm{DQO}_{\text {total }}(\mathrm{g} / \mathrm{L})$ & $5.5 \pm 0.1$ & $3.9 \pm 0.4$ & $7.5 \pm 0.1$ & $7.3 \pm 0.1$ & $7.2 \pm 0.1$ & $7.3 \pm 0.2$ \\
\hline $\mathrm{DQO}_{\text {soluble }}(\mathrm{mg} / \mathrm{L})$ & ND & $200 \pm 10$ & $300 \pm 40$ & $500 \pm 10$ & $500 \pm 30$ & $500 \pm 10$ \\
\hline Azúcares totales (mg/L) & $1800 \pm 200$ & $200 \pm 40$ & $500 \pm 60$ & $400 \pm 20$ & $400 \pm 20$ & $400 \pm 20$ \\
\hline Azúcares solubles (mg/L) & $10 \pm 3$ & $20 \pm 3$ & $10 \pm 4$ & $10 \pm 1$ & $10 \pm 1$ & $10 \pm 1$ \\
\hline $\mathrm{AGV}(\mathrm{mg} / \mathrm{L})$ & $70 \pm 10$ & $70 \pm 10$ & $100 \pm 30$ & $120 \pm 80$ & $120 \pm 40$ & $100 \pm 50$ \\
\hline
\end{tabular}

ND: no detectado; AGV: Ácidos grasos volátiles

\section{Resultados y discusión}

\subsection{Reactor acidogénico}

En la Tabla 3; se observa que para una relación LP:LS de 30/70 a 1 día de TRH (etapas II y III), al incrementar la carga orgánica volumétrica de 3.9 a $7.5 \mathrm{~kg} \mathrm{DQO} / \mathrm{m}^{3} \cdot \mathrm{d}$ se mejoró la eficiencia en la remoción de DQO, pasando de un $16.8 \%$ a un $34.5 \%$, alcanzando una eficiencia en la velocidad de hidrólisis del 51\%, un 33.9\% de destrucción de SSV y una eficiencia en la formación de DQO soluble del 76.1\%, observando una disminución en la formación de AGV pasando del 69 al 61\%, debido a la naturaleza del lodo alimentado, predominantemente secundario en donde se tiene una menor disponibilidad de materiales orgánicos solubles fermentables, en relación al lodo primario que presenta una baja fracción volátil disponible (Noyola, 1998). La producción de biogás fue de 7.7 $\mathrm{mL} / \mathrm{d}$, con una composición del $61.4 \%$ de $\mathrm{CO}_{2} \mathrm{y}$ $38.6 \%$ de $\mathrm{CH}_{4}$.

Durante la etapa IV, con una proporción de LP:LS de 50:50, un día de TRH y una carga orgánica volumétrica de $7.3 \mathrm{~kg} \mathrm{DQO} / \mathrm{m}^{3} \cdot \mathrm{d}$, similar a la etapa III, se presentó un aumento en la remoción de materia orgánica (41.1\%), formación de DQO soluble de $40.5 \%$, y una producción de biogás de 24
$\mathrm{mL} / \mathrm{d}$, con una composición del $61.6 \%$ de $\mathrm{CO}_{2}$ y $38.4 \%$ de $\mathrm{CH}_{4}$. Durante la etapa V, a la misma proporción de LP:LS (50:50), a 2 días de TRH, pero con una carga orgánica volumétrica similar a la etapa II (3.6 kg DQO $\left./ \mathrm{m}^{3} \mathrm{~d}\right)$, se observó un incremento sobre la eficiencia de remoción de DQO del 56.8\%, una formación de productos de hidrólisis expresada como DQO soluble del 48.3\% y una destrucción de SSV del 68.6\%. Tatsuo y col. (1993) reportaron una destrucción de SSV del $33.1 \%$ en un sistema acidogénico-mesofílico a $35^{\circ} \mathrm{C}$ y 20 días de TRS. Por su parte, Ghosh y col. (1995), con un arreglo en dos fases; mesofílico-mesofílico, lograron un $71 \%$ de destrucción de SSV en reactores completamente mezclados. Han y Dague (1997), en un reactor termofílico a 5 días de TRH y $56 \pm 1^{\circ} \mathrm{C}$, seguido de un reactor mesofílico a 10 días de TRH y $35 \pm 1{ }^{\circ} \mathrm{C}$, con lodo primario, reportaron una reducción de SSV del 46.8\%. Vandenburgh y Ellis (2002), con lodo primario y $4.9 \%$ de ST, en un sistema mesofílicomesofílico, lograron una reducción del $61.5 \%$ de SSV a un TRH de 20 días. Shana y col. (2003), en un reactor acidogénico de mezcla completa (CSTR) a $35^{\circ} \mathrm{C}$, reportaron un $29 \%$ de hidrólisis de la materia orgánica, Mahmoud y col. (2004) reportaron un 60\% de hidrólisis de lodo primario a un TRH de 10 a 15 días y $25^{\circ} \mathrm{C}$. 
Tabla 3. Características del lodo hidrolizado en el reactor acidogénico mesofílico.

\begin{tabular}{|c|c|c|c|c|c|c|}
\hline \multirow{2}{*}{ Parámetro } & \multicolumn{6}{|c|}{ Etapa } \\
\hline & I & II & III & IV & $\mathbf{V}$ & VI \\
\hline Período de operación (d) & $71-113$ & $124-167$ & 174-184 & $316-426$ & $470-525$ & $533-736$ \\
\hline $\mathrm{pH}$ & $5.4 \pm 0.4$ & $5.8 \pm 0.5$ & $5.4 \pm 0.3$ & $5.7 \pm 0.2$ & $5.1 \pm 0.2$ & $7.2 \pm 0.4$ \\
\hline ST (g/L) & $3.0 \pm 0.4$ & $3.3 \pm 0.3$ & $6.0 \pm 2.3$ & $5.5 \pm 1.3$ & $3.6 \pm 1.2$ & $3.1 \pm 0.8$ \\
\hline $\mathrm{SST}(\mathrm{g} / \mathrm{L})$ & $2.5 \pm 0.4$ & $2.9 \pm 0.4$ & $5.5 \pm 2.0$ & $4.4 \pm 1.2$ & $2.1 \pm 0.8$ & $1.8 \pm 0.5$ \\
\hline SSV (g/L) & $1.7 \pm 0.3$ & $2.0 \pm 0.5$ & $3.5 \pm 1.4$ & $2.9 \pm 0.7$ & $1.4 \pm 0.6$ & $1.4 \pm 0.4$ \\
\hline SSV destruidos (\%) & 31.0 & 27.3 & 33.9 & 33.2 & 68.6 & 63.0 \\
\hline g SSV/g SST & 0.67 & 0.69 & 0.64 & 0.65 & 0.64 & 0.74 \\
\hline Eficiencia de remoción de DQO (\%) & 40.5 & 16.8 & 34.5 & 41.1 & 56.8 & 72.4 \\
\hline DQO $_{\text {soluble }}$ formada (\%) & ND & 75.3 & 76.1 & 40.5 & 48.3 & 26.6 \\
\hline Hidrólisis (\%) & 61.0 & 32.1 & 51.3 & 40.4 & 66.7 & 79.9 \\
\hline $\mathrm{AGV}(\mathrm{mg} / \mathrm{L})$ & $360 \pm 190$ & $220 \pm 87$ & $250 \pm 76$ & $280 \pm 130$ & $320 \pm 69$ & $160 \pm 93$ \\
\hline Incremento de AGV (\%) & 99 & 69 & 61 & 64 & 68 & 59 \\
\hline Incremento de azúcares solubles (mg/L) & 14 & 26 & 45 & 19 & 22 & 10 \\
\hline Biogás $_{\mathrm{TPS}}(\mathrm{mL} / \mathrm{d})$ & $11.2 \pm 9.8$ & $6.3 \pm 0.6$ & $7.7 \pm 8.4$ & $24.0 \pm 17.1$ & $19.6 \pm 5.8$ & $52.6 \pm 14.3$ \\
\hline $\mathrm{CH}_{4}$ en el biogás (\%) & 38.0 & 26.2 & 38.6 & 38.4 & 31.2 & 68.2 \\
\hline $\mathrm{CO}_{2}$ en el biogás (\%) & 62.0 & 73.8 & 61.4 & 61.6 & 68.8 & 31.8 \\
\hline
\end{tabular}

TPS: temperatura y presión estándar; DQO: demanda química de oxígeno; $\mathrm{CH}_{4}$ : metano; $\mathrm{CO}_{2}$ : dióxido de carbono

Además, se observó un incremento del 68\% en los AGV formados, probablemente a la presencia de materia orgánica fácilmente fermentable (Yang $y$ col., 2003). Acompañado de una producción de biogás de $19.6 \mathrm{~mL} / \mathrm{d}$, con una composición de $\mathrm{CO}_{2}$ mayor (68.8\%) y menor proporción de $\mathrm{CH}_{4}(31.2 \%)$, en relación a la etapa anterior (etapa IV). Observando que bajo estas condiciones de operación; (proporción de LP:LS de 50:50, carga orgánica volumétrica de $3.6 \mathrm{Kg} \mathrm{DQO} / \mathrm{m}^{3}$ d y 2 días de TRH), se lograron resultados similares a los reportados en reactores de mezcla completa. La separación de la digestión anaerobia de lodos en dos etapas, permitió además de tener un buen control del sistema, regular las cargas orgánicas volumétricas, y una reducción de SSV y SST mayor, al obtenido en digestores anaerobios de alta tasa (27 al 46\%) reportado por Metcalf y Eddy (2003), y al mencionado por Noyola, (1998) que va de un 25 a un $45 \%$ para SST. En cuyas condiciones de operación, se contempla: el mezclado, alimentación uniforme, calentamiento y recirculado de lodo digerido.

Durante la etapa VI, con proporción de LP:LS similar a las etapas IV y V, a 3 días de TRH y una menor carga orgánica volumétrica $(2.4 \mathrm{~kg}$ $\left.\mathrm{DQO} / \mathrm{m}^{3} \cdot \mathrm{d}\right)$, mejoró la eficiencia de remoción de la materia orgánica en un $72.4 \%$, pero no las eficiencias de formación de DQO soluble y AGV formados, siendo del 26.6 y 59\% respectivamente. Resultando ser mayor al 53.3\% reportado por Tatsuo y col. (1993) y menor al 73\% reportado por Shana y col. (2003). Así mismo, la destrucción de SSV lograda fue de un 63\%, siendo mayor al reportado por Shana y col. (2003) y por Tatsuo y col. (1993) del 27.7 y $14.7 \%$ respectivamente. Observando en esta etapa del experimento, un incremento en la producción de biogás de $52.6 \mathrm{~mL} / \mathrm{d}$ predominando el $\mathrm{CH}_{4}$ en un $68.2 \%$ y disminuyendo el $\mathrm{CO}_{2} \quad$ (31.8\%), al favorecerse el desarrollo de las condiciones metanogénicas ( $\mathrm{pH}>7.1$ ), debido al aumento del TRH.

La Fig. 1, muestra la velocidad y la eficiencia de hidrólisis de los sólidos suspendidos volátiles en el reactor acidogénico, observando que la mejor velocidad (0.163 g/Ld), con una eficiencia del 66\% se obtuvo a un TRS de 18.1 días, con una proporción de LP:LS de 50/50 y Bv de $3.6 \mathrm{Kg} \mathrm{DQO} / \mathrm{m}^{3}$.d (etapa $\mathrm{V})$, debido probablemente a la naturaleza y tamaño de partícula del lodo alimentado como lo reportan Dimock y Morgenroth, (2006). Con la misma proporción de LP:LS, pero menor $\mathrm{Bv}(2.4 \mathrm{Kg}$ $\mathrm{DQO} / \mathrm{m}^{3} \mathrm{~d}$ ), a 33 días de TRS (etapa VI), mejoró la eficiencia de hidrólisis (80\%), pero disminuyó la velocidad $(0.07 \mathrm{~g} / \mathrm{L} \cdot \mathrm{d})$. El mismo comportamiento se observa para las etapas II y III con una LP:LS de 30:70. Estos resultados muestran que a menor tiempo de retención de sólidos mayor es la velocidad de hidrólisis; por lo que un equilibrio entre la carga orgánica volumétrica y el TRS, permitirá mejorar tanto la eficiencia como la velocidad de hidrólisis de los sólidos suspendidos volátiles.

$\mathrm{Al}$ incrementarse el pH a 7 (etapa VI), con el consecuente desarrollo de las condiciones metanogénicas, se afectó la velocidad de hidrólisis, pero no su eficiencia, debido a la carga orgánica volumétrica presente en la mezcla alimentada. De Tommaso y Van Benschoten, (1996) reportaron resultados favorables en la destrucción de SSV a pH ácidos. Al favorecer las condiciones de la primera etapa de la digestión anaerobia ( $\mathrm{pH}$ ácidos, mayor proporción de $\mathrm{CO}_{2}$ en el biogás) permite una mejor disponibilidad de los productos solubles presentes en el lodo y una mayor disolución de los compuestos embebidos en las membranas celulares (Eastman y Ferguson, 1981). 


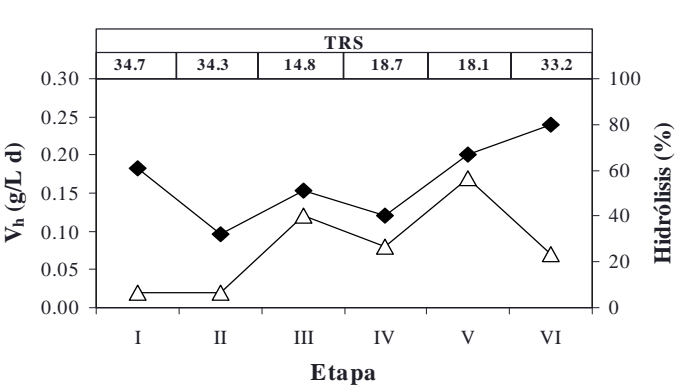

Fig. 1. Efecto del TRS en la velocidad $\left(\mathrm{V}_{\mathrm{h}}, \triangle\right) \mathrm{y}$ eficiencia $(\diamond)$ de hidrólisis de la mezcla de lodo primario y secundario, en el reactor acidogénico mesofílico.

\subsection{Reactor metanogénico termofílico}

La Tabla 4, muestra las características del lodo producido por este reactor y las condiciones de operación. Con un TRH de 1 día y carga orgánica volumétrica entre 3.2 y $4.9 \mathrm{~kg} \mathrm{DQO} / \mathrm{m}^{3} \cdot \mathrm{d}$ (etapas II y III), hubo un aumento en la destrucción de SSV pasando del 61 al 66\% y una disminución en la eficiencia de eliminación de la materia orgánica (43.5 a $31 \%$ ) y de la producción de biogás (22.7 a $15 \mathrm{mlCH}_{4} /$ gSSVrem), con un decremento del TRS de 34.9 a 12.5 días. Durante la etapa IV; con una carga orgánica volumétrica menor $\left(2.1 \mathrm{~kg} \mathrm{DQO} / \mathrm{m}^{3} \cdot \mathrm{d}\right)$ y un TRS similar a la etapa III, no mejoró la eficiencia sobre la eliminación de DQO (37\%) ni la producción de biogás (18.2 $\mathrm{mlCH}_{4} / \mathrm{gSSV}$ rem ), pero si la eficiencia de destrucción de SSV (70\%). Con 4 días de TRH (etapa V) y la consecuente reducción de Bv a $0.8 \mathrm{Kg} / \mathrm{m}^{3}$.d., se observó una mejora sobre la eliminación de DQO (65.8\%), un aumento en la remoción de AGV (75\%) y una producción de biogás de $93.7 \mathrm{mlCH}_{4} / \mathrm{gSSVrem}$, sin embargo, disminuyó la eficiencia de destrucción de SSV a un 55\% con respecto a la etapa anterior. Tatsuo y col. (1993), reportaron una reducción del 58.8\% de SSV pero en un reactor completamente mezclado (CSTR), mostrando poca diferencia a la obtenida en este estudio.

A 6 días de TRH y menor carga orgánica (etapa VI), se observó una disminución sobre la eficiencia de eliminación de DQO (40.6\%), un incremento en la destrucción de SSV (66\%). Huyard y col. (2000), en un sistema completamente mezclado acidogénico termofílico; alimentado con una mezcla de lodo primario-secundario con un contenido del 2.5 al $5 \%$ de sólidos y a 2 días de TRH, seguido por un reactor metanogénico mesofílico con 10.5 días de TRH con recirculación de lodo, lograron una reducción del 61\% de SSV. Shana y col. (2003) lograron un 55.6\% de reducción de SSV trabajando con una fase de digestión ácida acoplado a un digestor acidogénico mesofílico, con una mezcla de 70:30 de lodo primario y secundario, un contenido del 5.5 al $6 \%$ de sólidos.

Bajo estas mismas condiciones (etapa VI) se observó una remoción de $\mathrm{AGV}$ en un $73 \%$ y una $\begin{array}{llll}\text { producción de biogás de } 107.7 & \end{array}$ $\mathrm{mlCH}_{4} / \mathrm{gSSVremovido,} \mathrm{cercano} \mathrm{al} \mathrm{reportado} \mathrm{por}$ Cecchi y col. (1992), en reactores de una sola fase (129 mL de $\mathrm{CH}_{4} / \mathrm{gSSV}_{\text {removido }}$ y mayor al reportado por Ghosh y col. (1995), en un arreglo mesofílicomesofílico (20 mL de $\mathrm{CH}_{4} / \mathrm{gSSV}_{\text {removido }}$ ) y un $69 \%$ de metano en el biogás producido. Cheunbarn y Pagilla (2000), en un sistema en dos fases: termofílicamesofílica, con un incremento gradual de TRH de 7.4 a 14 días a $37^{\circ} \mathrm{C}$, alimentado con una mezcla de LP y LS, reportaron una producción de biogás con una composición de $\mathrm{CH}_{4}$ en un $61 \%$.

Tabla 4. Características del lodo estabilizado en el reactor metanogénico termofílico.

\begin{tabular}{|c|c|c|c|c|c|c|}
\hline \multirow{2}{*}{ Parámetro } & \multicolumn{6}{|c|}{ Etapa } \\
\hline & $\mathbf{I}$ & II & III & IV & $\mathbf{V}$ & VI \\
\hline Período de operación (d) & 71-113 & $124-167$ & $174-184$ & $316-426$ & $470-525$ & $533-736$ \\
\hline $\mathrm{Bv}\left(\mathrm{kg} \mathrm{DQO} / \mathrm{m}^{3} \mathrm{~d}\right)$ & 3.3 & 3.2 & 4.9 & 2.1 & 0.8 & 0.3 \\
\hline $\mathrm{TRH}(\mathrm{d})$ & 1.0 & 1.0 & 1.0 & 2.0 & 4.0 & 6.0 \\
\hline TRS (d) & 19.3 & 34.9 & 12.5 & 11.4 & 17.0 & 22.9 \\
\hline $\mathrm{ST}(\mathrm{g} / \mathrm{L})$ & $2.1 \pm 0.6$ & $1.9 \pm 0.7$ & $3.2 \pm 1.3$ & $3.0 \pm 0.6$ & $2.7 \pm 1.1$ & $1.8 \pm 0.9$ \\
\hline $\mathrm{SST}(\mathrm{g} / \mathrm{L})$ & $1.6 \pm 0.4$ & $1.6 \pm 0.7$ & $2.6 \pm 0.7$ & $1.4 \pm 0.8$ & $1.6 \pm 0.8$ & $0.6 \pm 0.2$ \\
\hline $\operatorname{SSV}(g / L)$ & $0.9 \pm 0.4$ & $0.8 \pm 0.3$ & $1.2 \pm 0.7$ & $0.9 \pm 0.3$ & $0.6 \pm 0.3$ & $0.5 \pm 0.2$ \\
\hline SSV destruidos (\%) & 48.0 & 61.0 & 66.0 & 70.0 & 55.0 & 66.0 \\
\hline G SSV/g SST & 0.54 & 0.49 & 0.45 & 0.61 & 0.38 & 0.73 \\
\hline $\mathrm{DQO}_{\text {total }}(\mathrm{g} / \mathrm{L})$ & $2.3 \pm 0.3$ & $1.8 \pm 0.3$ & $3.4 \pm 0.1$ & $2.7 \pm 0.3$ & $1.7 \pm 0.3$ & $1.2 \pm 0.7$ \\
\hline Eficiencia de remoción de $\mathrm{DQO}_{\text {total }}(\%)$ & 30.5 & 43.5 & 31.0 & 37.0 & 65.8 & 40.6 \\
\hline $\mathrm{AGV}(\mathrm{mg} / \mathrm{L})$ & $120 \pm 17$ & $100 \pm 18$ & $140 \pm 20$ & $130 \pm 36$ & $81 \pm 30$ & $40 \pm 16$ \\
\hline Eficiencia de remoción de AGV (\%) & 68.0 & 55.0 & 46.0 & 55.0 & 75.0 & 73.0 \\
\hline Biogás $_{\text {TPS }}(\mathrm{mL} / \mathrm{d})$ & $63.0 \pm 47.7$ & $30.9 \pm 16.4$ & $49.7 \pm 31.9$ & $51.3 \pm 30.5$ & $95.6 \pm 48.4$ & $131.7 \pm 36.0$ \\
\hline $\mathrm{CH}_{4}$ en el biogás (\%) & 82.3 & 90.3 & 70.1 & 71.0 & 72.5 & 74.4 \\
\hline $\mathrm{CO}_{2}$ en el biogás (\%) & 17.7 & 9.7 & 29.9 & 29.0 & 27.5 & 25.6 \\
\hline $\mathrm{mL} \mathrm{CH}_{4} / \mathrm{g} \mathrm{SSV}$ removido & 64.0 & 22.7 & 15.0 & 18.2 & 93.7 & 107.7 \\
\hline
\end{tabular}

TPS: temperatura y presión estándar; DQO: demanda química de oxígeno; $\mathrm{CH}_{4}$ : metano; $\mathrm{CO}_{2}$ : dióxido de carbono 
Tabla 5. Perfil de concentración de microorganismos patógenos y tasas de eliminación.

\begin{tabular}{|c|c|c|c|c|c|}
\hline \multirow{2}{*}{ Parámetro } & \multicolumn{5}{|c|}{ Etapa } \\
\hline & II & III & IV & $\mathbf{V}$ & VI \\
\hline TRH (d) & 1.0 & 1.0 & 2.0 & 4.0 & 6.0 \\
\hline $\mathrm{Bv}\left(\mathrm{kg} \mathrm{DQO} / \mathrm{m}^{3} \mathrm{~d}\right)$ & 3.2 & 4.9 & 2.1 & 0.8 & 0.3 \\
\hline Coliformes fecales en el influente ${ }^{a}$ & $4.8 \times 10^{8}$ & $4.0 \times 10^{8}$ & $4.3 \times 10^{8}$ & $2.8 \times 10^{8}$ & $3.1 \times 10^{8}$ \\
\hline Coliformes fecales en el efluente ${ }^{\mathrm{b}}$ & $4.0 \times 10^{8}$ & $2.8 \times 10^{8}$ & $4.3 \times 10^{7}$ & $2.2 \times 10^{7}$ & $9.7 \times 10^{6}$ \\
\hline Coliformes fecales eliminados ${ }^{c}$ & $8.0 \times 10^{7}$ & $1.2 \times 10^{8}$ & $3.8 \times 10^{8}$ & $2.6 \times 10^{8}$ & $2.9 \times 10^{8}$ \\
\hline Reducción de coliformes fecales $\left(\log _{10}\right)$ & 7.9 & 8.1 & 8.6 & 8.4 & 8.5 \\
\hline Eficiencia de eliminación (\%) & 16.7 & 30.0 & 89.9 & 92.1 & 96.8 \\
\hline Salmonella spp en el influente ${ }^{\mathrm{a}}$ & $4.3 \times 10^{8}$ & $4.6 \times 10^{8}$ & $4.0 \times 10^{8}$ & $3.8 \times 10^{8}$ & $3.7 \times 10^{8}$ \\
\hline Salmonella spp en el efluente $\mathrm{e}^{\mathrm{b}}$ & $2.9 \times 10^{8}$ & $1.2 \times 10^{8}$ & $7.9 \times 10^{7}$ & $3.2 \times 10^{7}$ & $5.0 \times 10^{6}$ \\
\hline Salmonella spp eliminados ${ }^{c}$ & $1.4 \times 10^{8}$ & $3.4 \times 10^{8}$ & $3.2 \times 10^{8}$ & $3.5 \times 10^{8}$ & $3.7 \times 10^{8}$ \\
\hline Reducción de Salmonella spp $\left(\log _{10}\right)$ & 8.1 & 8.5 & 8.5 & 8.5 & 8.6 \\
\hline Eficiencia de eliminación (\%) & 31.4 & 73.0 & 80.3 & 91.5 & 98.7 \\
\hline Huevos de helminto en el influente ${ }^{\mathrm{d}}$ & 30 & 19 & 19 & 20 & 20 \\
\hline Huevos de helmino en el efluente ${ }^{\mathrm{e}}$ & 22 & 13 & 12 & 7 & 3 \\
\hline Huevos de helminto eliminados ${ }^{\mathrm{f}}$ & 8 & 6 & 7 & 13 & 17 \\
\hline Eficiencia de eliminación (\%) & 26.7 & 31.6 & 36.8 & 65.0 & 85.0 \\
\hline
\end{tabular}

TPS: temperatura y presión estándar; DQO: demanda química de oxígeno; $\mathrm{CH}_{4}$ : metano; $\mathrm{CO}_{2}$ : dióxido de carbono

La Tabla 5; muestra el perfil de concentración y la tasa de eliminación de microorganismos patógenos en el reactor metanogénico termofílico. Observando, que a una $\mathrm{Bv}$ de $4.9 \mathrm{Kg} / \mathrm{m}^{3} \mathrm{~d}$ (etapa III), a partir de una concentración inicial de coliformes fecales de $4 \times 10^{8}$ (NMP/g ST), Salmonella spp de $4.6 \times 10^{8}$ (NMP/g ST) y 19 Huevos de helminto; se obtuvo una reducción de 8.1, $8.5 \log _{10}$ para coliformes fecales y Salmonella spp y un 31.6\% en la reducción de huevos de helminto. Mientras que a cargas orgánicas menores (etapas IV, V y VI) la eficiencia de destrucción de patógenos fue mayor y directamente proporcional al incremento del TRH: 8.6, 8.4 y $8.5 \log _{10}$ para coliformes fecales; 8.5, 8.5 y $8.6 \log _{10}$ para Salmonella spp y un porcentaje de reducción de huevos de helminto del 36.8, 65 y 85 \% respectivamente.

Han y Dague (1997), en un arreglo termofílico-mesofílico de dos fases alimentado con lodo primario y TRH global entre 10 y 15 días, lograron una reducción de coliformes fecales en 2.49 $\log _{10}$. Huyard y col. (2000), lograron en un sistema de dos fases; termofílico-mesofílico alimentado con una proporción de LP:LS de 60:40, una reducción de coliformes fecales y huevos de helminto en: 5.5 y 2.6 $\log _{10}$ en el reactor termofílico a 2 días de TRH. Cheunbarn y Pagilla (2000), redujeron el número de coliformes fecales de $10^{8} \mathrm{NMP} / \mathrm{g}$ ST a valores menores a $10^{2} \mathrm{NMP} / \mathrm{g}$ ST (8 a $2 \log _{10}$ ). Rojas y col. (2000), lograron en un sistema de dos fases; mesofílico-termofílico con un TRH de 15 y 20 días, con lodo secundario a una concentración inicial de $1 \mathrm{X} 10^{5} \mathrm{NMP} / \mathrm{g}$ ST de coliformes fecales, una reducción en $4.99 \log _{10} \mathrm{y}$ para huevos de helminto en un 97\%. Gantzer y col. (2001), reportaron una reducción de $1.36 \log _{10}$ de coliformes fecales. Cabirol y col. (2002), en un sistema de dos fases; mesofílicotermofílico lograron una reducción de huevos de helminto en $1.54 \log _{10}$ en mesofília y de $1.84 \log _{10}$ en termofília. En otro estudio, Song y col. (2004), reportaron una reducción de coliformes fecales en $1.99 \log _{10}$. Estos resultados indican que los sistemas completamente agitados como los casos anteriores con TRH mayores a 10 días, pueden alcanzar eficiencias de reducción de patógenos mayores a los reportados en este estudio, debido a que los reactores UASB presentan zonas muertas y cortos circuitos hidráulicos, por la falta de mezclado, provocando una baja eficiencia en la eliminación de patógenos como lo mencionan, Cabirol y col. (2002).

\section{Conclusiones}

El proceso en dos etapas mejoró la formación de compuestos solubles, aunque no se alcanzaron altas eficiencias en la reducción de patógenos. Los mejores resultados en el reactor acidogénico fueron a 2 días de TRH, proporción de LP:LS de 50:50, una $\mathrm{Bv}$ de $3.6 \mathrm{Kg} \mathrm{DQO} / \mathrm{m}^{3} \mathrm{~d}$ y con un $68.6 \%$ de eficiencia en la destrucción de SSV (etapa V). Las eficiencias alcanzadas en la destrucción de SSV en este reactor fueron similares a las reportadas por algunos autores, tomando en cuenta la falta de mezclado en los reactores UASB. Las mejores velocidades de hidrólisis se obtuvieron a TRH y TRS menores a los reportados en la literatura lo que indica que separar la digestión anaerobia en dos etapas favoreció la solubilización de la materia orgánica y la destrucción de los SSV.

Los mejores resultados en el reactor metanogénico termofílico fueron los obtenidos en la etapa VI, logrando una mayor eliminación de coliformes fecales y Salmonella spp. La falta de mezclado en el reactor no permitió alcanzar las eficiencias esperadas para producir un biosólido clase A o B, según la NOM-004-ECOLSEMARNAT-2002. Sin embargo, con la eficiencia de eliminación de huevos de helminto de $85 \%$, el 
biosólido obtenido cumple con los parámetros establecidos para biosólidos clase B.

Con el sistema propuesto se tuvo como ventajas: un mejor control del sistema durante su operación, formación de productos de hidrólisis en más del $80 \%$ y la reducción de SSV similares a los reportados en digestores anaerobios de alta tasa. La principal desventaja fue que la falta de mezclado en los reactores pudo provocar zonas muertas y por consiguiente una baja eliminación de microorganismos patógenos. Los resultados obtenidos en este estudio servirán de base para profundizar sobre el tema de la digestión anaerobia de lodos en dos etapas con reactores UASB, con el fin de encontrar las mejores condiciones de operación para producir biosólidos clase A.

\section{Agradecimientos}

El primer autor agradece el apoyo al Consejo Nacional de Ciencia y Tecnología (CONACYT) por la beca otorgada para cursar el doctorado en biotecnología dentro del programa de doctorado de la Universidad Autónoma Metropolitana-Iztapalapa, incluido en el padrón de Postgrados de Excelencia, con el convenio 471-0.

\section{Referencias}

Aguilar, F. y Llaguno, V. (2003). Manual de prácticas del curso y temario teórico por objetivos. Protozoología Médica Veterinaria; Departamento de Parasitología Instituto Politécnico Nacional, México DF.

Aguilar, R. y Álvarez, M. (2007). Síntesis evolutiva del proceso para la licuefacción de metano. Revista Mexicana de Ingeniería Química 6(1), 81-88.

Ahumada, I., Escudero, P., Carrasco, A., Castillo, G., Ascar, L. y Fuentes, E. (2004). Use of sequential extraction to assess the influence of sewage sludge amendment on metal mobility in chilean soil. Journal of Environmental Monitoring 6, 327-334.

Anise, U.A. y Darwin, L.S. (1995). Kinetics of pathogen on destruction during storage of dewatered biosolids. Water Environmental Research 67, 143-149.

APHA, AWWA, WPFC. (1995). Standard methods for the examination of water and wastewater. $19^{\text {th }}$ ed. American Public health Association, Washington, D.C., U.S.A.Balagurusamy, N. (2005). Anaerobic Bioremediation an untapped potential. Revista Mexicana de Ingeniería Química 4(3), 273-287.

Cabirol, N., Rojas Oropeza M., Noyola A. (2002). Removal of helminthes eggs by anaerobic thermophilic sludge digestion. Water Science and Technology 45(10), 269-274.

Cecchi, F., Pavan, P., Musacco, A., Mata, A. y Sans, C. (1992). Comparison between thermophilic and mesophilic anaerobic digestion of sewage sludge coming from urban wastewater treatment plants. Water Science and Technology 26(11), 2409-2412.

Cheunbarn, T. y Pagilla, K. (2000). Anaerobic thermophilic/mesophilic dual-stage sludge treatment. Journal of Environmental Engineering 126(9), 796-801.

De Tommaso y Van Benschoten J. (1996). “An Experimental Study of Organic Matter Coagulation by $\mathrm{Al}$ and Fe Salts”, Annual Conference Proceedings, American Water Works Association, Toronto, Canada. Water Research 349-366.

Dimock, R. y Morgenroth, E. (2006). The influence of particle size on microbial hydrolysis of protein particles in activated sludge. Water Research 40, 2064-2074.

Dubois, M., Gilles, K.A., Hamilton, J.K., Roberts, P.A., Smith, F. (1956). Colorimetric method for determination of sugars and related substances. Analytical Chemistry 28, 350-356.

Dumontet, S., Scopa, A., Kerje, S. y Krovacek, K. (2001). The importance of pathogenic organisms in sewage and sewage sludge. Journal of the Air and Waste Management Association 51(6), 848-860.

Eastman, J.A. y Ferguson, J.F. (1981). Solubilization of particulate organic carbon during the acid phase of anaerobic digestion. Journal WPCF 53(3), 352-366.

Environmental Protection Agency (EPA) (1996). A Plain English Guide to the EPA, Part 503 Biosolids Rule. U.S. EPA/832/R-93-003. Vandenburgh, S.R. y Ellis, T.G. (2002). Effect of varying solids concentration and organic loading on the performance of temperature phased anaerobic digestion process. Water Environmental Research 74(2), 142-148.

Foundation for Water Research. Sewage sludge disposal operational and Environmental Issues. Review of Current Knowledge (ROCK). Foundation for Water Research. United Kingdom. 1999.

Gantzer, C., Gaspard, P., Galvez, L., Huyard, A., Dumouthier, N. y Schwartzbrod, J. (2001). Monitoring of bacterial and parasitological contamination during various treatment of sludge. Water Research 35(16), 3763-3770.

Ghosh, S., Bouy, K., Dressel, L., Miller, T., Wilcox, G. y Loos, D. (1995). Pilot and a full-scale two-phase anaerobic digestion of municipal sludge. Water Environmental Research 67(2), 206-214.

Han, Y. y Dague, R. (1997). Laboratory studies on temperature-phased anaerobic digestion of domestic primary sludge. Water Environmental Research 69(6), 1139-1143.

Huyard, A., Ferran, B. y Audie, J.M. (2000). Two phase anaerobic digestion process: sludge 
stabilization and pathogens reduction. Water Science and Technology 42(9), 41-47.

Lettinga, G., Van Vesel, A., Hobma de Zeeuv, S.W. y Klapwijk, A. (1980). Use of the up flow sludge blanket (USB) reactor concept for biological wastewater treatment. Biotechnology and Bioengineering 12, 699734.

Lowry, O.H., Rosen Brough, N.J., Farr, A.L. y Randall, R.J. (1951). Protein measurement with the fooling phenol reagent. Journal of Biology and Chemistry, 265-275.

Mahmoud, N., Zeeman, G., Gijzen, H. y Lettinga, G. (2004). Anaerobic stabilization and conversion of biopolymers in primary sludge-effect of temperature and sludge retention time. Water Research 38(4), 983-991.

Metcalf y Eddy. (2003). Ingeniería de aguas residuales: Tratamiento, Vertido $y$ Utilización. México. Editorial Mc-Graw-Hill, México.

Norma Oficial Mexicana NOM-004-SEMARNAT2002. Protección ambiental. Lodos, biosólidos, especificaciones y límites máximos permisibles de contaminantes para su aprovechamiento y disposición final. Diario Oficial. México. 15 de agosto de 2003.

Noyola, A. (1998). Digestión anaerobia de lodos. Memorias del curso "Digestión anaerobia de lodos y aguas residuales”. Federación Mexicana de Ingeniería Sanitaria y Ciencias Ambientales, A.C. México.

Pike, E.B., Carrington, E.G. y Harman, S.A. (1989). Destruction of salmonellas, enterovirus and ova of parasites in wastewater sludge by pasteurisation and anaerobic digestion. Water Science and Technology 20(11-12), 337-343.

Roberts, R., Son, Le. y Forster, C. (1999). A thermophilic-mesophilic dual digestion system for treating waste activated sludge. Journal of chemical technology and Biotechnology 74, 445-450.

Rojas, O. y Cabirol, N. (2000). Remoción de indicadores patógenos y parásitos (coliformes fecales y huevos de helminto) en lodos municipales de tipo biológico por digestión anaerobia mesofílica y termofílica. Memorias del VI Taller y Seminario Latinoamericano de Digestión Anaerobia en Pernambuco, Brasil.

Ros, M., Pascual, J., Garcia, C., Hernández, M. e Insam, H. (2006). Hydrolyses activities, microbial biomass and bacterial community in a soil after long-term amendment with different compost. Soil Biology and Biochemistry 38, 3443-3452.

Shana, A., Asaadi, M., Morchoisne, T. y Marsh, P. (2003). Acid phase digestion pre-treatment and its impact on conventional mesophilic anaerobic digestion. Innovation $y$ Development, Thames Water, Spencer House, Reading RG2 0JN.

Shelton, D.R. y Tiedje, J.M. (1984). General method for determining anaerobic biodegradation potential. Applied Environmental Microbiology 47, 850-857.

Song, Y., Kwon, S.J. y Woo, J.H. (2004). Mesophilic and thermophilic temperature co-phase anaerobic digestion compared with singlestage mesophilic- and thermophilic digestion of sewage sludge. Water Research 38(7), 1653-1662.

Tatsuo, S., Kenso, K. y Yoshikasu, N. (1993). Anaerobic waste-activated sludge digestion a bioconversion mechanism and kinetic model. Biotechnology and Bioengineering 41(11), 1082-1091.

Tiehm, K., Nickel, M., Zellhorn y Neis, U. (2001). Ultrasonic waste activated sludge disintegration for improving anaerobic stabilization. Water Research 35(8), 20032009.

Vandenburgh, S.R. y Ellis, T.G. (2002). Effect of varying solids concentration and organic loading on the performance of temperature phased anaerobic digestion process. Water Environmental Research 74 (2), 142-148.

Wilkie, A. (2005). Anaerobic digestion; Biology and benefits. Dairy manure management: Treatment, handling and community relations. Natural resource, agriculture and engineering service. Cornell University, Ithaca, NY. NRAES-176, 63-72.

Yang, K., Yu, Y. y Hwang, S. (2003). Selective optimization in thermophilic acidogenesis of cheese-whey wastewater to acetic and butyric acids: partial acidification and methanation. Water Research 37, 2467-2477.

Zitomer, D.H., Lynch, D.L., Kemp, J.S., y Kade, F. (2005). "Occurrence and prevention of high VFA in temperature phased digestion”. Proceedings of the $10^{\text {th }}$ World Congress Anaerobic Digestion. Montreal, Canada. 